FELIPE DE OLIVEIRA CINTRA

\title{
MODELAGEM MATEMÁTICA E OTIMIZAÇÃO DA PRODUÇÃO \\ DE EXOPOLISSACARÍDEO DE Haemophilus influenzae TIPO B
}

Dissertação apresentada ao Programa de Pós-Graduação Interunidades em Biotecnologia USP / Instituto Butantan / IPT para a obtenção do Título de Mestre em Biotecnologia. 
FELIPE DE OLIVEIRA CINTRA

\section{MODELAGEM MATEMÁTICA E OTIMIZAÇÃO DA PRODUÇÃO \\ DE EXOPOLISSACARÍDEO DE Haemophilus influenzae TIPO B}

Dissertação apresentada ao Programa de Pós-Graduação Interunidades em Biotecnologia USP / Instituto Butantan / IPT para a obtenção do Título de Mestre em Biotecnologia.

Área de concentração: Biotecnologia

Orientadora: Dr. ․ㅡ Mickie Takagi

Versão corrigida. A versão original eletrônica encontra-se disponível tanto na Biblioteca do ICB quanto na Biblioteca Digital de Teses e Dissertações da USP (BDTD) 
DADOS DE CATALOGAÇÃO NA PUBLICAÇÃO (CIP)

Serviço de Biblioteca e Informação Biomédica do

Instituto de Ciências Biomédicas da Universidade de São Paulo

(C) reprodução total

Cintra, Felipe de Oliveira.

Modelagem matemática e otimização da produção de exopolissacarídeo de Haemophilus influenzae tipo b / Felipe de Oliveira Cintra. -- São Paulo, 2014.

Orientador: Prof. Dr. Mickie Takagi.

Dissertação (Mestrado) - Universidade de São Paulo. Instituto de Ciências Biomédicas. Programa de Pós-Graduação Interunidades em Biotecnologia USP/IPT/Instituto Butantan. Área de concentração:

Biotecnologia. Linha de pesquisa: Desenvolvimento de bioprocessos para produção, purificação e conjugação de antígenos vacinais e adjuvantes.

Versão do título para o inglês: Mathematical modelling and optimization of the production of exopolysaccharide from Haemphilus influenzae type $b$.

1. Haemophilus 2. Polissacarídeos bacterianos 3. Modelos matemáticos 4. Planejamento de experimentos ótimos 5. Vacinas 6. Bactérias Gram-negativas I. Takagi, Prof. Dr. Mickie II. Universidade de São Paulo. Instituto de Ciências Biomédicas. Programa de PósGraduação Interunidades em Biotecnologia USP/IPT/Instituto Butantan III. Título. 
Candidato(a): $\quad$ Felipe de Oliveira Cintra.

Título da Dissertação: $\quad$ Modelagem matemática e otimização da produção de exopolissacarídeo de Haemophilus influenzae tipo b.

Orientador(a): $\quad$ Prof. Dr. Mickie Takagi.

A Comissão Julgadora dos trabalhos de Defesa da Dissertação de Mestrado, em sessão pública realizada a .................................................., considerou
( ) Aprovado(a)
( ) Reprovado(a)

Examinador(a): Assinatura:

Nome:

Instituição:

Examinador(a): Assinatura:

Nome:

Instituição:

Presidente: Assinatura:

Nome:

Instituição: 
São Paulo, 09 de agosto de 2012.

Protocolo: I-950/12

Dra. Mickie Takagi

Laboratório de Fermentação / Centro de Biotecnologia Instituto Butantan

Referente Projeto: "Modelagem matemática e otimização da produção de exopolissacarídeo de Haemophilus influenzae tipo b".

A Comissão de Ética no Uso de Animais do Instituto Butantan (CEUAIB) informa que o projeto acima referido é isento de análise por parte desta Comissão, pois não faz uso de animais vertebrados em sua execução.

Cordialmente,

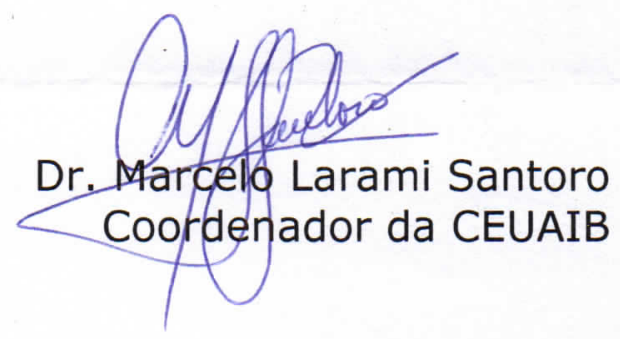


Aos amigos que caminharam junto nos últimos quase quatro anos, por terem dividido parte de suas vidas comigo. Àqueles que estiveram presentes por todo esse tempo, e àqueles que estiveram de passagem. Juntos pudemos sonhar com o futuro, com o nosso próprio potencial. Compartilhamos ideias, experiências, frases de impacto. Aprendemos juntos, erramos juntos, crescemos juntos. A pessoa que serei de agora em diante será um pouco de cada momento que tivemos. Agradeço pelas palavras ouvidas, pelas reclamações suportadas, pelas críticas, pelas risadas. E me arrependo, de não ter explorado por completo a personalidade e individualidade de cada um de vocês.

Aos professores, que participaram nesta etapa e nas anteriores. Aos de dentro da sala de aula, e aos de fora dela. Aos que em algum momento plantaram qualquer semente de dúvida, aos que nunca estiveram satisfeitos, aos que mostraram o caminho e não a resposta. Aos que pediram a excelência como o mínimo.

À família, por ser meu porto seguro. Por ter mantido as portas abertas durante tanto tempo. Apesar das distâncias, físicas, temporais ou pessoais, cada passo que dei no caminho certo foi guiado por vocês.

Aos colaboradores deste projeto, colegas de laboratório, coordenadores e técnicos, que contribuíram com cada experimento, resultado e discussão. Nenhum trabalho é de uma pessoa apenas, e este pertence a vocês também.

À orientadora, que também é chefe e líder. Entre tantos motivos que tenho a agradecer, escolho um. Obrigado pela liberdade. Liberdade de aprender a todo momento, de ensinar, de contestar, de errar e experimentar. Liberdade de me desenvolver acadêmica e profissionalmente, de procurar meu próprio potencial ao máximo. Nada teria maior valor. 
"There was still plenty of food and fuel and so on for all the human beings on the planet, as numerous as they had become, but millions upon millions of them were starting to starve to death now. The healthiest of them could go without food for only about forty days, and then death would come.

And this famine was as purely a product of oversize brains as Beethoven's Ninth Symphony.

(...)

So I have to say that human brains back then had become such copious and irresponsible generators of suggestions as to what might be done with life, that they made acting for the benefit of future generations seem one of many arbitrary games which might be played by narrow enthusiasts-like poker or polo or the bond market, or the writing of science-fiction novels.

More and more people back then, and not just Andrew Maclntosh, had found ensuring the survival of the human race a total bore." 


\section{RESUMO}

Cintra FO. Modelagem matemática e otimização da produção de exopolissacarídeo de Haemophilus influenzae tipo b. [dissertação (Mestrado em Biotecnologia)]. São Paulo: Instituto de Ciências Biomédicas, Universidade de São Paulo; 2014.

Haemophilus influenzae tipo b (Hib) é uma bactéria patogênica ao ser humano, responsável por pneumonias, septicemias e meningites. O polissacarídeo capsular conjugado a proteína é utilizado como antígeno em vacinas polivalentes, onde representa mais que a metade do custo total da formulação. $O$ alto custo da vacina Hib provém, entre outros, das altas perdas durante os processos de cultivo, purificação e conjugação devido à instabilidade química do polissacarídeo. Este trabalho tem por finalidade otimizar o processo de produção do polissacarídeo, levando-se em conta a interface cultivo/purificação. Primeiramente, foi feita a escolha de um modelo cinético que descreve o crescimento celular com inibição por acetato, a formação mista de acetato e a formação de polissacarídeo não-associada ao crescimento com inibição por acetato. Em seguida, foi realizado um desenho experimental para avaliar os efeitos de $\mathrm{pH}$ e temperatura sobre os parâmetros do modelo. Ficou demonstrado que a velocidade de crescimento é máxima em pH 6,73 $\left(0,644 \mathrm{~h}^{-1}\right) ;$ a constante de inibição pelo acetato é maior na região alcalina

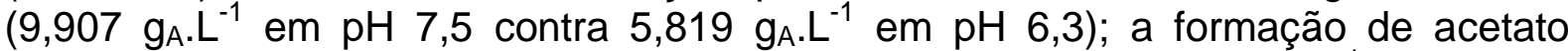
associada ao crescimento é maior no limite superior de $\mathrm{pH}\left(0,796 \mathrm{~g}_{\mathrm{A}} \cdot \mathrm{gx}^{-1} \mathrm{em} \mathrm{pH} 7,5\right.$

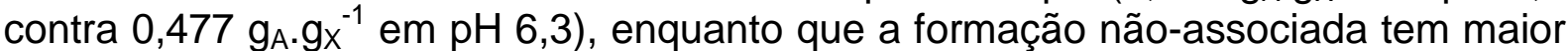
influencia da temperatura, com um máximo em $37^{\circ} \mathrm{C}$ e pH $6,3\left(0,141 \mathrm{~g}_{\mathrm{A}} \cdot \mathrm{gx}^{-1} \cdot \mathrm{h}^{-1}\right)$; a formação de polissacarídeo apresenta um máximo em condições fisiológicas $(45,271$ $\mathrm{mg}_{\mathrm{p}} \cdot \mathrm{gx}^{-1} \cdot \mathrm{h}^{-1} \mathrm{em} \mathrm{pH} 7,2$ e $37,1^{\circ} \mathrm{C}$ ), com a inibição pelo acetato também maior em $\mathrm{pH}$ alcalino $\left(12,083 \mathrm{~g}_{\mathrm{A}} \cdot \mathrm{L}^{-1}\right.$ em pH 7,5 contra $\left.6,541 \mathrm{~g}_{\mathrm{A}} \cdot \mathrm{L}^{-1} \mathrm{em} \mathrm{pH} 6,3\right)$; a liberação de polissacarídeo ao sobrenadante também é maior em $\mathrm{pH}$ mais alto ( $88 \% \mathrm{em} \mathrm{pH} 7,5$ contra $55 \%$ em pH 6,3). Tanto a produtividade de polissacarídeo quanto sua massa molecular mostraram um valor máximo em $\mathrm{pH} 7,1$, porém a produtividade foi maior em temperaturas mais altas $\left(117,89 \mathrm{mg} \cdot \mathrm{L}^{-1} \cdot \mathrm{h}^{-1} \mathrm{em} 37^{\circ} \mathrm{C}\right.$ contra $67,24 \mathrm{mg} \cdot \mathrm{L}^{-1} \cdot \mathrm{h}^{-1} \mathrm{em}$ $29^{\circ} \mathrm{C}$ ) enquanto que para a massa molecular foi observado o contrário $(642 \mathrm{kDa}$ em $29^{\circ} \mathrm{C}$ contra $472 \mathrm{kDa}$ em $37^{\circ} \mathrm{C}$ ). A partir destes resultados, as condições otimizadas de cultivo foram definidas como $\mathrm{pH}$ de 7,1 e temperatura de $30^{\circ} \mathrm{C}$. Nestas condições, a massa molecular obtida foi cerca de $78 \%$ maior $(643 \mathrm{kDa})$ que nas condições da literatura de $37{ }^{\circ} \mathrm{C}$ e pH 7,5 (361 kDa), com uma produção de polissacarídeo equivalente nos dois casos $\left(1400 \mathrm{mg}_{\mathrm{P}} \mathrm{L}^{-1}\right)$. Esse aumento resultou em maior recuperação na primeira etapa de purificação (de 44 para $75 \%$ ), comprovando assim que a nova condição otimizada de cultivo pode contribuir no aumento dos rendimentos nas etapas subsequentes de purificação e conjugação do polissacarídeo, garantir maior eficiência do processo, possibilitar a diminuição de escala e impactar na redução do custo final da vacina. Suporte financeiro de Fundação Butantan e BNDES (№ 11.2.0322.1/2012).

Palavras-chave: Haemophilus. Polissacarídeos bacterianos. Modelos matemáticos. Planejamento de experimentos ótimos. Vacinas. Bactérias Gram-negativas. 


\begin{abstract}
Cintra FO. Mathematical modelling and optimization of the production of exopolysaccharide from Haemophilus influenzae type b. [dissertation (Master in Biotechnology)]. São Paulo: Instituto de Ciências Biomédicas, Universidade de São Paulo; 2014.

Haemophilus influenzae type $\mathrm{b}(\mathrm{Hib})$ is a bacterium that is pathogenic to the human being, causing pneumonia, sepsis and meningitis. The capsular polysaccharide conjugated to a protein is used as antigen in polyvalent vaccines, where it represents more than half of the total price of the formulation. This high cost for the Hib vaccine arises among other reasons from the low recovery ratios throughout the culture, purification and conjugation processes, due to the chemical instability of the polysaccharide. This work considers the interface between culture and purification as the subject for the optimization of the polysaccharide production. First, a kinetic model was selected, that describes the cellular growth as being inhibited by acetate; acetate formation as being of the mixed type; and polyssacharide formation as being non-growth associated and also undergoing acetate inhibition. Then, a design of experiments was carried out in order to evaluate the effects of $\mathrm{pH}$ and temperature on the kinetic parameters. It was demonstrated that the rate of growth is maximum at $\mathrm{pH} 6.73\left(0.644 \mathrm{~h}^{-1}\right)$; the inhibition constant is higher at alkaline $\mathrm{pH}\left(9.907 \mathrm{~g}_{\mathrm{A}} \cdot \mathrm{L}^{-1}\right.$ at $\mathrm{pH}$ 7.5 against $5.819 \mathrm{~g}_{\mathrm{A}} \cdot \mathrm{L}^{-1}$ at $\mathrm{pH}$ 6.3); the growth associated acetate formation is also higher at alkaline $\mathrm{pH}\left(0.796 \mathrm{~g}_{\mathrm{A}} \cdot \mathrm{gx}^{-1}\right.$ at $\mathrm{pH} 7.5$ against $0.477 \mathrm{~g}_{\mathrm{A} . \mathrm{gx}^{-1}}$ at $\mathrm{pH}$ 6.3) while the non-associated part is more influenced by temperature, achieving $0.141 \mathrm{~g}_{\mathrm{A}} \cdot \mathrm{gx}^{-1} \cdot \mathrm{h}^{-1}$ at $37^{\circ} \mathrm{C}$ and $\mathrm{pH} 6.3$; the polysaccharide formation presented an optimum at physiological conditions (45.271 $\mathrm{mg}_{\mathrm{p}} \cdot \mathrm{gx}^{-1} \cdot \mathrm{h}^{-1}$ at $\mathrm{pH} 7.2$ and $\left.37.1^{\circ} \mathrm{C}\right)$, with the inhibition constant also higher at elevated $\mathrm{pH}\left(12.083 \mathrm{~g}_{\mathrm{A}} \cdot \mathrm{L}^{-1}\right.$ at $\mathrm{pH} 7.5$ against $6.541 \mathrm{gA}_{\mathrm{A}} \mathrm{L}^{-1}$ at $\mathrm{pH} 6.3$ ); the rate of polysaccharide release from the cells was also increased at higher $\mathrm{pH}(88 \%$ at $\mathrm{pH} 7.5$ against $55 \%$ at $\mathrm{pH} 6.3)$; both polysaccharide productivity and molecular mass were optimal at $\mathrm{pH} 7.1$, though productivity was increased by temperature $\left(117.89 \mathrm{mgp} \cdot \mathrm{L}^{-1} \cdot \mathrm{h}^{-1}\right.$ at $37^{\circ} \mathrm{C}$ against $67,24 \mathrm{mgp} \cdot \mathrm{L}^{-1} \cdot \mathrm{h}^{-1}$ at $29^{\circ} \mathrm{C}$ ) while the opposite was true for the molecular mass $\left(642 \mathrm{kDa}\right.$ at $29^{\circ} \mathrm{C}$ against $472 \mathrm{kDa}$ at $37^{\circ} \mathrm{C}$ ). From these results, the optimal conditions were defined as $\mathrm{pH} 7.1$ and $30{ }^{\circ} \mathrm{C}$. In these conditions, the molecular mass was $78 \%$ higher $(643 \mathrm{kDa})$ than the described in the literature, with $\mathrm{pH} 7.5$ and $37^{\circ} \mathrm{C}(361 \mathrm{kDa})$, achieving the same amount of polysaccharide $\left(1400 \mathrm{mg}_{\mathrm{p}} \cdot \mathrm{L}^{-1}\right)$. This new scenery resulted in higher recovery at the first step of purification (from 44 to $75 \%$ ), thus confirming that the new conditions may also improve the yields in the following steps of purification and conjugation, ensuring better efficiency, enabling reduction of scale and minimizing the final cost of the vaccine. Supported by Fundação Butantan and BNDES ( ${ }^{\circ}$ 11.2.0322.1/2012).
\end{abstract}

Keywords: Haemophilus. Bacterial polysaccharides. Mathematical models. Design of experiments. Vaccines. Gram-negative bacteria. 


\section{LISTA DE FIGURAS}

Figura 1 - Evolução da média dos preços por dose das vacinas DTP, Hib, HepB e

suas combinações contratados pela UNICEF junto aos produtores .................22

Figura 2 - Rede metabólica central de H. influenzae........................................25

Figura 3 - Cadeia de transporte de elétrons de $H$. influenzae ............................27

Figura 4 - Representação do locus cap de Hib..................................................28

Figura 5 - Estrutura química da molécula de PRP .............................................

Figura 6 - Dados experimentais e modelo ajustado para o ensaio 1 ....................54

Figura 7 - Dados experimentais e modelo ajustado para o ensaio 2 .......................54

Figura 8 - Dados experimentais e modelo ajustado para o ensaio 3 ......................55

Figura 9 - Dados experimentais e modelo ajustado para o ensaio 4 ....................55

Figura 10 - Dados experimentais e modelo ajustado para o ensaio 5 .....................55

Figura 11 - Dados experimentais e modelo ajustado para o ensaio 6 ….................56

Figura 12 - Dados experimentais e modelo ajustado para o ensaio 7 …................56

Figura 13 - Dados experimentais e modelo ajustado para o ensaio 8 ….................56

Figura 14 - Dados experimentais e modelo ajustado para o ensaio 9 ....................57

Figura 15 - Dados experimentais e modelo ajustado para o ensaio 10 …...............57

Figura 16 - Superfície de resposta para $\mu_{\max }$ com o modelo estatístico ajustado ....59

Figura 17 - Superfície de resposta para $k_{x}$ com o modelo estatístico ajustado ........61

Figura 18 - Superfície de resposta para $n_{x}$ com o modelo estatístico ajustado ........62

Figura 19 - Comparação dos valores observados de biomassa com a simulação do crescimento sem o efeito de inibição pelo ácido acético .................................63

Figura 20 - Superfície de resposta para $\alpha_{A}$ com o modelo estatístico ajustado .......65

Figura 21 - Superfície de resposta para $\beta_{A}$ com o modelo estatístico ajustado .......66

Figura 22 - Superfície de resposta para $\beta_{P}$ com o modelo estatístico ajustado .......69

Figura 23 - Superfície de resposta para $k_{P}$ com o modelo estatístico ajustado ........71

Figura 24 - Superfície de resposta para $n_{P}$ com o modelo estatístico ajustado ........72

Figura 25 - Perfis de PRP total e livre em cada condição de cultivo........................75

Figura 26 - Superfície de resposta para proporção de PRP liberada ao sobrenadante com o modelo estatístico ajustado .......................................... 74

Figura 27 - Perfil da máxima produtividade de PRP em relação aos valores de pH e

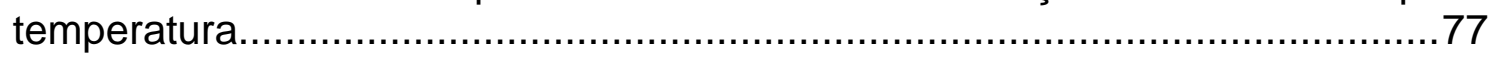

Figura 28 - Perfis de massa molecular em relação à evolução da concentração de

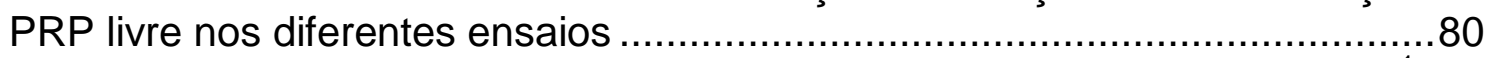

Figura 29 - Perfil da massa molecular de PRP na concentração de $500 \mathrm{mg}_{\mathrm{P} . \mathrm{L}^{-1}}$ em relação aos valores de $\mathrm{pH}$ e temperatura. .................................................... 82

Figura 30 - Perfil cinético para o cultivo em batelada alimentada nas condições de

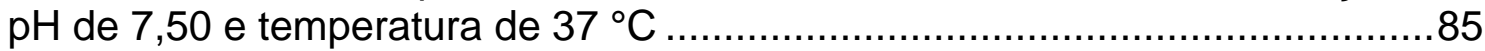

Figura 31 - Perfil cinético para o cultivo em batelada alimentada nas condições de

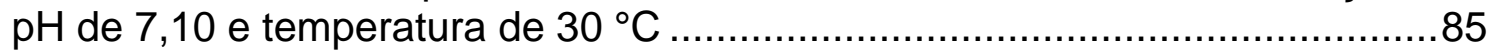

Figura 32 - Perfil de massa molecular em relação à concentração de PRP livre para os cultivos em batelada alimentada .............................................................. 86 


\section{LISTA DE TABELAS}

Tabela 1 - Configuração do DCCR quanto ao $\mathrm{pH}$ e à temperatura para avaliação da

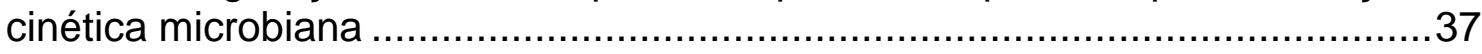

Tabela 2 - Composição do meio ágar chocolate …............................................38

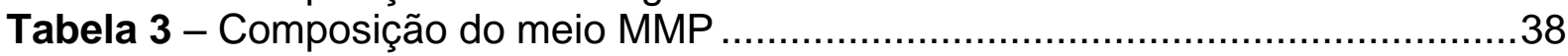

Tabela 4 - Modelos de formação de biomassa testados ......................................43

Tabela 5 - Modelos de formação de acetato e PRP testados .................................43

Tabela 6 - Modelos de inibição sobre o acetato e PRP testados .............................44

Tabela 7 - Modelos parciais testados para as variáveis biomassa e acetato............44

Tabela 8 - Modelos combinados testados para a variável PRP.............................45

Tabela 9 - Valores de W\% obtidos para os modelos parciais de formação de biomassa, formação de acetato e inibição sobre o acetato em cada ensaio. ...51

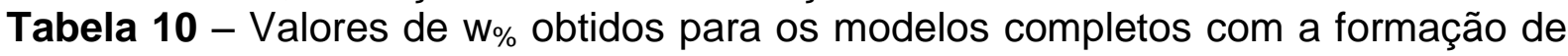
PRP e inibição sobre o PRP em cada ensaio.............................................52

Tabela 11 - Valores de $\mu_{\max }$ obtidos para as variações de $\mathrm{pH}$ e temperatura ...........58

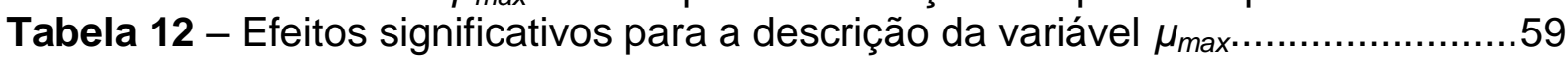

Tabela 13 - Valores de $k_{x}$ obtidos para as variações de $\mathrm{pH}$ e temperatura ..............60

Tabela 14 - Efeitos significativos para a descrição da variável $k_{x} \ldots \ldots \ldots \ldots \ldots \ldots \ldots \ldots \ldots . . . . .60$

Tabela 15 - Valores de $n_{x}$ obtidos para as variações de $\mathrm{pH}$ e temperatura...............61

Tabela 16 - Efeitos significativos para a descrição da variável $n_{X} \ldots \ldots \ldots \ldots \ldots \ldots \ldots \ldots \ldots . . . . . .61$

Tabela 17 - Valores de $\alpha_{A}$ obtidos para as variações de $\mathrm{pH}$ e temperatura..............64

Tabela 18 - Efeitos significativos para a descrição da variável $\alpha_{A} \ldots \ldots \ldots \ldots \ldots \ldots \ldots \ldots \ldots . . . . .65$

Tabela 19 - Valores de $\beta_{A}$ obtidos para as variações de $\mathrm{pH}$ e temperatura..............66

Tabela 20 - Efeitos significativos para a descrição da variável $\beta_{A} \ldots \ldots \ldots \ldots \ldots \ldots \ldots \ldots \ldots . . . .66$

Tabela 21 - Valores de $\beta_{P}$ obtidos para as variações de $\mathrm{pH}$ e temperatura ..............68

Tabela 22 - Efeitos significativos para a descrição da variável $\beta_{P} \ldots \ldots \ldots \ldots \ldots \ldots \ldots \ldots \ldots . . . . .69$

Tabela 23 - Valores de $k_{P}$ obtidos para as variações de $\mathrm{pH}$ e temperatura ..............70

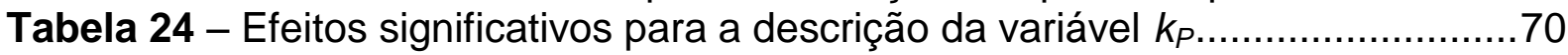

Tabela 25 - Valores de $n_{P}$ obtidos para as variações de $\mathrm{pH}$ e temperatura..............71

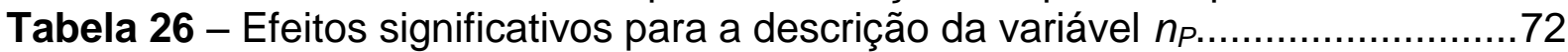

Tabela 27 - Proporção de PRP liberada ao sobrenadante em cada condição de cultivo........................................................................................

Tabela 28 - Efeitos significativos para a descrição da proporção de PRP liberada ao sobrenadante ..................................................................................... 74

Tabela 29 - Produtividade máxima de PRP liberada ao sobrenadante em cada condição de cultivo ...........................................................................76

Tabela 30 - Efeitos significativos para a descrição da proporção de PRP liberada ao

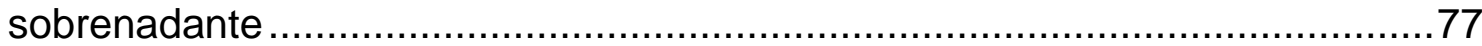

Tabela 31 - Massa molecular do PRP livre no instante onde a concentração equivale a $500 \mathrm{mg}_{\mathrm{P}} \mathrm{L}^{-1} \mathrm{em}$ cada condição de cultivo ....................................... 81

Tabela 32 - Efeitos significativos para a descrição da massa molecular de PRP

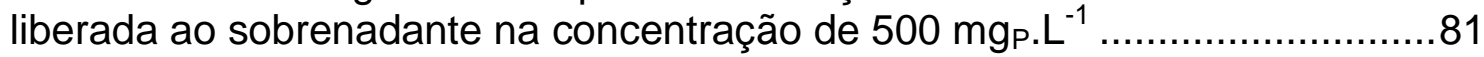

Tabela 33 - Parâmetros cinéticos ajustados aos cultivos em batelada alimentada.. 86

Tabela 34 - Rendimentos do processo e projeções entre as condições padrão e otimizada 


\section{LISTA DE ABREVIATURAS E SIGLAS}

2PG: 2-fosfoglicerato

3PG: 3-fosfoglicerato

aKG: $\alpha$-cetoglutarato

Ac: Acetato

Ac-CoA: Acetil-Coenzima A

Ac-P: Acetil fosfato

$A I C_{C}$ : Critério de informação de Akaike corrigido

ADP: Adenosina difosfato

ATP: Adenosina trifosfato

BPG: Bisfosfoglicerato

CAT: Ciclo dos ácidos tricarboxilicos

CDP-ROH: Citidina difosfato ribitol

COD: Concentração de oxigênio dissolvido

CTAB: Brometo de cetiltrimetilamônio

CTE: Cadeia de transporte de elétrons

DHAP: Di-hidroxiacetona fostfato

DCCR: Delineamento composto central rotacional

$\mathrm{DO}_{540}$ : Densidade ótica a $540 \mathrm{~nm}$

DTP: Difiteria-Tétano-Pertussis (formulação vacinal)

EDO: Equação diferencial ordinária

Ery-4P: Eritrose 4-fosfato

GAVI: Global Alliance for Vaccine Innovation

G3P: Gliceraldeído 3-fosfato

FBP: Frutose 1,6-bisfosfato

For: Formiato

Fru-6P: Frutose 6-fosfato

Fum: Fumarato

Glc: Glicose

Glc-6P: Glicose 6-fosfato

Glu: Glutamato

Hep-7P: Sedoheptulose 7-fosfato

HepB: Hepatite B

Hib: Haemophilus influenzae tipo b

HPAEC-PAD: Cromatografia de troca aniônica de alta eficiência com detecção por amperometria pulsada.

HPLC: Cromatografia líquida de alta eficiência

HPSEC-RI: Cromatografia de exclusão por tamanho de alta eficiência com detecção por índice de refração

Lac: Lactato

Mal: Malato

MFT: Microfiltração tangencial

MK: Menaquinona

$\mathrm{MKH}_{2}$ : Menaquinol

MMP: Modified Medium Peptone

NAD: Nicotinamida adeninda dinucleotídeo

OAA: Oxaloacetato

OMS: Organização Mundial da Saúde 
PEP: Fosfoenolpiruvato

PRP: Poli-ribosil-ribitol-fosfato

Pyr: Piruvato

Rbl: Ribulose 5-fosfato

Rib-5P: Ribose 5-fosfato

ROH-5P: Ribitol 5-fosfato

RNA: Acido ribonucleico

Suc: Succinato

Suc-CoA: Succinil-Coenzima A

UNICEF: United Nations Children's Fund

UFC: Unidades formadoras de colônia

UFT: Ultrafiltração tangencial

vvm: volume de ar por volume de meio por minuto

Xyl-5P: Xilulose 5-fosfato 


\section{LISTA DE SÍMBOLOS}

$\alpha_{A}$ : Constate de formação de acetato associada ao crescimento

$\alpha_{P}$ : Constate de formação de PRP associada ao crescimento

$\beta_{A}$ : Constate de formação de acetato não associada ao crescimento

$\beta_{P}$ : Constate de formação de PRP não associada ao crescimento

$\Delta p$ : Força próton-motora

$\Delta \varphi$ : Diferença de potencial transmembrana

$\mu$ : Velocidade específica de crescimento celular

$\mu_{\max }$ : Máxima velocidade específica de crescimento celular

$A$ : Concentração de acetato

$B$ : Concentração de um produto genérico do metabolismo

$F$ : Constante de Faraday

I: Fator de inibição pelo acetato

$k_{A}$ : Coeficiente de inibição do acetato sobre a formação de acetato

$k_{P}$ : Coeficiente de inibição do acetato sobre a formação de PRP

$k_{X}$ : Coeficiente de inibição do acetato sobre a formação de biomassa

$M_{n}$ : Média numérica da massa molecular

$M_{w}$ : Média mássica da massa molecular

$n_{A}$ : Expoente do fator de inibição sobre 0 acetato

$n_{P}$ : Expoente do fator de inibição sobre o PRP

$n_{X}$ : Expoente do fator de inibição sobre a biomassa

$P$ : Concentração de PRP

$R$ : Constante universal dos gases

$R^{2}$ : Coeficiente de determinação

$X$ : Concentração de biomassa

$w_{\%}$ : Peso de Akaike 
1 INTRODUÇÃO

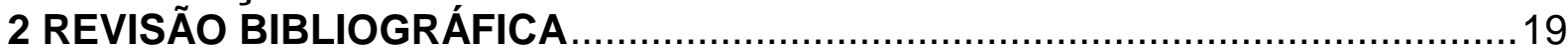

2.1 Haemophilus influenzae: do microrganismo à vacina ..............................19

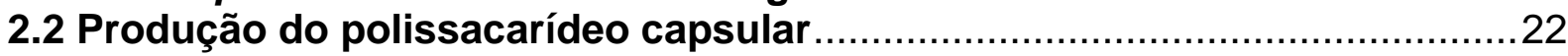

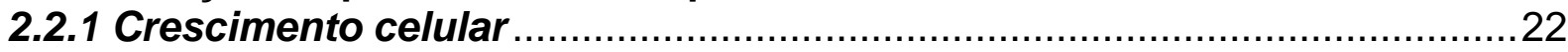

2.2.1.1 Rede metabólica .............................................................................23

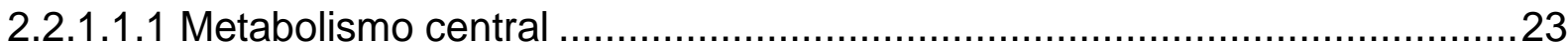

2.2.1.1.2 Cadeia de transporte de elétrons e fosforilação oxidativa ..........................26

2.2.1.1.3 Síntese de PRP ........................................................................27

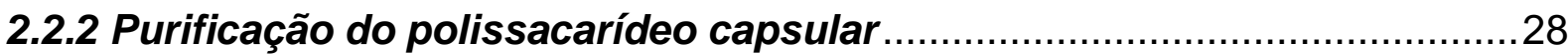

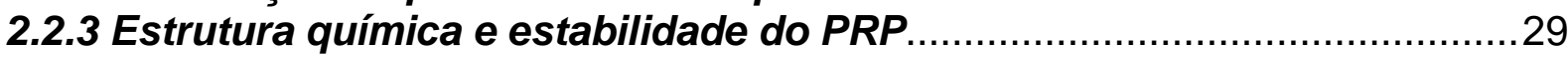

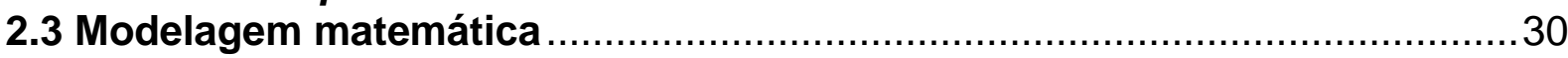

2.3.1 Modelos descritos para as cinéticas microbianas ...................................30

2.3.2 A velocidade de crescimento e a influência do $\mathrm{pH}$ e da temperatura ........32

2.3.3 A formação de produto e a influência do $\mathrm{pH}$ e da temperatura ...................33

2.3.4 A inibição pelo ácido e a influência do pH..............................................

2.3.5 A geração de energia e a influencia do $\mathrm{pH}$ e da temperatura......................35

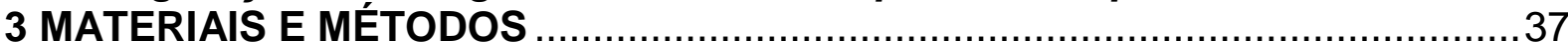

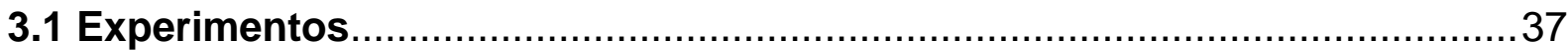

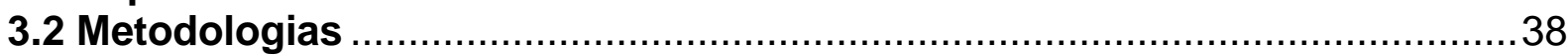

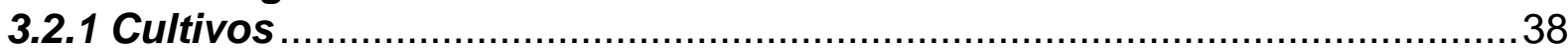

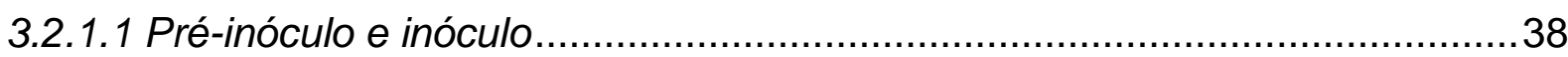

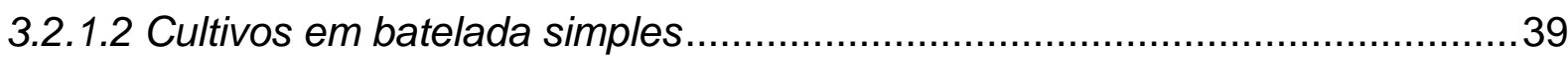

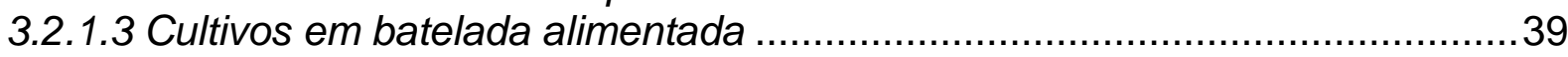

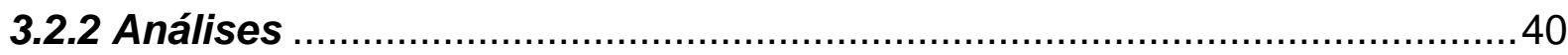

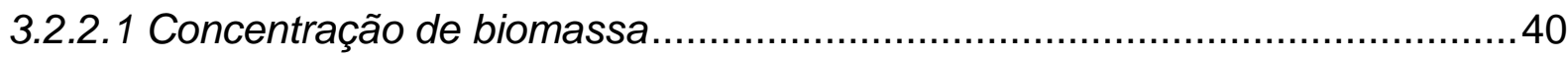

3.2.2.2 Concentração de ácidos orgânicos e carboidratos.......................................40

3.2.2.3 Concentração de PRP............................................................................. 41

3.2.2.4 Determinação da massa molecular ........................................................ 41

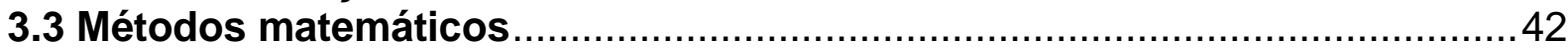

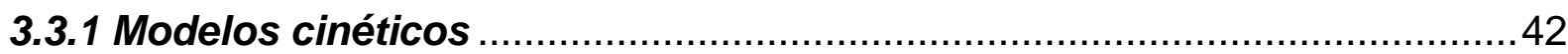

3.3.1.1 Ajuste de parâmetros .................................................................. 45

3.3.1.2 Seleção do melhor modelo cinético.................................................... 46

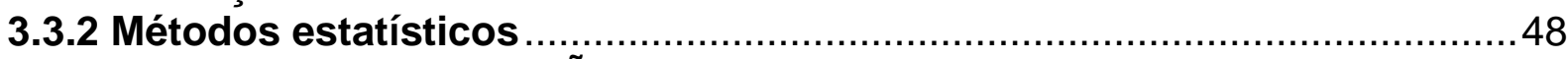

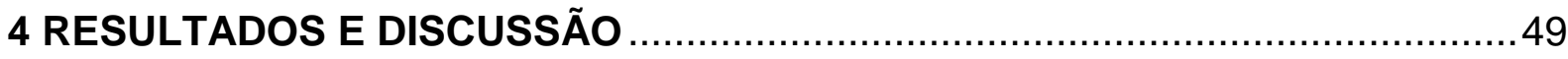

4.1 Escolha do modelo cinético para o cultivo de Hib ...................................50

4.2 Efeitos do $\mathrm{pH}$ e temperatura sobre a cinética microbiana ..........................57

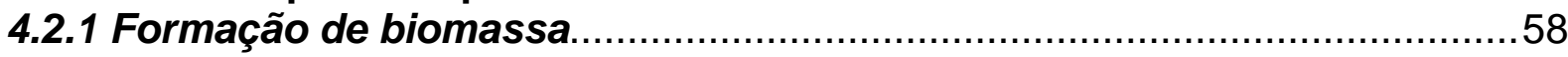

4.2.1.1 Máxima velocidade específica de crescimento ............................................58

4.2.1.2 Fator de inibição pelo acetato sobre o crescimento ...................................59

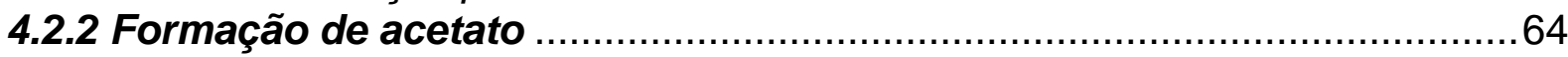

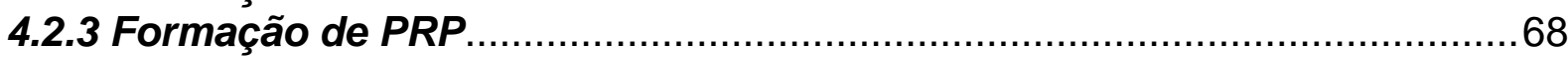

4.2.3.1 Constante de formação específica de PRP..............................................68

4.2.3.2 Fator de inibição pelo acetato sobre a formação de PRP ............................70

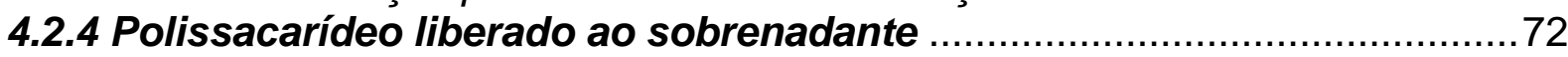

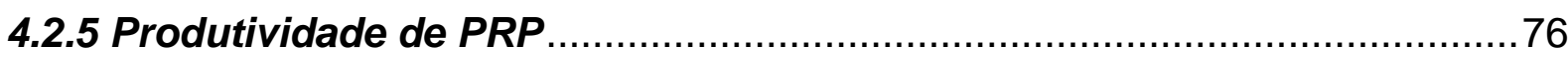

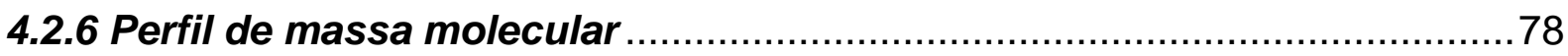


4.3 Comparação entre os processos padrão e otimizado ............................. 84

4.3.1 Etapa de crescimento celular............................................................. 84

4.3.2 Primeira etapa de purificação e projeções do processo global.................87

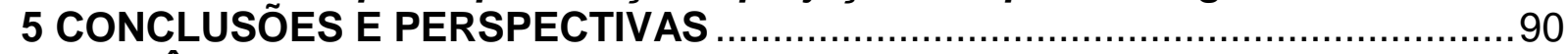

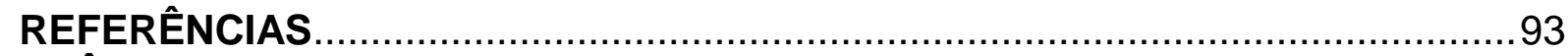

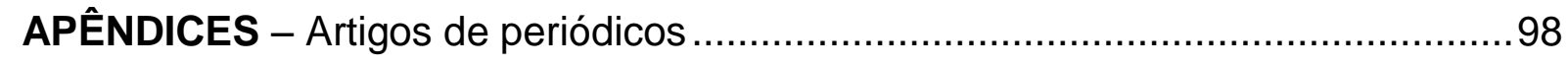




\section{INTRODUÇÃO}

Haemophilus influenzae tipo b (Hib) é uma bactéria de grande importância médica, sendo responsável por graves infecções em indivíduos de baixa imunidade, como crianças menores de cinco anos de idade e idosos. A Hib é capaz de originar quadros clínicos severos, entre eles as pneumonias, septicemias e meningites, sendo que a última é a forma pela qual a bactéria se torna mais perigosa, levando o enfermo a óbito ou causando sequelas neurológicas graves. As infecções por Hib têm sido controladas com sucesso desde a década de 1980 nos países desenvolvidos através da vacinação com o polissacarídeo capsular conjugado a um carreador proteico. A extensão da cobertura da vacinação a países subdesenvolvidos tem sido incentivada por órgãos internacionais de saúde, como a Organização Mundial da Saúde (OMS), através da inclusão do componente Hib em vacinas polivalentes, como a combinação com as vacinas tríplice de difteria, tétano e pertussis (DTP) e com a vacina de hepatite $B(H e p B)$.

A produção da vacina conjugada de Hib é realizada pelas grandes indústrias farmacêuticas, e vem sendo implementada em institutos públicos nos últimos anos. Entretanto, os processos de produção são demasiadamente caros, tornando a inserção do componente Hib como integrante das vacinas um dos principais fatores que dificultam a inclusão destas nos programas de imunização globais. $O$ projeto institucional no qual este trabalho se insere possui três frentes:

1) otimização do processo de cultivo celular e produção de polissacarídeo;

2) otimização e simplificação dos protocolos de separação celular e purificação;

3) otimização da conjugação do polissacarídeo e caracterização do produto final.

Os estudos da etapa de cultivo celular e produção de polissacarídeo são centrados na caracterização dos processos bioquímicos envolvidos, com a caracterização dos principais fatores que determinam a produtividade do polissacarídeo capsular e a recuperação do mesmo nas etapas seguintes de purificação. Neste contexto, os objetivos gerais do trabalho desenvolvido nesta etapa são:

- definir os fenômenos químicos e bioquímicos envolvidos na formação e isolamento do polissacarídeo capsular; 
- caracterizar a interface cultivo/purificação como um ponto de grande atenção para a otimização da produção do polissacarídeo;

- simular os processos de produção e purificação a fim de entender os mecanismos envolvidos, além de fornecer ferramentas para a predição das condições ótimas de produção.

Uma vez definida a interface cultivo/purificação como uma etapa essencial para o desenvolvimento dos bioprocessos relacionados à produção do polissacarídeo, novos critérios de otimização são encontrados. Estes critérios devem levar em consideração não apenas a produtividade mássica do polissacarídeo capsular, mas também a qualidade da molécula, o que irá influenciar na recuperação do processo de purificação. Para isso, se faz necessário encontrar modelos teóricos que permitam relacionar os fatores importantes para o crescimento celular com a purificação, e vice-versa. Assim, os objetivos específicos deste trabalho serão:

- relacionar as condições de cultivo à estabilidade química do polissacarídeo e à sua massa molecular durante o processo;

- definir as condições de cultivo que alteram as cinéticas de produção durante o crescimento através de modelos estatísticos, comparando-os aos modelos formais descritos na literatura;

- otimizar o processo de produção do polissacarídeo no sentido de maximizar sua massa molecular;

- criar bases para um modelo global que relacione a máxima produtividade de PRP com as taxas de recuperação durante a purificação.

Inicialmente será apresentada uma revisão bibliográfica, onde serão abordadas: a importância da vacinação contra Hib no cenário das políticas públicas de saúde; a produção do antígeno vacinal e os gargalos de desenvolvimento que dificultam a obtenção de um processo de baixo custo; os fatores químicos e bioquímicos que resultam nos gargalos observados; e as ferramentas da Engenharia Bioquímica que podem dar subsídio à otimização do processo, tal como a modelagem matemática. Posteriormente, serão apresentados os experimentos realizados e as metodologias utilizadas na obtenção e tratamento dos dados e os experimentos realizados; em seguida, os resultados obtidos juntamente com as discussões; e finalizando-se com as conclusões. A parte experimental do trabalho 
foca na busca por alternativas para manutenção da integridade da molécula durante o processo de produção e avalia o impacto das alternativas tomadas nos demais parâmetros do processo. 


\section{REVISÃO BIBLIOGRÁFICA}

\subsection{Haemophilus influenzae: do microrganismo à vacina}

Haemophilus influenzae é uma bactéria Gram negativa patogênica ao ser humano, podendo causar infecções como otite, celulite, artrite séptica, osteomielite, pericardite, epiglotite, septicemia, pneumonia e meningite. Foi isolada pela primeira vez em 1896 durante uma pandemia de influenza, sendo erroneamente caracterizada como o agente etiológico desta doença (Kuhnert, Christensen, 2008). Já no ano de 1995, a $H$. influenzae foi o primeiro organismo de vida livre a ter seu genoma completamente sequenciado (Fleischmann et al., 1995).

Existem 6 sorotipos da bactéria que são diferenciados pela composição química do polissacarídeo capsular (classificados com as letras de 'a' a 'f'), além das linhagens não tipáveis que não possuem cápsula (World Health Organization, 2006). O sorotipo b (Hib) é a linhagem mais virulenta e responsável pelas formas de infecção mais perigosas, aparecendo em até $90 \%$ dos casos de infecção por $H$. influenzae (Yogev et al., 1990). Em comparação com os outros agentes etiológicos de meningites bacterianas não epidêmicas, como Neisseria meningitidis e Streptococcus pneumoniae, Hib é o mais prevalente em populações não vacinadas. Crianças menores de 5 anos, idosos e indivíduos imunodeprimidos são os mais propensos a infecções por Hib, sendo que até $20 \%$ dos casos levam a óbito mesmo com administração adequada de antibióticos, e entre os sobreviventes cerca de 30 a $40 \%$ desenvolvem sequelas neurológicas severas como deficiência auditiva, retardo mental, convulsões, atraso no desenvolvimento cognitivo e paralisia (Wilfert, 1990). Em 2000, mais de 8 milhões de casos de infecção e aproximadamente 371 mil óbitos por Hib foram estimados em todo o mundo, sendo que esta estimativa pode ser subestimada devido à dificuldade de diagnóstico em países sem recursos adequados, além da interferência da administração de antibióticos no resultado dos exames (Watt et al., 2009).

No caso do sorotipo $b$, a bactéria possui uma cápsula polissacarídica constituída de poli-ribosil-ribitol-fosfato (PRP), que é o principal fator de virulência e se apresenta como o antígeno utilizado na vacina contra infecções por Hib, sendo eficiente na indução de imunidade artificial e muito seguro, raramente conduzindo a reações adversas (Crisel et al., 1975; WHO, 2006). A primeira vacina para Hib foi 
introduzida pela primeira vez no mundo em 1985 na América do Norte, e era constituída somente pelo polissacarídeo purificado. No entanto, esta vacina era ineficiente em proteger crianças com menos de 18 meses de idade devido à incapacidade de originar uma resposta imune T-dependente. Isto foi contornado com a introdução da vacina conjugada em 1987, onde o polissacarídeo é ligado covalentemente a uma proteína carregadora, como os toxoides diftérico (DT) ou tetânico (TT) ou a proteína de membrana externa de Neisseria meningitidis grupo B (Bisgard et al., 1998). A vacina de polissacarídeo conjugado, utilizada até hoje, é capaz de proteger eficientemente crianças a partir de seis meses de idade. Em 1991 a vacina de Hib foi introduzida nas companhas de vacinação da Europa, e no Brasil apenas em 1999. Em 2010, a vacina já era fornecida publicamente em praticamente todos os países desenvolvidos, entre os continentes europeu e americano. $\mathrm{Na}$ África, a maioria dos países chegou a introduzir a vacina, porém a cobertura de vacinação não atingia a totalidade da população. As regiões que ainda não haviam introduzido a vacina em 2010 são o Oriente Médio, Ásia e parte da Oceania (WHO, 2013).

A introdução da vacina de Hib nos países em desenvolvimento vem sendo encorajada pela Organização Mundial da Saúde (OMS) e pela Global Alliance for Vaccine Innovation (GAVI), que a partir de 2005 colocaram em prática um programa denominado Hib Initiative, alocando 37 milhões de dólares num período de 4 anos em programas de disseminação de pesquisas e dados científicos sobre a bactéria e a doença a fim de conscientizar os governos e as instituições de saúde pública sobre a necessidade de prevenção desta enfermidade. Esta iniciativa foi responsável por agilizar a inclusão da vacina nos países menos desenvolvidos; o atraso médio, quando comparado com os países desenvolvidos, foi de cerca de 10 anos. (Global Alliance for Vaccine Innovation, 2013)

Mesmo com a introdução da vacina na grande maioria dos países a cobertura ainda não atinge a totalidade da população em muitos lugares, mantendo as taxas de infecção altas. Nos continentes africano e asiático alguns países apresentam taxas de infecção superiores a 1000 casos por 100.000 crianças abaixo dos 5 anos de idade, entre eles os países da África Oriental e Austral, Iraque, Índia, China, os países do sudeste asiático, Paraguai, Suriname, Guiana e alguns países da América Central, enquanto estimativas acima de 2000 casos são observadas em países da 
África Central e Ocidental, Paquistão, Afeganistão e em alguns países da Península Indochinesa (GAVI, 2013).

Já no restante do mundo, as taxas se mantêm baixas devido ao eficiente programa de vacinação. A grande incidência nos países subdesenvolvidos mostra a necessidade de suporte externo para o sucesso do programa de vacinação, que é o objetivo maior da GAVI. A maioria destes países, com poucas exceções, já possui aprovação para receber o suporte financeiro e de suprimentos da GAVI para prevenção do Hib, ou se encontram em processo de aprovação.

Atualmente, os programas públicos de vacinação não fornecem a vacina de Hib isoladamente, mas numa formulação conjunta com a DTP (difteria-tetanuspertussis), formando a tetravalente infantil, com a incorporação da vacina de hepatite B (HepB) na tetravalente, formando a pentavalente, ou ainda com a introdução da vacina inativada de poliomielite à pentavalente, formando a hexavalente. A formulação combinada DTP-Hib-HepB é a formulação que recebe o incentivo da OMS e da GAVI para inclusão nos programas públicos de vacinação, sendo esta a formulação fornecida pelos produtores mundiais para as organizações no próximo triênio, e também a formulação do calendário público brasileiro desde 2012 (Ministério da Saúde, 2014; Sociedade Brasileira de Imunizações, 2012; United Nations Children's Fund, 2013).

Entre os fornecedores mundiais das vacinas DTP, HepB, Hib e suas combinações estão a Biological E Ltd., a LG Life Sciences, Crucell Switzerland AG, a Panacea Biotec Ltd., a Shantha Biotechnics Ltd., o Serum Institute of India Ltd., a GlaxoSmithKline Biologicals S.A., a Sanofi Pasteur, a Novartis Vaccines and Diagnostics, a Persero, a CSL Limited e a BioFarma (UNICEF, 2013). A Figura 1 mostra o valor médio dos preços por dose durante o período de 2001 a 2013, especificando o preço das formulações tríplice (DTP), tetravalente Hib (DTP-Hib), tetravalente HepB (DTP-HepB) e pentavalente (DTP-HepB-Hib). Nela, pode-se visualizar claramente que o custo do componente Hib equivale a mais da metade do custo total da formulação.

Apesar da aparente queda no custo da vacina pentavalente a partir de 2010, os preços contratados pela UNICEF junto às farmacêuticas para o triênio de $2014 \mathrm{a}$ 2016 mostram uma tendência de estabilização, variando entre US $\$ 1,85$ e US\$2,80 por dose (UNICEF, 2013). Com estes dados, fica evidente que a diminuição do custo de produção da vacina de Hib é essencial para permitir a abrangência mundial da 
cobertura de forma sustentável pelos órgãos públicos de saúde. Esta redução será possibilitada pela otimização dos processos de produção, minimizando as perdas e os gastos com insumos de produção.

Figura 1 - Evolução da média dos preços por dose das vacinas DTP, Hib, HepB e suas combinações contratados pela UNICEF junto aos produtores

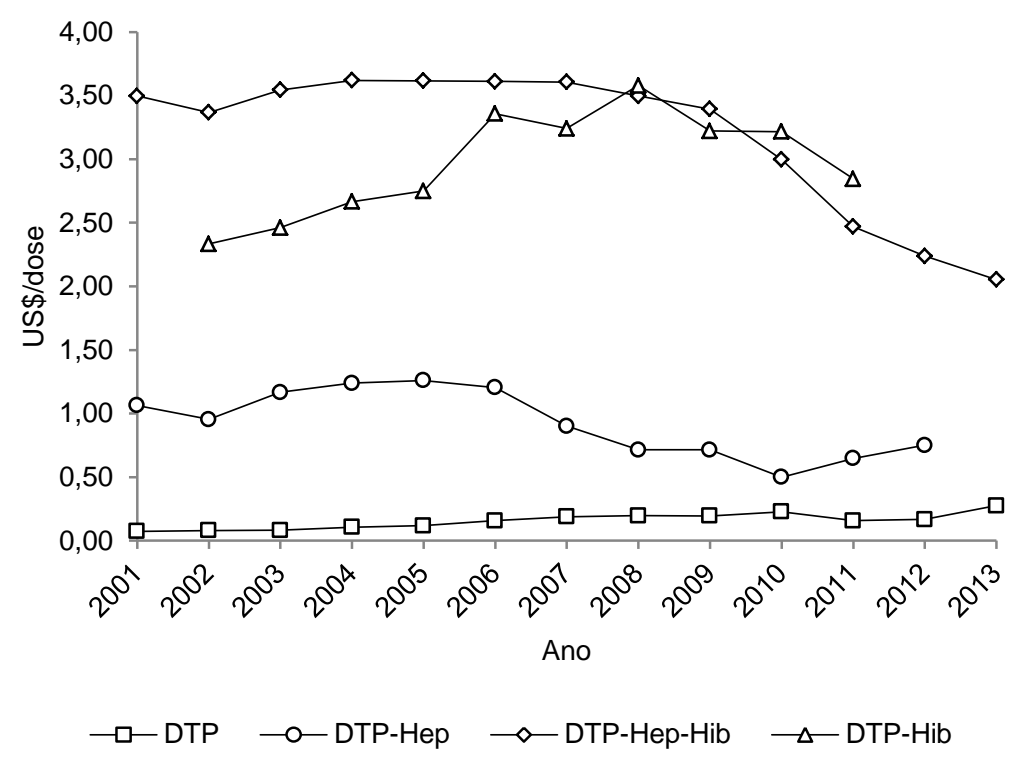

FONTE: Adaptado de UNICEF (2013).

\subsection{Produção do polissacarídeo capsular}

A produção da vacina conjugada de Hib pode ser dividida em três processos principais: crescimento celular (upstream), purificação (downstream) e conjugação do polissacarídeo ao carreador proteico. No primeiro processo, as células de Hib são propagadas in vitro em condições adequadas, onde o polissacarídeo capsular é liberado para o sobrenadante espontaneamente (Anderson, Smith, 1977). A seguir, faz-se uma revisão dos processos descritos na literatura e dos fenômenos bioquímicos inerentes à etapa de crescimento celular.

\subsubsection{Crescimento celular}

O crescimento celular de Hib em reatores ocorre em meios de cultura complexos, em processos de batelada simples ou alimentada. Reporta-se classicamente na literatura a obtenção de uma quantidade de PRP entre 400 e 500 $\mathrm{mgRP.}_{\mathrm{P}} \mathrm{L}^{-1}$ (Hamidi, Beurret, 2009; Takagi et al., 2003), enquanto a otimização do processo através das alterações das condições de cultivo, tais como vazão e modo 
de aeração, inclusão do controle de pH e controle da concentração de oxigênio dissolvido (COD) foi capaz de elevar a produção acima de $900 \mathrm{mg}_{\mathrm{p} . \mathrm{L}^{-1}}$ (Takagi et al., 2006, 2007). Outros trabalhos de otimização exploram a condução de bateladas alimentadas, com a obtenção de $1300 \mathrm{mg}_{\mathrm{p} . \mathrm{L}^{-1}}$ (Merritt et al., 2000) e $1800 \mathrm{mg}_{\mathrm{p} . \mathrm{L}^{-1}}$ (Silva, 2010). Em todos os casos, a temperatura do cultivo foi mantida em valores fisiológicos, enquanto o $\mathrm{pH}$ foi controlado em valores pouco acima da neutralidade, como 7,30 (Merritt et al., 2000) e 7,50 (Silva, 2010; Takagi et al., 2006, 2007).

A condução dos processos de alimentação do biorreator evidencia que a biomassa tende a atingir valores máximos a partir do qual o crescimento não é mais possível, mesmo com a disponibilidade dos nutrientes. Silva (2010) demonstrou que o acúmulo de acetato no meio de cultura causa efeitos de inibição sobre a célula. A limitação no fornecimento de substrato é uma prática comum para se evitar a formação de subprodutos tóxicos; no caso de Hib, porém, a produção de acetato acompanhou o crescimento celular em qualquer regime de alimentação, sendo a limitação do substrato ineficaz em impedir a sua formação. No mesmo trabalho, ficou evidente que a concentração de acetato muito elevada pode afetar o metabolismo até o ponto onde a bactéria se torna incapaz de até mesmo assimilar a glicose. Esta limitação é possivelmente explicada pela configuração metabólica da bactéria, e a inibição causada pelo subproduto é um importante fator a ser levado em consideração no desenvolvimento do processo (Fleischmann et al., 1995; Silva, 2010).

\subsubsection{Rede metabólica}

\subsection{Metabolismo central}

A Hib é uma bactéria de crescimento fastidioso, exigindo a presença de fatores de crescimento específicos, além de fontes complexas de aminoácidos e vitaminas. Os dois fatores de crescimento que caracterizam a bactéria são o NAD e a hemina, sendo que a bactéria é incapaz de se desenvolver na ausência deles (Evans et al., 1974). Esta exigência surge de deleções naturalmente presentes nas vias de síntese desses cofatores. A bactéria é incapaz de realizar a via de novo da síntese da piridina-nucleotídeos por não possuir muitas das enzimas necessárias, sendo capaz de realizar a síntese de NAD apenas a partir de nicotinamida mononucleotídeo 
(Reidl et al., 2000). No caso da hemina, a dependência se dá devido à presença de apenas uma das sete enzimas responsáveis pela formação do heme a partir do ácido amino-levulínico, essencial para a formação dos citocromos, sendo que a enzima presente é a última da via e apenas realiza a inclusão do íon ferroso na protoporfirina IX (Biberstein et al., 1963; Loeb, 1995). Além destas, existem outras deleções dentro da rede metabólica da Hib que dificultam seu crescimento. Algumas delas são as inúmeras deleções em etapas de síntese de aminoácidos, nucleosídeos e cofatores, fazendo com que muitos deles sejam essenciais para a bactéria. A análise in silico das capacidades metabólicas de Hib evidenciou que o sistema enzimático da bactéria necessita dos aminoácidos arginina, cisteína e glutamato, além do cofator ácido pantotênico e das pirimidinas tiamina e uracila (Schilling, Palsson, 2000). A via de transformação da serina em cisteína, com a assimilação de um grupo sulfeto, existe no genoma de Hib; no entanto a bactéria é incapaz de reduzir o sulfato a sulfeto pela via aeróbia e por isso se considera que seja dependente do fornecimento de cisteína. Contudo, é observado em alguns casos o desenvolvimento da bactéria em ausência do aminoácido, sugerindo que a mesma possua vias anaeróbias de redução do sulfato ainda não descritas (Tatusov et al., 1996).

Pode-se considerar que as deleções mais notáveis dentro do genoma da Hib estão no ciclo dos ácidos tricarboxilicos (CAT), onde estão ausentes a citrato sintase, a aconitase e a isocitrato desidrogenase. Na seção respectiva da Figura 2, pode-se perceber que a ausência dos três passos iniciais resulta no fato de que as estruturas carbônicas provenientes da glicólise nunca chegam a entrar no ramo oxidativo do ciclo, podendo resultar no acúmulo de moléculas de oxidação incompleta tais como o acetato, lactato e formiato.

A Figura 2 mostra que a Hib possui praticamente apenas o braço esquerdo (redutor) do CAT, o que é característico de bactérias anaeróbias. Além disso, verifica-se também que no ciclo está presente a enzima fumarato redutase, em contraponto à ausência da enzima que realiza a reação contrária, a succinato desidrogenase, indicando que este trecho do metabolismo se dedica à formação de moléculas percursoras da biossíntese a partir do succinato, e não à oxidação dos substratos (Kyoto Encyclopedia of Genes and Genomes, 2013). 
Figura 2 - Rede metabólica central de $H$. influenzae.

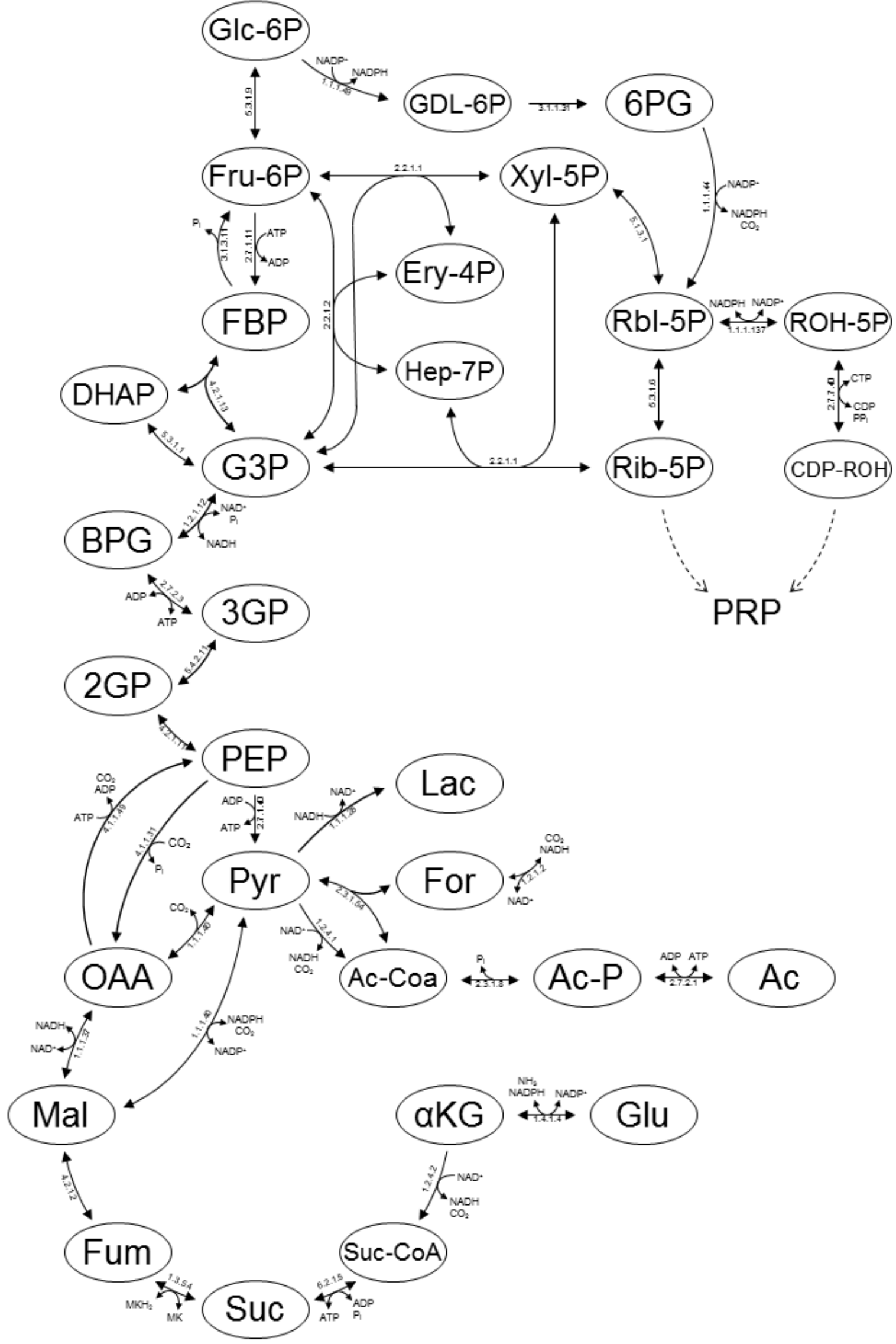

FONTE: Interpretação de fontes literárias (Cecchini et al., 2002; KEGG, 2013; Pereira, Brown, 2004; Zolli et al., 2001). 
Como não existe fluxo de carbonos da glicólise para o ramo oxidativo do CAT, os aminoácidos que derivam do a-cetoglutarato não podem ser gerados pela própria bactéria devido à ausência do esqueleto carbônico dos a-cetoácidos.

Com a incapacidade de formação do a-cetoglutarato, a bactéria fica impossibilitada de realizar a assimilação de nitrogênio inorgânico, apesar de possuir a enzima glutamato desidrogenase. Isso explica a alta demanda da bactéria por glutamato, que se fornecido externamente pode ser transformado em parte dos demais aminoácidos. Além disso, sugere-se que o glutamato possa alimentar o CAT a partir da desaminação a a-cetoglutarato (Fleischmann et al., 1995).

Tendo em vista que o fluxo de carbonos proveniente da glicólise não é direcionado ao CAT, nota-se que estes devem se acumular nas moléculas de oxidação incompleta, como o acetato, lactato e formiato. Entre estes, o acetato se destaca como o principal subproduto do metabolismo, atingindo elevadas concentrações durante o cultivo e sendo capaz de inibir o crescimento da célula. Silva (2010) procurou impedir a formação do acetato através da limitação no fornecimento de substrato; no entanto, verificou-se o acumulo indiscriminado do subproduto.

\subsection{Cadeia de transporte de elétrons e fosforilação oxidativa}

Assim como no CAT, se observa na cadeia de transporte de elétrons (CTE) outras semelhanças do metabolismo de Hib com os organismos anaeróbios, como por exemplo o uso de menaquinonas no lugar de ubiquinonas no transporte de elétrons (Schilling, Palsson, 2000). Além de a bactéria não possuir a via de síntese das ubiquinonas, os complexos do CTE apresentam afinidade pelos carregadores de menor potencial (menaquinonas). Na Figura 3 são apresentados as principais etapas no transporte de elétrons dos cofatores enzimáticos reduzidos (NADH) para os aceptores finais $\left(\mathrm{O}_{2}\right)$.

O primeiro complexo apresentado na Figura 3 é uma NADH desidrogenase que se utiliza de menaquinonas como aceptor de elétrons para a regeneração do cofator $\mathrm{NAD}^{+}$. Diferentemente dos complexos equivalentes em organismos aeróbios, no caso de Hib não existe transporte de prótons para o lado externo da membrana plasmática nesta etapa (KEGG, 2013). 
Figura 3 - Cadeia de transporte de elétrons de $H$. influenzae

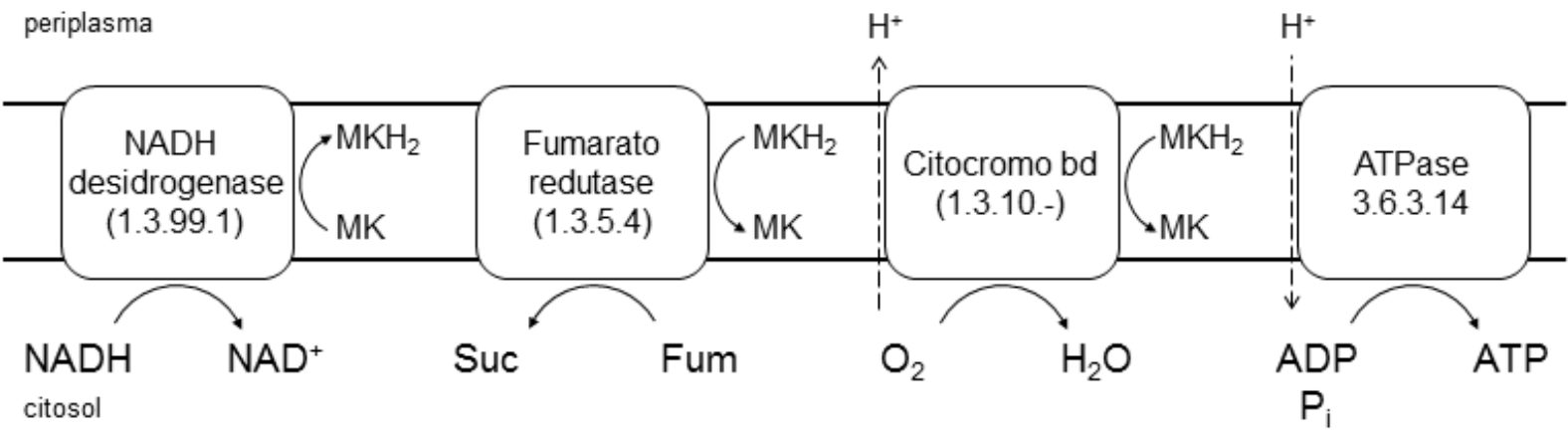

FONTE: Adaptado de KEGG (2013).

No segundo complexo se observa a fumarato redutase, que participa também do CAT. Esta enzima, que também está presente em Escherichia coli, apresenta maior eficiência na redução de fumarato a succinato na presença de um pool de menaquinona/menaquinol que na reação contrária de desidrogenação do succinado (Cecchini et al., 2002), sugerindo que no caso de Hib este complexo atue por regenerar o menaquinol proveniente da NADH desidrogenase e permitir a respiração através do fumarato. $O$ terceiro complexo é uma oxigênio redutase da família de citocromos bd. Esta é uma enzima prevalente em organismos patogênicos e que crescem em ambientes limitados em oxigênio; justamente, a característica mais notável desta enzima é a altíssima afinidade pelo aceptor. Outra característica importante é que este complexo é capaz de gerar um gradiente de prótons trasmembrana (Borisov et al., 2011). O quarto e último complexo é uma ATPase e não apresenta grandes diferenças em relação às enzimas homólogas de outros procariotos, realizando a fosforilação do ADP através da força próton-motora (KEGG, 2013). A configuração peculiar da cadeia respiratória de Hib, em conjunto com a alta produção de moléculas de oxidação incompleta como o acetato, é apontada como um motivo para classificar o metabolismo da bactéria como "fermentação assistida pela respiração", onde a CTE serve apenas como forma de possibilitar o balanço redox desfavorecido pela oxidação incompleta dos substratos (Othman et al., 2014).

\subsection{Síntese de PRP}

A síntese de polissacarídeo nas linhagens de $H$. influenzae é determinada pela presença de um cassete específico chamado de locus cap. Entre todos os sorotipos, 
o locus pode ser dividido em três regiões. Na região I, estão presentes quatro genes, chamados de bexA, bexB, bexC e bexD, que estão relacionados com o transporte assistido por ATP do polissacarídeo através da membrana celular e estão presentes nos seis sorotipos (Kroll, Moxon, 1988). A região II é especifica para cada sorotipo e contém os genes relativos à síntese do polissacarídeo capsular (Eldere et al., 1995). Já a região III contém os genes hcsA e hcsB que são essenciais para o transporte do polissacarídeo através da membrana externa, estando também presente em todos os sorotipos (Sukupolvi-Petty et al., 2006).

Figura 4 - Representação do locus cap de Hib

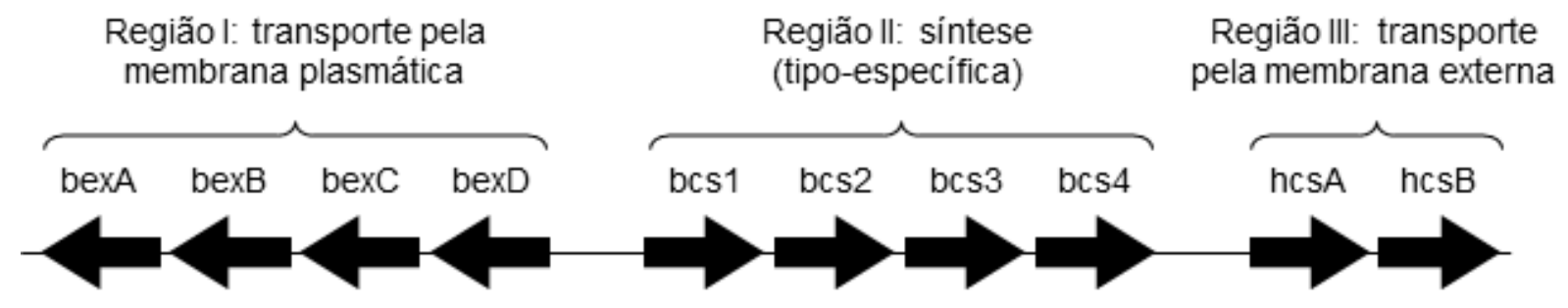

FONTE: Interpretação de fontes literárias (Eldere et al., 1995; Kroll, Moxon, 1988; Sukupolvi-Petty et al., 2006).

No caso do sorotipo b, a região II contém quatro genes, bcs1, bcs2, bcs3 e bcs4. Entre eles, apenas o primeiro foi extensamente descrito. Este gene codifica uma enzima bifuncional, uma fusão de duas proteínas da via das pentoses fosfato, que atua na reação de redução da ribulose-5-fosfato a ribitol-5-fosfato, e em seguida fazendo a transferência de um grupo citidilil para dar origem ao CDP-ribitol, que então segue para a biossíntese do polímero de PRP (Pereira, Brown, 2004; Zolli et al., 2001). As próximas etapas, apesar de não serem elucidadas, envolvem a ligação alternada dos grupos ribose e ribitol (Eldere et al., 1995). Dessa forma, é sugestivo que a formação do PRP se dá a partir da via das pentoses fosfato, como ilustrado na Figura 2.

\subsubsection{Purificação do polissacarídeo capsular}

$\mathrm{Na}$ etapa de purificação do PRP, as células são removidas do caldo fermentado, a partir do qual a molécula começa a ser isolada. Os métodos clássicos de isolamento do PRP incluem etapas de precipitação com etanol, fenol, entre outros solventes orgânicos, e uma série de centrifugações e ultracentrifugações para a separação das frações de interesse, sendo que estas vêm sendo substituídas por 
micro e ultrafiltração tangencial (MFT e UFT). Os trabalhos mais recentes referentes à purificação do PRP ainda incluem a substituição dos solventes orgânicos por enzimas hidrolíticas, o uso de detergentes aniônicos e minimização das etapas de precipitação com uso de etanol (Albani et al., 2012, 2015).

Tem-se verificado que, em cultivos de longa duração, as porcentagens de recuperação do produto se apresentam em níveis muito baixos, em comparação com cultivos mais curtos, podendo chegar a 50\% nas primeiras etapas de UFT e evoluindo para uma recuperação global de até menos que $20 \%$ no final do processo (Albani et al., 2012, 2015). Em investigação quanto aos motivos da menor recuperação, Silva (2010) mostrou que a massa molecular do PRP decresce ao longo do cultivo. Assim, com o decorrer do cultivo de longa duração, a concentração do produto de interesse aumenta em contraponto à massa molecular. A produtividade global do processo (up e downstream) pode então ser alterada, levando à perda de grande parte do PRP que foi produzido em excesso pela otimização do crescimento celular. Assim, a introdução da UFT para o isolamento do PRP a partir do sobrenadante traz novos parâmetros a serem analisados e controlados para garantir a eficiência do processo, sendo eles a massa molecular durante o cultivo e a sua estabilidade.

\subsubsection{Estrutura química e estabilidade do PRP}

O PRP é um polímero formado por unidades de um dímero de ribitol e ribose, unidos de um lado por uma ligação glicosídica e do outro por uma ligação fosfodiéster (Crisel et al., 1975). A configuração desta ligação, em proximidade com as hidroxilas da ribose, se assemelha àquela do ácido ribonucleico (RNA), como mostrado na Figura 5.

Assim como no caso do RNA, a ligação fosfodiéster do PRP é suscetível à catálise alcalina da reação de transesterificação do grupo fosfato, levando ao rompimento da ligação química entre a ribose e o ribitol e separação da molécula em grupos menores (Egan et al., 1982). Esta reação é essencialmente catalisada pela presença de íons hidroxila, podendo ser ainda mais intensificada com a presença de cátions mono- ou bivalentes (Li, Breaker, 1999). 
Figura 5 - Estrutura química da molécula de PRP

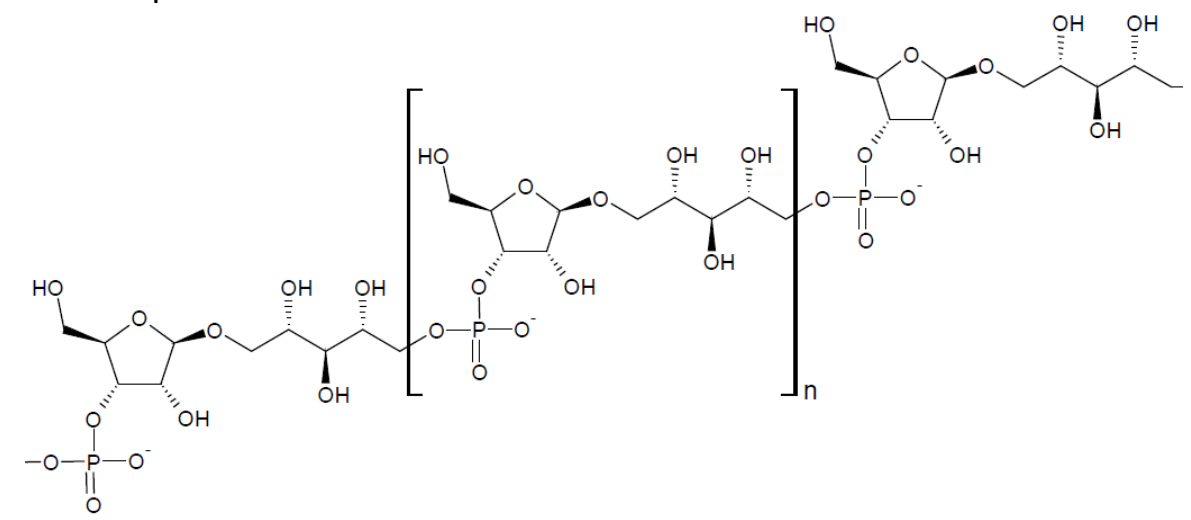

FONTE: Adaptado de Crisel et al. (1975)

Cintra e Takagi (2015) demonstraram que a diminuição do pH para valores abaixo da neutralidade e da temperatura para valores menores que o fisiológico garante maior estabilidade à molécula de PRP. Ficou comprovado também que a adição de íons $\mathrm{Na}^{+}$permite o aumento da velocidade de degradação em pH's menos elevados (vide Apêndice B). Estes resultados mostram que, entre os processos de produção de PRP apresentados na literatura, o de maior produtividade é realizado em condições favoráveis à despolimerização do PRP, com pH de 7,50 e temperatura de $37{ }^{\circ} \mathrm{C}$ (Silva, 2010). Além disso, o processo descrito foi realizado com alimentação, atingindo longos períodos de cultivo e com a adição de grandes quantidades de $\mathrm{NaOH}$ para o controle de $\mathrm{pH}$, o que eleva a concentração de íons monovalentes no meio e intensifica o processo de degradação. Com elevadas taxas de degradação durante o cultivo, apesar da alta produtividade mássica, a massa molecular do PRP que é direcionado à purificação terá baixos valores, contribuindo diretamente para perdas nas etapas de UFT.

\subsection{Modelagem matemática}

\subsubsection{Modelos descritos para as cinéticas microbianas}

A modelagem matemática das cinéticas microbianas é uma importante e versátil ferramenta para o desenvolvimento e otimização de bioprocessos. Os perfis de maior interesse para a modelagem são o crescimento celular, formação de produtos e consumo de substrato. As equações que descrevem estes perfis geralmente são interdependentes, com a formação de biomassa sendo afetada pela 
concentração de produtos e substrato, enquanto estes são determinados pela concentração de biomassa e taxa de divisão celular.

O crescimento celular sob ausência de limitação pelo substrato será determinado apenas pelos efeitos de inibição dos produtos tóxicos do metabolismo. Um dos modelos primeiramente descritos para a inibição do crescimento celular devido a produtos do metabolismo foi sugerido por Hinshelwood (1946), que definiu que a velocidade específica de crescimento diminui linearmente com a concentração de produto, como descrito pela equação (1). O próprio autor, no entanto, demonstrou que a correlação da velocidade de crescimento com a concentração de produto nem sempre é linear.

$$
\frac{d X}{d t}=\left(\mu_{\max }-k_{X} * A\right) * X
$$

$\mathrm{Na}$ equação acima, $X$ é a concentração de biomassa, $\mu_{\max }$ é a máxima velocidade específica de crescimento, atingida quando não há inibição (ausência de produto) nem limitação pelo substrato, $k_{X}$ é uma constante empírica, chamada de constante de inibição, e $A$ representa a concentração do produto responsável pela inibição, que equivale ao acetato no caso do metabolismo de Hib.

A não linearidade prevista para a equação (1) pode ser corrigida por modelos alternativos. Dois modelos são largamente utilizados na literatura. O primeiro usa um termo de inibição na forma exponencial como visto na equação (2), sendo aplicável a processos contínuos e descontínuos (Aiba et al., 1968).

$$
\frac{d X}{d t}=\mu_{\max } * \exp \left(-k_{X} * A\right) * X
$$

O segundo modelo toma a forma hiperbólica descrita pela equação (3), e foi construído considerando que a inibição do produto sobre a célula se assemelha à inibição não-competitiva de uma enzima (Stepanova et al., 1965). A adição de um expoente $\left(n_{X}\right)$ sobre o termo que contém a concentração do inibidor, como visto na equação (4), confere maior flexibilidade ao modelo, permitindo melhor ajuste. Isto é justificado pela maior cobertura à problemas de inibição, como feito também para o caso do estudo de enzimas (Yano, Koga, 1973).

$$
\frac{d X}{d t}=\mu_{\max } * \frac{1}{1+{ }^{A} / k_{X}} * X
$$




$$
\frac{d X}{d t}=\mu_{\max } * \frac{1}{1+\left(A / k_{X}\right)^{n_{X}}} * X
$$

Quanto à formação de produtos, a velocidade de formação é geralmente descrita como sendo proporcional à taxa de divisão celular (constituindo a formação associada ao crescimento) ou à concentração absoluta de células (constituindo a formação não associada ao crescimento). Luedeking e Piret (1959) demonstraram que é possível a ocorrência de formação mista, ou seja, a formação de produto é definida pela soma das frações produzidas com e sem associação ao crescimento, como definido na equação (5).

$$
\frac{d B}{d t}=\alpha_{B} * \frac{d X}{d t}+\beta_{B} * X
$$

$\mathrm{Na}$ equação acima, $B$ é a concentração de um produto genérico do metabolismo microbiano, $\alpha_{B}$ é a constante de associação ao crescimento e $\beta_{B}$ é a constante não associada ao crescimento. Alguns autores ainda estendem o modelo de formação de produto ao considerar o fenômeno de inibição por um dos produtos do metabolismo, como Liu et al.(2008), que consideram a inibição pelo lactato sobre a formação de ácido hialurônico e do próprio lactato incluindo o termo hiperbólico da equação (3) na equação (5).

\subsubsection{A velocidade de crescimento e a influência do pH e da temperatura}

O crescimento de uma célula pode ser considerado como o conjunto de reações enzimáticas envolvidas na formação dos constituintes celulares. É de se esperar que a dependência destas reações siga a forma geral da lei de Arrhenius, segundo a qual a velocidade de reação aumenta exponencialmente com o oposto do inverso da temperatura. Sob esta visão, as velocidades de reação são aumentadas devido à maior energia cinética das moléculas e maiores frequências de colisão entre os substratos e catalisadores. No entanto, alguns autores demonstram que o formato de curva esperado para a lei de Arrhenius não é seguido pela velocidade de crescimento microbiano. Ratkowsky et al. (1982) demonstraram que para vários microrganismos a raiz quadrada da velocidade de crescimento se comporta como uma reta, que pode ser extrapolada até o ponto onde se prevê a cessação do crescimento celular. Esta temperatura equivale à temperatura mínima para que o 
crescimento celular ocorra. Assim, os autores sugerem relação mostrada na equação (6), que mostra a raiz quadrada da velocidade de crescimento como sendo diretamente proporcional à distância da temperatura à temperatura mínima.

$$
\sqrt{\mu}=b *\left(T-T_{\min }\right)
$$

$\mathrm{Na}$ equação acima, $\mu$ é a velocidade específica de crescimento, $b$ é uma constante de proporcionalidade e $T_{\min }$ é a temperatura mínima de crescimento.

Já as temperaturas muito elevadas causam o aumento da entropia e destruição de estruturas importantes das proteínas, levando à desnaturação e cessação das reações enzimáticas, impedindo assim o crescimento celular. Em um trabalho posterior, a equação (6) é estendida pela predição da queda da velocidade de crescimento em temperaturas mais altas, através do novo termo incluído na equação (7) (Ratkowsky et al., 1983).

$$
\sqrt{\mu}=b *\left(T-T_{\min }\right) *\left(1-\exp \left(1-c\left(T-T_{\max }\right)\right)\right)
$$

Neste caso, c é uma constante e $T_{\max }$ é a temperatura acima da qual nenhum crescimento ocorre. Os autores demonstraram que a queda de crescimento com o aumento de temperatura é abrupta, e que a equação se ajusta bem a quase todos os microrganismos.

Além da temperatura, o pH também é capaz de alterar as velocidades de crescimento de uma célula. Como descrito para muitos organismos, existe um $\mathrm{pH}$ ótimo de crescimento. $\mathrm{O}$ efeito do $\mathrm{pH}$ pode ser considerado como independente da temperatura, sequindo a forma geral da equação (7) considerada para a descrição do efeito do pH (Rosso et al., 1995). Neste caso, os termos referentes à temperatura são replicados, substituindo-se as variáveis por aquelas relativas ao $\mathrm{pH}$.

\subsubsection{A formação de produto e a influência do pH e da temperatura}

Assim como a formação de biomassa, a formação de produto e os efeitos de $\mathrm{pH}$ e temperatura podem ser estudados segundo as reações enzimáticas envolvidas. O acumulo de algum produto do metabolismo no meio de cultura pode ser rastreado pelas reações metabólicas que levam à sua formação. Geralmente, a 
velocidade de formação é determinada por uma etapa limitante dentro da rede metabólica, e portanto pode ser estudada como uma enzima isolada.

Assim como no crescimento celular, a lei de Arrhenius é incapaz de explicar a dependência da taxa de reação com a temperatura. No entanto, Kavanau (1950) notou que esta lei poderia ser ajustada caso o valor de temperatura fosse deslocado, criando uma referência em relação a um valor de temperatura inicial. $O$ autor argumenta que isso ocorre devido às modificações que a temperatura tem sobre a estrutura das enzimas, como a maior força das pontes de hidrogênio intramoleculares. Em temperaturas mais baixas, a formação destas pontes resulta na criação de enzimas cataliticamente inativas, ou seja, enzimas cujos sítios ativos e alostéricos se tornam incapazes de funcionar devido à incapacidade de quebrar e reajustar as ligações necessárias para o andamento da reação, tais como a exposição do sítio catalítico ao substrato ou a aproximação de algum grupo funcional. Com o aumento da temperatura, menor será a energia necessária para a quebra dessas ligações, aumentando a quantidade de moléculas cataliticamente ativas.

$\mathrm{O} \mathrm{pH}$ tem a propriedade de alterar as atividades enzimáticas agindo diretamente na estrutura da proteína, alterando a distribuição de cargas dos componentes estruturais. Define-se que o afastamento da condição ótima da enzima se dá através da alteração de carga de um grupo ionizável dentro da proteína. Portanto, são imaginadas três formas da enzima: a $\mathrm{EH}_{2}$, que é definida como a forma com uma protonação a mais que a necessária para a configuração ótima da enzima, a $\mathrm{EH}^{-}$, que é a configuração ótima, e a $\mathrm{E}^{2-}$, que é a configuração com uma protonação a menos que o necessário. Assim, a proporção de enzimas ativas irá definir a velocidade da reação, como descrito pelas constantes de equilíbrio químico mostradas na equação (8), sendo $k_{1}$ a constante de equilíbrio entre as formas $\mathrm{EH}^{-} \mathrm{e}$ $\mathrm{EH}_{2}$, e $k_{2}$ a constante de equilíbrio entre $\mathrm{E}^{2-}$ e $\mathrm{EH}^{-}$. A velocidade de reação da enzima, $v$, pode então ser definida pela concentração de prótons, que é calculado a partir do $\mathrm{pH}$, como mostra a equação (8). Existe um $\mathrm{pH}$ ótimo onde $v$ atinge seu valor máximo, $v_{\max }$ (Kupcsulik, Sevella, 2005).

$$
v=\frac{v_{\max }}{1+k_{1}[H]+k_{2} /[H]}
$$




\subsubsection{A inibição pelo ácido e a influência do pH}

A influência do $\mathrm{pH}$ e da temperatura sobre a inibição do crescimento celular pode ser definida pela constante de dissociação do ácido envolvido. No caso dos ácidos orgânicos, que possuem constantes de dissociação relativamente altas, a sua solução aquosa apresentará uma quantidade considerável de moléculas não dissociadas. O mecanismo de inibição das formas ácida e iônica é diferente e aditivo, sendo que a forma ácida, ou não dissociada, inibe o crescimento com maior intensidade. Em bactérias Gram negativas, a presença da membrana externa constituída de LPS confere uma carga negativa à superfície da célula. A forma ionizada do ácido apresenta baixa permeabilidade à membrana, por também apresentar carga negativa. Já a forma protonada tem maior permeabilidade, migrando do meio extracelular para o citoplasma. Em pH's mais baixos, a quantidade de moléculas de ácido protonado se eleva de forma logarítmica, prevendo que a tolerância da bactéria será menor (Brul, Coote, 1999).

\subsubsection{A geração de energia e a influencia do pH e da temperatura}

Através da cadeia de transporte de elétrons, o potencial redox obtido pela oxidação do substrato é transferido para a criação de um potencial transmenbrana, que é utilizado pela célula como força motora para o transporte de solutos e para a geração de energia ou síntese de ATP. Segundo a teoria quimiosmótica, a eficiência do processo de fosforilação do ADP a ATP é determinada pela força próton-motora $(\Delta p)$, que é definida por dois termos: a diferença de potencial elétrico $(\Delta \varphi)$ e 0 gradiente de prótons, como mostrado na equação (9). Na equação, $R$ é a constante universal dos gases e $F$ é a constante de Faraday (Mitchell, 1961).

$$
\Delta p=\Delta \varphi+\frac{2,3 R T}{F} \Delta p H
$$

A mudança do $\mathrm{pH}$ e da temperatura do meio de crescimento da célula tem, portanto, influencia direta sobre a eficiência de produção de energia. A diminuição do gradiente de prótons entre o meio extracelular e o citosol pode causar, por exemplo, um aumento na extrusão de cátions através da membrana para aumentar o potencial elétrico transmembrana. Este fenômeno é observado, por exemplo, em 
bactérias alcalófilas, onde o gradiente de prótons chega a ser negativo devido ao alto $\mathrm{pH}$ do meio extracelular (Krulwich, 1995). Outras vias de geração de ATP podem ser ainda utilizadas para contrabalancear a perda de eficiência na geração quimiosmótica, como a fosforilação a nível de substrato. Pela análise da equação (9), pode-se verificar que a variação do $\mathrm{pH}$ tem um efeito maior sobre $\Delta p$ do que a variação da temperatura: mantendo-se todas as outras variáveis constantes, uma variação de $10^{\circ} \mathrm{C}$ resultaria numa variação de $1,98 \mathrm{mV}$ em $\Delta p$, enquanto a variação de apenas 1 unidade em $\Delta p H$ resultaria numa variação de 61,44 mV. 


\section{MATERIAIS E MÉTODOS}

\subsection{Experimentos}

$\mathrm{O}$ efeito do $\mathrm{pH}$ e da temperatura sobre o crescimento celular e formação de produtos foi feito através da construção de um delineamento composto central rotacional (DCCR) de dois níveis. Seguindo este desenho, foram realizados os cultivos, como descrito à frente no item 3.2.1. Definiu-se um intervalo de temperatura de 29 a $37^{\circ} \mathrm{C}$, e de $\mathrm{pH}$ entre os valores de 6,30 a 7,50. A configuração do DCCR foi feita de modo que nenhum ensaio ultrapassasse este valor, portanto os limites foram fixados nos pontos axiais do desenho, e foram calculados os níveis positivos e negativos como mostra a Tabela 1.

Tabela 1 - Configuração do DCCR quanto ao $\mathrm{pH}$ e à temperatura para avaliação da cinética microbiana

\begin{tabular}{lrrrr}
\hline & \multicolumn{3}{c}{ Valor Codificado } & \multicolumn{2}{c}{ Valor real } \\
\hline Ensaio & $\mathrm{T}_{\mathrm{C}}$ & $\mathrm{pH}_{\mathrm{C}}$ & $\mathrm{T}\left({ }^{\circ} \mathrm{C}\right)$ & $\mathrm{pH}$ \\
1 & 0,00 & 0,00 & 33,0 & 6,90 \\
2 & 0,00 & 0,00 & 33,0 & 6,90 \\
3 & 1,00 & 1,00 & 35,8 & 7,32 \\
4 & 1,00 & $-1,00$ & 35,8 & 6,48 \\
5 & $-1,00$ & 1,00 & 30,2 & 7,32 \\
6 & $-1,00$ & $-1,00$ & 30,2 & 6,48 \\
7 & 0,00 & 1,43 & 33,0 & 7,50 \\
8 & 0,00 & $-1,43$ & 33,0 & 6,30 \\
9 & 1,43 & 0,00 & 37,0 & 6,90 \\
10 & $-1,43$ & 0,00 & 29,0 & 6,90 \\
\hline
\end{tabular}

Além destes 10 ensaios, foram realizados mais dois: um nas condições reportadas na literatura de $\mathrm{pH} 7,5$ e $37^{\circ} \mathrm{C}$ (Silva, 2010), e outra nas condições otimizadas definidas neste trabalho de $\mathrm{pH} 7,1$ e $30^{\circ} \mathrm{C}$ (vide item 4.2.6). 


\subsection{Metodologias}

\subsubsection{Cultivos}

\subsubsection{Pré-inóculo e inóculo}

A linhagem GB3291 de Hib foi adquirida do Instituto Adolfo Lutz na forma liofilizada. As células foram expandidas em tubos inclinados de ágar chocolate cuja composição é descrita na Tabela 2, ressuspendidas no meio de Greaves (1960) e armazenadas em nitrogênio líquido com viabilidades acima de $10^{9} \mathrm{UFC} \cdot \mathrm{mL}^{-1}$. Para a realização dos cultivos, as células foram descongeladas e incubadas em meio MMP, cuja composição é listada na Tabela 3 , durante no mínimo 6 h, de forma estática e sob atmosfera de $\mathrm{CO}_{2}$, a $37^{\circ} \mathrm{C}$ (Takagi et al., 2006). Ao atingir $\mathrm{DO}_{540}$ de no mínimo 0,500, a suspensão bacteriana foi transferida para três frascos de Erlenmeyer contendo $200 \mathrm{~mL}$ de meio MMP fresco cada. O volume transferido foi definido como o necessário para se atingir as $\mathrm{DO}_{540}$ iniciais de $0,025,0,050$ e 0,075. Os frascos foram incubados em shaker orbital (INNOVA 44 - New Brunswick), a 150rpm e $37^{\circ} \mathrm{C}$. Após atingir $\mathrm{DO}_{540}$ de no mínimo 5,0 em aproximadamente $13 \mathrm{~h}$, que equivale ao final da fase de crescimento exponencial, a suspensão foi transferida para o reator em quantidade suficiente para atingir uma $\mathrm{DO}_{540}$ inicial de 0,150 .

Tabela 2 - Composição do meio ágar chocolate

\begin{tabular}{|c|c|}
\hline Infusão de cérebro e coração - BD (g.. $\left.{ }^{-1}\right)$ & 370 \\
\hline Ágar - BD $\left(g \cdot \mathrm{L}^{-1}\right)$ & 20 \\
\hline Sangue equino* - Instituto Butantan (v/v) & $10 \%$ \\
\hline
\end{tabular}

* O sangue foi adicionado de forma estéril após a autoclavação do meio, com o mesmo ainda liquefeito a uma temperatura de aproximadamente $80^{\circ} \mathrm{C}$.

Tabela 3 - Composição do meio MMP

\begin{tabular}{|c|c|}
\hline Glicose - Merck $\left(g \cdot \mathrm{L}^{-1}\right)$ & 5,0 \\
\hline Extrato de Levedura UF - BD $\left(g \cdot \mathrm{L}^{-1}\right)$ & 5,0 \\
\hline Soytone - BD $\left(g \cdot \mathrm{L}^{-1}\right)$ & 10,0 \\
\hline $\mathrm{Na}_{2} \mathrm{HPO}_{4}-$ Sigma-Aldrich $\left(\mathrm{g} \cdot \mathrm{L}^{-1}\right)$ & 13,1 \\
\hline $\mathrm{NaH}_{2} \mathrm{PO}_{4} \cdot \mathrm{H}_{2} \mathrm{O}-$ Nuclear $\left(\mathrm{g} \cdot \mathrm{L}^{-1}\right)$ & 3,3 \\
\hline $\mathrm{KH}_{2} \mathrm{PO}_{4}-\operatorname{Merck}\left(\mathrm{g} \cdot \mathrm{L}^{-1}\right)$ & 2,5 \\
\hline $\mathrm{NaCl}-$ Anidrol $\left(\mathrm{g} \cdot \mathrm{L}^{-1}\right)$ & 5,0 \\
\hline Hemina bovina - Sigma-Aldrich $\left(\mathrm{mg} \cdot \mathrm{L}^{-1}\right)$ & 30,0 \\
\hline NAD - Sigma-Aldrich (mg. $\left.\mathrm{L}^{-1}\right)$ & 15,0 \\
\hline \multicolumn{2}{|c|}{$\mathrm{pH}$ ajustado para 7,5 (HCI 6N - Merck) } \\
\hline
\end{tabular}




\subsubsection{Cultivos em batelada simples}

O meio utilizado no reator foi baseado no meio MMP, com modificações quanto às concentrações de extrato de levedura e de glicose, que foram aumentadas para $20 \mathrm{~g} . \mathrm{L}^{-1}$ a fim de se permitir um período maior de crescimento celular e garantindo o excesso de substrato durante todo o cultivo. A proporção de fosfato de sódio mono e bibásico foi também alterada segundo os valores de $\mathrm{pK}_{\mathrm{a}}$ dos grupos fosfato para minimizar a quantidade e íons adicionada na correção do $\mathrm{pH}$.

Os cultivos foram conduzidos em reatores de bancada (Bioflo 2000 NewBrunswick) de 13L totais, contendo $6 \mathrm{~L}$ úteis de meio. Os reatores foram controlados quanto à temperatura, ao $\mathrm{pH}$, pela adição de $\mathrm{NaOH} 5 \mathrm{M}$, nos valores determinados na Tabela 1, e à concentração de oxigênio dissolvido (COD) através da variação da velocidade de agitação, em 30\% da saturação e com vazão de ar comprimido a 0,5 vvm. Amostragem de volumes menores que $30 \mathrm{~mL}$ foram feitas durante o processo para as análises de interesse.

\subsubsection{Cultivos em batelada alimentada}

Para os cultivos em batelada alimentada, iniciou-se o processo semelhantemente ao item anterior. No entanto o meio utilizado inicialmente foi o meio MMP original (Tabela 3). Para o meio de alimentação foram modificadas apenas as concentrações de glicose e de extrato de levedura, sendo elevadas a 200 g. $\mathrm{L}^{-1}$. A princípio, o cultivo foi mantido em $\mathrm{pH} 7,50$ e a $37^{\circ} \mathrm{C}$, o que se chamou de condição padrão. Nestas condições, a alimentação foi feita a uma vazão específica de $21 \mathrm{~mL} \cdot \mathrm{L}^{-1} \cdot \mathrm{h}^{-1}$ (Silva, 2010). O início da alimentação se deu no momento em que a glicose do meio original se esgotou. Esse momento foi avaliado através de um pico no valor de COD e na medição da quantidade de glicose por kit enzimático (vide item 3.2.2.2). Após os resultados obtidos pelo DCCR, definiu-se uma nova condição com $\mathrm{pH}$ de 7,10 e temperatura de $30^{\circ} \mathrm{C}$, que foi denominada de condição otimizada (vide item 4.2). Nesta condição, a vazão de alimentação foi definida com base no acompanhamento da velocidade de consumo de glicose em $17 \mathrm{~mL} \cdot \mathrm{L}^{-1} \cdot \mathrm{h}^{-1}$. 


\subsubsection{Análises}

\subsubsection{Concentração de biomassa}

A concentração de biomassa durante o preparo dos inóculos e também ao longo dos cultivos foi medida por turbidimetria no comprimento de onda de $540 \mathrm{~nm}$. As amostras foram diluídas em meio de cultura para uma leitura real máxima de 0,500 . As amostras dos cultivos também foram submetidas à medição de massa seca, por gravimetria. Alíquotas de 1,8 $\mathrm{mL}$ foram distribuídas em tubos de centrífuga de $2 \mathrm{~mL}$, centrifugadas por 5 minutos a $15,000 \mathrm{~g}$. As células foram ressuspendidas em $1 \mathrm{~mL}$ de $\mathrm{NaCl} 150 \mathrm{mM}$ e novamente centrifugadas, seguindo para secagem em estufa a $70^{\circ} \mathrm{C}$, sendo então pesadas em balança analítica. A massa seca obtida foi dividida pelo volume de amostra inicial e a concentração de células foi expressa em g. $\mathrm{L}^{-1}$. O erro experimental foi estimado através da medição de três replicadas em cada amostra.

\subsubsection{Concentração de ácidos orgânicos e carboidratos}

As concentrações de acetato e de glicose foram medidas por cromatografia líquida de alta eficiência (HPLC - high performance liquid chromatography), com a coluna de exclusão iônica Aminex HPX-87H (Bio-Rad). Como fase móvel, foi utilizada solução aquosa de $\mathrm{H}_{2} \mathrm{SO}_{4} 5 \mathrm{mM}$. O fluxo foi mantido a $0,6 \mathrm{~mL}$. $\mathrm{min}^{-1}$, em temperatura de $40^{\circ} \mathrm{C}$. Leituras foram feitas numa frequência de $2 \mathrm{~Hz}$ num detector de absorbância UV-VIS (SCL-10Avp - Shimadzu) a $210 \mathrm{~nm}$ para o ácido, e num detector de índice de refração (RID10A - Shimadzu) para o carboidrato, sendo os dados aquisitados pelo software Class-VP (Shimadzu). As amostras foram diluídas 10 vezes em $\mathrm{H}_{2} \mathrm{SO}_{4} 25 \mathrm{mM}$. As curvas padrão foram construídas com o padrão comercial de glicose e acetato de sódio fornecido pelo fabricante da coluna (Bio-rad, números de catálogo 125-0585 e 125-0586 respectivamente).

A medição da concentração de glicose foi feita também por kit enzimático para o acompanhamento durante os processos de batelada alimentada. Um volume de 10 $\mu \mathrm{L}$ de amostra foi adicionado a $1 \mathrm{~mL}$ do reagente comercial GLICOSE BIO LIQUID (Laborclin Ltd.), incubado a $37{ }^{\circ} \mathrm{C}$ por $10 \mathrm{~min}$. A absorbância foi lida em espectrofotômetro a um comprimento de onda de $510 \mathrm{~nm}$. 


\subsubsection{Concentração de PRP}

Duas frações de PRP foram medidas: a fração livre no sobrenadante da cultura e a fração associada às células. A fração livre foi medida diretamente do sobrenadante da cultura. Para a fração associada, foi feita uma modificação do método de extração do polissacarídeo a partir da célula descrito por Kroll e Moxon (1988). As células da cultura foram centrifugadas, como mencionado no item 3.2.2.1, e lavadas com $\mathrm{NaCl} 150 \mathrm{mM}$, ressuspendidas em tampão com pH ajustado para 7,50 contendo $10 \mathrm{mM}$ de EDTA, $10 \mathrm{mM}$ de $\mathrm{Na}_{2} \mathrm{HPO}_{4}$ e $150 \mathrm{mM}$ de $\mathrm{NaCl}$ e incubadas a $37^{\circ} \mathrm{C}$ por pelo menos duas horas, sendo novamente centrifugadas. As células então foram descartadas e o PRP extraído foi medido a partir do sobrenadante.

A concentração de PRP foi medida por cromatografia de troca aniônica de alta eficiência com detecção por amperometria pulsada (HPAEC-PAD - high performance anion exchange chromatography with pulsed amperometry detection). A um volume de $540 \mu \mathrm{L}$ de amostra foi adicionado $180 \mu \mathrm{L}$ de $\mathrm{NaOH} 400 \mathrm{mM}$. A mistura foi incubada a $37^{\circ} \mathrm{C}$ por $20 \mathrm{~h}$ para a hidrólise alcalina do polímero de PRP até o monômero de ribosil-ribitol-fosfato, e neutralizada com $180 \mu \mathrm{L}$ de ácido acético $400 \mathrm{mM}$. Foi adicionado ainda $100 \mu \mathrm{L}$ de uma solução contendo ribose-5-fosfato a $200 \mu \mathrm{M}$ e glicose-6-fosfato a $125 \mu \mathrm{M}$, que serviram como padrão interno. Um volume de $10 \mu \mathrm{L}$ dessa mistura foi injetado na coluna de troca aniônica CarboPac PA-10 acoplada à pré-coluna de retenção de aminoácidos AminoTrap, montadas no sistema cromatográfico ICS5000 com o controle e aquisição de dados pelo software Chromaleon (Thermo Fisher Scientific Inc.). A metodologia de análise incluiu os gradientes de $\mathrm{NaOH}$ e acetato de sódio descritos por de Haan et al. (2013), além dos potenciais eletroquímicos definidos pelos mesmos autores para a leitura dos carboidratos no eletrodo de ouro. A curva de calibração foi construída utilizando-se o padrão internacional de PRP (Mawas et al., 2005, 2007).

\subsubsection{Determinação da massa molecular}

Para a medição da massa molecular, as amostras foram previamente tratadas pelo método de precipitação com brometo de cetiltrimetilamônio (CTAB) descrito no Apêndice A (Cintra, Takagi, 2012). Um volume de $50 \mu \mathrm{L}$ foi aplicado a uma

cromatografia de exclusão por tamanho de alta eficiência (HPSEC - high performance size exclusion chromatography), utilizando-se três colunas PL Aquagel$\mathrm{OH}$ Mixed-H (Agilent Technologies) em série, a $30^{\circ} \mathrm{C}$ e com fluxo de $1 \mathrm{~mL} \cdot \mathrm{min}^{-1}$. 
Como fase móvel, foi usada uma solução de $\mathrm{NaCl} 100 \mathrm{mM}, \mathrm{Na}_{2} \mathrm{HPO}_{4}$ 13,22 mM, $\mathrm{NaH}_{2} \mathrm{PO}_{4}$ 6,78 mM e NaN $33 \mathrm{mM}$. A corrida e a detecção foram feitas no sistema cromatográfico Infinity 1260 (Agilent Technologies), sendo feitas leituras a uma frequência de $10 \mathrm{~Hz}$ num detector de índice de refração e os dados aquisitados pelo software ChemStation (Agilent Technologies).

Os tempos de eluição das frações de PRP foram transformados em valores de massa molecular, em kDa, através da construção de uma curva padrão a partir de pululanas de massa conhecida. Amostras de pululana de massas moleculares nominais de 5, 10, 20, 50, 100, 200, 300, 700, $1300 \mathrm{kDa}$ (Agilent Technologies) e $2500 \mathrm{kDa}$ (Sigma Aldrich) foram aplicadas à coluna, e o tempo de retenção médio dos picos de eluição foram correlacionados com os logarítimos dos valores de massa molecular através de uma relação linear.

Para a obtenção das médias numérica $\left(M_{n}\right)$ e mássica $\left(M_{w}\right)$ da massa molecular, as frações eluídas de PRP foram submetidas às fórmulas das equações (10) e (11) (Meunier, 1997).

$$
\begin{aligned}
& M_{n}=\sum \frac{h_{i}}{h_{i} / M_{i}} \\
& M_{w}=\sum \frac{h_{i} M_{i}}{h_{i}}
\end{aligned}
$$

Nas equações (10) e (11), $h_{i}$ é a altura do sinal para a fração $i$, e $M_{i}$ é o valor de massa molecular para a fração obtido através da curva padrão.

\subsection{Métodos matemáticos}

\subsubsection{Modelos cinéticos}

Os modelos apresentados no item 2.3.1 foram combinados entre si para a descrição das cinéticas de formação de biomassa, acetato e PRP. Para a formação de biomassa foram criados quatro modelos: A) o modelo de Aiba et al. (1968); B) o mesmo modelo estendido com a inclusão de um expoente sobre a concentração de acetato; C) o modelo de Stepanova et al. (1965); D) o modelo extendido de Yano e 
Koga (1973). Para se referir aos modelos de formação de biomassa, foi utilizada a lista de modelos $X$, que varia entre $A$ e $D$, como mostrado na Tabela 4.

Tabela 4 - Modelos de formação de biomassa testados

\begin{tabular}{cc}
\hline Código & Modelo $\mathrm{X}$ \\
\hline $\mathrm{A}$ & $\frac{d X}{d t}=\mu_{\text {max }} * \exp \left(-\left(k_{X} * A\right)\right) * X$ \\
$\mathrm{~B}$ & $\frac{d X}{d t}=\mu_{\max } * \exp \left(-\left(k_{X} * A\right)^{n_{X}}\right) * X$ \\
$\mathrm{C}$ & $\frac{d X}{d t}=\mu_{\max } * \frac{1}{1+\left(A / k_{X}\right)} * X$ \\
$\mathrm{D}$ & $\frac{d X}{d t}=\mu_{\max } * \frac{1}{1+\left(A / k_{X}\right)^{n_{X}}} * X$ \\
\hline
\end{tabular}

Para a formação de acetato e PRP, foram testadas combinações das três possíveis formas do modelo de Luedeking e Piret (1959), referentes à formação associada, não associada e mista, com os mesmos modelos de inibição vindos da formação de biomassa, além da consideração de que não existe inibição. Os modelos de formação foram codificados como " $A_{f}$ ", para a formação de acetato, e "P," para a formação de PRP, com os códigos A para a formação associada ao crescimento, B para a não associada, e C para a mista, como mostrado na Tabela 5. Em cada modelo de formação, as equações de Luedeking e Piret são multiplicadas por um fator $I$, que equivale ao fator de inibição sobre a formação de produto. Este fator é codificado pelos modelos " $A_{i}$ ", para a inibição sobre o acetato, e "P,", para a inibição sobre o PRP. A Tabela 6 resume os modelos testados, que incluem os quatro modelos utilizados na formação de biomassa, além da possibilidade de não haver inibição.

Tabela 5 - Modelos de formação de acetato e PRP testados

\begin{tabular}{ccc}
\hline Código & Modelo $\mathrm{A}_{\mathrm{f}}$ & Modelo $\mathrm{P}_{\mathrm{f}}$ \\
\hline $\mathrm{A}$ & $\frac{d A}{d t}=\alpha_{A} * \frac{d X}{d t} * I$ & $\frac{d P}{d t}=\alpha_{P} * \frac{d X}{d t} * I$ \\
$\mathrm{~B}$ & $\frac{d A}{d t}=\beta_{A} * X * I$ & $\frac{d P}{d t}=\beta_{P} * X * I$ \\
$\mathrm{C}$ & $\frac{d A}{d t}=\left(\alpha_{A} * \frac{d X}{d t}+\beta_{A} * X\right) * I$ & $\frac{d P}{d t}=\left(\alpha_{P} * \frac{d X}{d t}+\beta_{P} * X\right) * I$ \\
\hline
\end{tabular}


Tabela 6 - Modelos de inibição sobre o acetato e PRP testados

Código Modelo $A_{i}$

Modelo $\mathrm{P}$

$\mathrm{O}$

$$
I=1
$$

$$
I=1
$$

A

$$
I=\exp \left(-\left(k_{A} * A\right)\right)
$$

$$
I=\exp \left(-\left(k_{P} * A\right)\right)
$$

B

$$
I=\exp \left(-\left(k_{A} * A\right)^{n_{A}}\right)
$$$$
I=\exp \left(-\left(k_{P} * A\right)^{n_{P}}\right)
$$

C

$$
I=\frac{1}{1+\left(A / k_{A}\right)}
$$

$$
I=\frac{1}{1+\left(A / k_{P}\right)}
$$

D

$$
I=\frac{1}{1+\left(A / k_{A}\right)^{n_{A}}}
$$$$
I=\frac{1}{1+\left(A / k_{P}\right)^{n_{P}}}
$$

As equações referentes à formação de biomassa e acetato são independentes da concentração de PRP, mas dependentes entre si. Desse modo, primeiramente

\begin{tabular}{|c|c|c|c|c|c|c|c|c|c|c|c|c|c|c|c|}
\hline \multicolumn{4}{|c|}{ Códigos } & \multicolumn{4}{|c|}{ Códigos } & \multicolumn{4}{|c|}{ Códigos } & \multicolumn{4}{|c|}{ Códigos } \\
\hline MP & $x$ & $A_{f}$ & $A_{i}$ & MP & $X$ & $A_{f}$ & $A_{i}$ & MP & $x$ & $A_{f}$ & $A_{i}$ & MP & $x$ & $A_{f}$ & $A_{i}$ \\
\hline 01 & A & $A$ & O & 16 & B & $A$ & O & 31 & $C$ & A & O & 46 & D & A & O \\
\hline 02 & A & $A$ & A & 17 & B & $A$ & A & 32 & $C$ & A & A & 47 & D & A & \\
\hline 03 & A & $A$ & B & 18 & B & $A$ & B & . & $C$ & A & B & 48 & D & A & B \\
\hline 04 & A & $A$ & C & & B & $A$ & C & & $C$ & A & $C$ & 49 & D & A & \\
\hline 05 & A & $A$ & D & 20 & B & $A$ & D & 35 & $C$ & A & D & 50 & D & A & D \\
\hline 06 & A & $B$ & 0 & 21 & B & $B$ & 0 & 30 & $C$ & B & O & & D & B & \\
\hline 07 & A & $B$ & A & $2 c$ & B & B & A & 37 & $C$ & B & A & 52 & D & B & A \\
\hline 08 & A & B & B & 23 & B & $B$ & B & 38 & $C$ & B & B & 53 & D & B & B \\
\hline 09 & A & $B$ & C & & B & B & C & & $C$ & B & C & & D & B & \\
\hline 10 & A & $B$ & D & 25 & B & B & D & 10 & $C$ & $B$ & D & 55 & D & B & 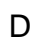 \\
\hline 11 & A & $C$ & 0 & 26 & B & $C$ & O & T & $C$ & C & O & 56 & D & $C$ & 0 \\
\hline 12 & A & $C$ & A & 27 & B & $C$ & A & 42 & $C$ & C & A & 57 & D & C & $A$ \\
\hline 13 & A & $C$ & B & 28 & B & $C$ & B & 43 & $C$ & C & B & 58 & D & $C$ & B \\
\hline 14 & A & $C$ & $C$ & 29 & B & $C$ & C & 44 & $C$ & C & $C$ & 59 & D & $C$ & C \\
\hline 15 & A & C & D & 30 & B & C & D & 45 & C & C & D & 60 & D & & \\
\hline
\end{tabular}
estudou-se os modelos para a formação de biomassa e acetato. Foram feitas as 60 permutações possíveis entre os modelos de formação de biomassa (Tabela 4), formação de acetato (Tabela 5) e inibição sobre a formação de acetato (Tabela 6). A combinação entre as três equações foi denominada de modelo parcial. Para cada combinação foi atribuído um código de modelo parcial "MP". A lista completa de modelos parciais testada, com as equações referentes, é mostrada na Tabela 7.

Tabela 7 - Modelos parciais testados para as variáveis biomassa e acetato 
Usando o método de seleção descrito à frente no item 3.3.1.2, apenas alguns desses cultivos serão escolhidos para a combinação com as equações de formação de PRP. A escolha isoladamente de apenas alguns dos modelos da Tabela 7 para a combinação com os modelos de PRP foi feita a fim de reduzir a quantidade total de modelos testados.

Tabela 8 - Modelos combinados testados para a variável PRP.

\begin{tabular}{ccccccccc}
\hline \multicolumn{3}{c}{ Códigos } & \multicolumn{3}{c}{ Códigos } & \multicolumn{3}{c}{ Códigos } \\
$\mathrm{MC}$ & $\mathrm{P}_{\mathrm{f}}$ & $\mathrm{P}_{\mathrm{i}}$ & $\mathrm{MC}$ & $\mathrm{P}_{\mathrm{f}}$ & $\mathrm{P}_{\mathrm{i}}$ & $\mathrm{MC}$ & $\mathrm{P}_{\mathrm{f}}$ & $\mathrm{P}_{\mathrm{i}}$ \\
\hline 01 & $\mathrm{~A}$ & $\mathrm{O}$ & 06 & $\mathrm{~B}$ & $\mathrm{O}$ & 11 & $\mathrm{C}$ & $\mathrm{O}$ \\
02 & $\mathrm{~A}$ & $\mathrm{~A}$ & 07 & $\mathrm{~B}$ & $\mathrm{~A}$ & 12 & $\mathrm{C}$ & $\mathrm{A}$ \\
03 & $\mathrm{~A}$ & $\mathrm{~B}$ & 08 & $\mathrm{~B}$ & $\mathrm{~B}$ & 13 & $\mathrm{C}$ & $\mathrm{B}$ \\
04 & $\mathrm{~A}$ & $\mathrm{C}$ & 09 & $\mathrm{~B}$ & $\mathrm{C}$ & 14 & $\mathrm{C}$ & $\mathrm{C}$ \\
05 & $\mathrm{~A}$ & $\mathrm{D}$ & 10 & $\mathrm{~B}$ & $\mathrm{D}$ & 15 & $\mathrm{C}$ & $\mathrm{D}$ \\
\hline
\end{tabular}

A combinação dos três modelos de formação de PRP (Tabela 5) e de inibição sobre o PRP (Tabela 6) geraram 15 modelos, aos quais foi atribuído um novo código de dois números, denominado "MC". A junção final com o modelo parcial escolhido resulta assim num código de modelo na forma "MP/MC". As equações combinadas para cada modelo MC é apresentada na Tabela 8.

\subsubsection{Ajuste de parâmetros}

As equações do modelo cinético escolhido foram resolvidas pelo método explicito de Runge-Kutta de ordem $(4,5)$. Para o ajuste dos parâmetros aos dados experimentais foi utilizado o método de regressão não-linear de LevenbergMarquardt. Foram usados os algoritmos implementados no programa GNU Octave 3.8.0 para a resolução dos dois métodos numéricos, com as funções ode45 para a resolução das equações diferenciais e leasqr para o ajuste aos dados experimentais. O vetor de parâmetros ajustado foi acrescentado em três unidades, referentes aos valores iniciais usados na resolução das equações diferenciais. Isto foi feito a fim de não conferir maior certeza ao ponto inicial da curva em relação aos demais. 


\subsubsection{Seleção do melhor modelo cinético}

A escolha do melhor modelo dentre os modelos sugeridos no item 3.3.1 foi feita através do critério de informação de Akaike corrigido para amostras pequenas (Burnham, Anderson, 2002). O critério é definido pela equação (12).

$$
A I C_{c}=-2 \ln (\mathcal{L}(\hat{\beta} \mid \mathbf{D}))+2 K+\frac{2 K(K+1)}{n-K-1}
$$

$\mathrm{Na}$ equação acima, $A I C_{c}$ é o critério de informação de Akaike corrigido, $\mathcal{L}(\hat{\beta} \mid \mathbf{D})$ é função de verossimilhança do modelo com o estimador $\hat{\beta}$ de máxima verissimilhança ajustado sobre o conjunto de dados $\mathbf{D}, K$ é o número de parâmetros estimáveis no modelo e $n$ é o número de amostras observadas em $\mathbf{D}$. A função $\mathcal{L}(\hat{\beta} \mid \mathbf{D})$ é calculada como descrito na equação (13), sob a premissa de que os erros das observações experimentais são distribuídos normalmente e de forma independente.

$$
\mathcal{L}(\hat{\beta} \mid \boldsymbol{D})=\prod_{i=1}^{n} \frac{1}{\sqrt{(2 \pi)^{p}\left|\boldsymbol{\Sigma}_{i}\right|}} \exp \left(-\frac{1}{2}\left(\boldsymbol{y}_{i}-f\left(t_{i}, \hat{\beta}\right)\right)^{\prime} \boldsymbol{\Sigma}_{i}^{-1}\left(\boldsymbol{y}_{i}-f\left(t_{i}, \hat{\beta}\right)\right)\right)
$$

Na equação acima, $p$ é o número de dimensões do modelo, ou seja, o número de variáveis medidas em cada amostra $i, \boldsymbol{\Sigma}_{i}$ é a matriz de correlação dos erros da $i$ ésima amostra, construída como uma matriz diagonal, onde os elementos não nulos são a variância observada para cada variável, e $f\left(t_{i}, \hat{\beta}\right)$ é o valor predito pelo modelo no tempo da amostra $i$.

Os valores de $A I C_{c}$ foram usados para comparar a qualidade dos modelos entre si através do uso dos pesos de Akaike, definidos pela equação (14).

$$
W_{\%(j)}=\frac{\exp \left(-\frac{1}{2}\left(A I C_{c_{0}}-A I C_{c_{j}}\right)\right)}{\sum_{q=1}^{m} \exp \left(-\frac{1}{2}\left(A I C_{c_{0}}-A I C_{c_{q}}\right)\right)}
$$

$\mathrm{Na}$ equação acima, $w_{\%(j)}$ é o peso do modelo $j$ dentro do conjunto de $m$ modelos sugeridos e $A I C_{c_{0}}$ é o menor valor de $A I C_{c}$ dentro do conjunto. Os valores de $w_{\%(j)}$ representam a estimativa da probabilidade de que o modelo $j$ represente 0 modelo real, dado o conjunto de dados observados e o conjunto de modelos 
sugeridos (Burnham, Anderson, 2002). Com a obtenção dos valores de $w_{\%(j)}$ para cada modelo, pode-se construir um intervalo de confiança de modelos para cada experimento, ordenando-se os modelos do maior para o menor valor do peso, e selecionando os modelos nesta ordem até que a soma dos pesos ultrapasse o limite do intervalo de confiança escolhido. Neste trabalho, escolhe-se o intervalo de confiança de $99,9 \%$. 


\subsubsection{Métodos estatísticos}

A influência do $\mathrm{pH}$ e da temperatura sobre cada um dos parâmetros cinéticos obtidos pelo modelo matemático escolhido foi analisada pelo software Statistica 10 (Statsoft). Os efeitos das variáveis foram mensurados por um modelo quadrático que considera 5 efeitos: o pH e a temperatura na forma linear e na forma quadrática, além da interação entre ambos. A significância estatística de cada efeito foi determinada pelo teste $\mathrm{t}$ de Student, onde o efeito estimado para cada variável é dividido pelo seu erro padrão, gerando a variável $t(v)$, onde $v$ são os graus de liberdade da estimativa. Um p-valor foi determinado, num nível de significância de 0,10 . Os efeitos cujo p-valor ultrapassasse o nível de significância foram removidos um a um, a partir do menos significativo, até que todos os efeitos considerados estivessem dentro do nível de significância. 


\section{RESULTADOS E DISCUSSÃO}

O processo de produção do polissacarídeo capsular de Hib apresenta algumas limitações na obtenção de alta produtividade devido às configurações metabólicas do microrganismo que o impedem de atingir altas densidades celulares, como visto no item 2.2.1.1. Os estudos recentes que fazem uso dos regimes de alimentação permitiram atingir maiores produtividades de PRP, no entanto ficou evidente que a qualidade da molécula produzida, definida pela sua massa molecular, ficou comprometida, afetando diretamente os processos de purificação (Albani et al., 2012, 2015; Silva, 2010).

Em estudos anteriores (vide Apêndice B), ficou demonstrado que $\mathrm{pH}$, temperatura e concentração de íons sódio agem diretamente sobre a estabilidade da molécula de PRP, contribuindo para sua despolimerização espontânea; neste panorama, a redução do $\mathrm{pH}$ e da temperatura do cultivo pode servir como auxílio na obtenção de moléculas de alta massa molecular, pois evitaria a degradação espontânea durante o próprio processo de crescimento celular (Cintra, Takagi, 2015). Mediante a esta informação, uma avaliação mais detalhada da etapa de crescimento celular quanto à qualidade do polissacarídeo torna-se de extrema importância para a produtividade global dos processos envolvidos.

Para isso, foram realizados 10 cultivos em diferentes condições, determinadas por um desenho experimental (DCCR de dois níveis e duas variáveis, como especificado no item 3.1). Os dados obtidos nesses cultivos foram usados para: 1) determinar qual modelo cinético descrito na literatura é o mais adequado para estudar o crescimento de Hib em diferentes condições; 2) realizar a avaliação estatística dos parâmentros cinéticos obtidos por este modelo para compreender as modificações metabólicas observadas mediante a alteração das condições de crescimento da bactéria; 3) avaliar os perfis de massa molecular e evidenciar a influencia das condições de cultivo sobre a qualidade da molécula de PRP produzida. Com os resultados obtidos, foi determinada uma condição de cultivo otimizada, seguindo o critério de se obter altos valores de produtividade de PRP combinados com altos valores de massa molecular. Nestas condições, foi feita a validação o processo, além de uma comparação à condição de cultivo descrita na literatura, com projeções a respeito do rendimento global de produção da vacina Hib. 


\subsection{Escolha do modelo cinético para o cultivo de Hib}

A escolha do melhor modelo cinético para descrever o processo de crescimento celular de Hib, com a formação de acetato e PRP, foi feita considerando-se todas as diferentes condições de cultivo determinadas no item 3.1 para avaliar a robustez e flexibilidade do modelo escolhido. Como descrito no item 3.3.1, primeiramente escolheu-se um modelo parcial para a descrição da formação de biomassa e acetato, sendo escolhido em seguida um modelo completo incluindose a formação de PRP. Neste trabalho, optou-se por não realizar a escolha de modelos para o consumo de substrato devido aos seguintes motivos: 1) a inibição pelo ácido interrompe o crescimento celular quando ainda há muito substrato disponível, tornando impossível o ajuste de modelos satisfatoriamente aos dados; 2) a bactéria é fastidiosa e dependente do fornecimento de vários substratos (glicose, glutamato, arginina, cofatores, etc.), dificultando a escolha de um único componente para o estudo. Sendo assim, o meio de cultivo foi preparado a fim de garantir que todos os componentes necessários estivessem sempre em excesso, eliminando os efeitos de limitação por qualquer substrato.

Em cada um dos 10 ensaios foi obtido o conjunto de modelos dentro do intervalo de 99,9 \% de confiança segundo os pesos de Akaike, como descrito no item 3.3.1.2. Da totalidade de 60 modelos parciais testados (Tabela 7) apenas 29 mostraram convergência em todos os 10 ensaios. Por isso, os modelos que não convergiram em pelo menos um dos ensaios foram removidos da análise. Na Tabela 9 são mostrados os 29 modelos obtidos e o peso de Akaike obtido em cada ensaio.

Ao se observar os resultados da Tabela 9, nota-se que apenas três modelos foram incluídos nos intervalos de confiança de todos os ensaios: os modelos parciais 23, 25 e 26. Nos três modelos, a formação de biomassa é descrita pela mesma equação, o modelo de Aiba et. al (1968) acrescido de um expoente sobre o fator de inibição (vide modelo B da Tabela 4). Já a formação de ácido é descrita diferentemente nos três modelos. Nos dois primeiros, a formação de ácido é apenas não-associada ao crescimento e sofre inibição. A diferença entre estes dois modelos está no fator de inibição; o modelo parcial 23 sugere a mesma forma de inibição do modelo de formação de biomassa, enquanto o modelo parcial 25 sugere a equação de Yano e Koga (1973). No último modelo sugere-se que a formação de acetato é mista, e que não há inibição metabólica. 
Tabela 9 - Valores de $w_{\%}$ obtidos para os modelos parciais de formação de biomassa, formação de acetato e inibição sobre o acetato em cada ensaio.

\begin{tabular}{|c|c|c|c|c|c|c|c|c|c|c|c|c|c|}
\hline \multicolumn{4}{|c|}{ Códigos } & \multicolumn{10}{|c|}{ Ensaios } \\
\hline MP & $X$ & $A_{f}$ & $A_{i}$ & 1 & 2 & 3 & 4 & & 6 & 7 & 8 & 9 & 10 \\
\hline 01 & $A$ & $A$ & $\mathrm{O}$ & ,01 & 0,01 & 0,01 & $<0,01$ & $<0,01$ & 0,01 & $<0,01$ & $<0,01$ & $<0,01$ & $\underline{0,03}$ \\
\hline 06 & $A$ & $B$ & $\mathrm{O}$ &, 01 & 0,01 & 0,01 & 0,01 & $<0,01$ & $=0,01$ & $<0,01$ & $<0,01$ & $<0,01$ & $<0,01$ \\
\hline 08 & $A$ & $B$ & $B$ & &, 01 & $<0,01$ & $<0,01$ & $<0,01$ & $<0,01$ & & 0,01 & & $\underline{55,11}$ \\
\hline 11 & $A$ & $C$ & $\mathrm{O}$ &, 01 & $<0,01$ & $<0,01$ & $<0,01$ & $<0,01$ & $<0,01$ & $<0,01$ & $<0,01$ & 01 & $\underline{3,93}$ \\
\hline 12 & A & C & A & &, 01 & 0,01 & 0,01 & $<0,01$ & $<0,01$ & $<0,01$ & & & $\underline{0,62}$ \\
\hline 13 & $A$ & $\mathrm{C}$ & B & &, 01 & $<$ & $<0,01$ & $<0,01$ & $<0,01$ & $<0,01$ &, 01 & & $\underline{2,70}$ \\
\hline 15 & A & $\mathrm{C}$ & $D$ & & $<0,01$ & $<0$ & 0,01 & $<0,01$ & $<0,01$ & $<0,01$ &, 01 & & $\underline{2,63}$ \\
\hline 16 & $B$ & $A$ & $\mathrm{O}$ & & & & & & & 13 & & &, 03 \\
\hline 21 & B & $B$ & $\mathrm{O}$ & 01 & $<0,01$ & $<$ & $<0,01$ & $<0,01$ & $<0,01$ & $<0,01$ & $<0,01$ & $<0,01$ & $<0,01$ \\
\hline 22 & B & B & A & & $\underline{92,50}$ & & & $\underline{27,39}$ & $\underline{7,23}$ & $\underline{0,94}$ &, 17 & & $\underline{0,30}$ \\
\hline$>23$ & B & $B$ & B & & $\underline{4,25}$ & & $\underline{55,39}$ & $\underline{5,10}$ & $\underline{56,21}$ & $\underline{4,76}$ & $\underline{60,94}$ & & $\underline{10,02}$ \\
\hline 24 & $B$ & $B$ & C & 76 & $\underline{0,20}$ & $<0,01$ & $<0,01$ & $\underline{60,21}$ & $<0,01$ & $\underline{0,33}$ & $\underline{0,06}$ & $\underline{30,67}$ & $\underline{2,10}$ \\
\hline & B & $B$ & $D$ & 69 & $\underline{1,74}$ & & $\underline{18}$ & $\underline{5,11}$ & $\underline{28}$ & $\underline{5,98}$ & 9,27 & & 19,24 \\
\hline$>26$ & B & C & $\mathrm{O}$ &, 77 & $\underline{1,26}$ & $\underline{88,21}$ & $\underline{1,96}$ & $\underline{1,44}$ & $\underline{0,13}$ & $\underline{13,00}$ & $\underline{0,20}$ & $\underline{10,18}$ & $\underline{2,69}$ \\
\hline $2 \varepsilon$ & $B$ & $C$ & $\mathrm{~B}$ & & 0,03 & & $\underline{12,1}$ & $\underline{0,23}$ & $\underline{3,72}$ & $\underline{0,12}$ & 28 & 05 & $\underline{0,07}$ \\
\hline 30 & $B$ & $C$ & $D$ & & 0,02 & 0,03 & $\underline{11,92}$ & $\underline{0,23}$ & $\underline{1,85}$ & $\underline{0,13}$ & $\underline{0,97}$ & & 0,03 \\
\hline 31 & $C$ & $A$ & 0 & &, 01 & 0,01 & $<0,01$ & 0,01 & $<0,01$ & $<0,01$ & 0,01 & 01 & 0,01 \\
\hline 36 & $C$ & B & O & & & & $<0,01$ & $<0,01$ & $<0,01$ & $<0,01$ &, 01 &, 01 & $<0,01$ \\
\hline 39 & $C$ & B & C &, 01 & $<0,01$ & $<0,01$ & $<0,01$ & $<0,01$ & $<0,01$ & $<0,01$ & $<0,01$ & $<0,01$ & $\underline{0,04}$ \\
\hline 41 & $C$ & $C$ & 0 & & & & $<0,01$ & $<0,01$ & $<0,01$ & $<0,01$ & & & $\underline{0,26}$ \\
\hline 46 & D & $A$ & 0 & & $<0,01$ & & $<0,01$ & $<0,01$ & $<0,01$ & $\underline{3,96}$ & $<0,01$ & 0,01 & 0,01 \\
\hline 51 & $D$ & $B$ & 0 & & & & & $<0,01$ & $<0,01$ & $<0,01$ & $<0,01$ & & $<0,01$ \\
\hline 52 & D & B & A & & & $\underline{0,04}$ & & $\underline{0,08}$ & $\underline{0,24}$ & $\underline{1,80}$ & 0,02 & $\underline{0,18}$ & $<0,01$ \\
\hline 54 & D & $B$ & C & 0,01 & $<0,01$ & $<0,01$ & $<0,01$ & $\underline{0,18}$ & $<0,01$ & $\underline{0,67}$ & $<0,01$ & $\underline{0,12}$ & 0,02 \\
\hline 55 & D & $B$ & D & & & $\underline{0,17}$ & & 0,02 & $\underline{1,45}$ & $\underline{9,51}$ & $\underline{0,07}$ & & $\underline{0,14}$ \\
\hline 56 & $D$ & $C$ & 0 & & $<0,01$ & $\underline{3,13}$ & $<0,01$ & $<0,01$ & $<0,01$ & $\underline{49,29}$ & $<0,01$ & 0,02 & $\underline{0,05}$ \\
\hline 58 & D & C & $B$ & & $<0,01$ & $<0,01$ & $<0,01$ & $<0,01$ & $\underline{0,13}$ & $\underline{0,36}$ & 0,01 & $<0,01$ & $<0,01$ \\
\hline 59 & $D$ & $C$ & $C$ & $<0,01$ & $<0,01$ & $\underline{0,12}$ & $<0,01$ & 0,01 & 0,01 & $\underline{7,88}$ & $<0,01$ & 0,01 & $<0,01$ \\
\hline 60 & D & C & D & $<0,01$ & $<0,01$ & $<0,01$ & $<0,01$ & $<0,01$ & $\underline{0,10}$ & $\underline{0,16}$ & $<0,01$ & $<0,01$ & $<0,01$ \\
\hline
\end{tabular}

Os códigos dos modelos são específicados conforme 0 item 3.3.1. Cada valor de $w_{\%}$ é sublinhado se o respectivo modelo parcial for inserido no intervalo de $99,9 \%$ de confiança do respectivo ensaio. À esquerda do código MP são indicados os modelos que apresentaram valores de W\% dentro do intervalo de confiança de $99,9 \%$ em todos os ensaios.

A presença de três modelos nos intervalos de confiança dos 10 ensaios indica que com os dados obtidos não é possível afirmar que algum dos três modelos é mais adequado que os outros dois, mas dá evidência de que os modelos restantes possam ser desconsiderados. Assim, estes três modelos foram escolhidos para dar prosseguimento ao processo de escolha. Cada um dos modelos parciais escolhidos 
foi combinado aos 15 modelos de formação de PRP listados na Tabela 8, originando 45 modelos completos a serem testados.

De forma semelhante, nem todos os modelos completos apresentaram convergência em todos os ensaios e foram removidos. Dos 45 modelos completos testados, apenas 12 convergiram satisfatoriamente. Na Tabela 10, apresenta-se os valores dos pesos de Akaike obtidos em cada ensaio para esses 12 modelos.

Tabela 10 - Valores de $\mathrm{w}_{\%}$ obtidos para os modelos completos com a formação de PRP e inibição sobre o PRP em cada ensaio.

\begin{tabular}{rrrrrrrrrrrrr}
\hline \multicolumn{1}{c}{ Códigos } & \multicolumn{10}{c}{ Ensaios } \\
MP/MC & $\mathrm{P}_{\mathrm{f}} \mathrm{P}_{\mathrm{i}}$ & 1 & 2 & 3 & 4 & 5 & 6 & 7 & 8 & 9 & 10 \\
\hline $23 / 01$ & $\mathrm{~A}$ & $\mathrm{O}$ & $<0,01$ & $<0,01$ & $<0,01$ & $\underline{0,08}$ & $<0,01$ & 0,02 & $<0,01$ & $<0,01$ & $<0,01$ & $<0,01$ \\
$25 / 01$ & $\mathrm{~A}$ & $\mathrm{O}$ & $<0,01$ & $<0,01$ & $<0,01$ & 0,03 & $<0,01$ & 0,01 & $<0,01$ & $<0,01$ & $<0,01$ & $<0,01$ \\
$25 / 06$ & $\mathrm{~B}$ & $\mathrm{O}$ & $<0,01$ & $<0,01$ & $<0,01$ & $<0,01$ & 0,01 & $<0,01$ & $<0,01$ & $<0,01$ & $<0,01$ & $\underline{0,09}$ \\
$25 / 15$ & $\mathrm{C}$ & $\mathrm{D}$ & $<0,01$ & $<0,01$ & $<0,01$ & 0,03 & $<0,01$ & $\underline{28,12}$ & $<0,01$ & $\underline{25,09}$ & $<0,01$ & 0,01 \\
$26 / 01$ & $\mathrm{~A}$ & $\mathrm{O}$ & $<0,01$ & $<0,01$ & $<0,01$ & 0,01 & $<0,01$ & $<0,01$ & $<0,01$ & $<0,01$ & $<0,01$ & $<0,01$ \\
$26 / 06$ & $\mathrm{~B}$ & $\mathrm{O}$ & $<0,01$ & $<0,01$ & $<0,01$ & $<0,01$ & 0,01 & $<0,01$ & 0,01 & $<0,01$ & $<0,01$ & 0,02 \\
$26 / 07$ & $\mathrm{~B}$ & $\mathrm{~A}$ & $\underline{5,75}$ & $<0,01$ & $\underline{0,12}$ & $<0,01$ & $\underline{29,09}$ & $<0,01$ & $\underline{0,08}$ & $<0,01$ & $<0,01$ & $\underline{17,35}$ \\
$26 / 08$ & $\mathrm{~B}$ & $\mathrm{~B}$ & $\underline{6,33}$ & $\underline{34,04}$ & $\underline{0,12}$ & $\underline{66,16}$ & $\underline{1,03}$ & $<0,01$ & $<0,01$ & $\underline{37,53}$ & $\underline{78,24}$ & $\underline{30,13}$ \\
$26 / 09$ & $\mathrm{~B}$ & $\mathrm{C}$ & $<0,01$ & $<0,01$ & $<0,01$ & $<0,01$ & $\underline{23,41}$ & $<0,01$ & $\underline{0,07}$ & $<0,01$ & $<0,01$ & $\underline{11,81}$ \\
$26 / 10$ & $\mathrm{~B}$ & $\mathrm{D}$ & $\underline{1,93}$ & $\underline{54,69}$ & $\underline{0,20}$ & $\underline{32,50}$ & $\underline{1,06}$ & $\underline{71,84}$ & $\underline{2,46}$ & $\underline{35,78}$ & $\underline{21,11}$ & $\underline{31,62}$ \\
$26 / 11$ & $\mathrm{C}$ & $\mathrm{O}$ & $\underline{85,99}$ & $\underline{11,25}$ & $\underline{99,56}$ & $\underline{0,86}$ & $\underline{45,38}$ & $<0,01$ & $\underline{97,35}$ & $<0,01$ & $<0,01$ & $\underline{7,95}$ \\
$26 / 13$ & $\mathrm{C}$ & $\mathrm{B}$ & $<0,01$ & 0,01 & $<0,01$ & $\underline{0,33}$ & 0,01 & $<0,01$ & 0,03 & $\underline{1,61}$ & $\underline{0,65}$ & $\underline{1,02}$ \\
\hline
\end{tabular}

Os códigos dos modelos são específicados conforme o item 3.3.1. Cada valor de $\mathrm{W}_{\%}$ é sublinhado se o respectivo modelo parcial for inserido no intervalo de $99,9 \%$ de confiança do respectivo ensaio. À esquerda do código MP são indicados os modelos que apresentaram valores de w\% dentro do intervalo de confiança de $99,9 \%$ em todos os ensaios.

A inserção de mais uma variável na análise dos modelos permitiu uma maior discriminação na qualidade dos modelos, ao conferir mais uma dimensão na quantificação dos erros de ajuste, além de aumentar a quantidade de parâmetros a serem penalizados. Apenas um modelo completo, o 26/10, se apresentou nos intervalos de confiança dos 10 ensaios, como se observa na Tabela 10. Este modelo determina, em primeiro lugar, o tipo de formação de acetato, que ficou indefinido na análise dos modelos parciais. A formação de acetato sugerida é a formação mista sem inibição, que é teoricamente mais simples que as outras duas hipóteses obtidas. Já a formação de PRP se mostrou como não associada ao crescimento, e sofrendo inibição por parte do acetato. Contudo a forma de inibição sobre o PRP neste modelo é aquela descrita por Yano e Koga (1973), diferente da que descreve a inibição sobre o crescimento. 
A análise dos pesos de Akaike em duas etapas permitiu selecionar, com embasamento estatístico, um único modelo a ser usado na descrição das cinéticas de Hib. As equações (15), (16) e (17) resumem as três equações que serão utilizadas nos próximos itens do trabalho para descrever a cinética de crescimento de Hib.

$$
\begin{gathered}
\frac{d X}{d t}=\mu_{\text {max }} * \exp \left(-\left(k_{X} * A\right)^{n_{X}}\right) * X \\
\frac{d A}{d t}=\left(\alpha_{A} * \frac{d X}{d t}+\beta_{A} * X\right) \\
\frac{d P}{d t}=\beta_{P} * \frac{1}{1+\left(A / k_{P}\right)^{n_{P}}} * X
\end{gathered}
$$

Neste modelo, observa-se a inibição da concentração de acetato tanto sobre o crescimento celular quanto sobre a formação de PRP. A formação de acetato é mista, apresentando uma fração associada ao crescimento, e outra não associada. Este regime de formação pode ser comparado à formação de lactato descrita por Luedeking e Piret (1959), onde os autores mostram que a formação do ácido não pode ser considerada apenas proporcional à velocidade de crescimento ou à concentração de células. Ambos os ácidos são formados como subprodutos da geração de energia e potencial redutor para a produção dos constituintes da biomassa, explicando o fator de associação ao crescimento, mas também são formados devido à necessidade da manutenção de um pool energético para a manutenção dos processos não associados à formação de biomassa, tais como a manutenção do potencial transmembrana, regulação do pH citosólico, regulação da concentração intracelular de íons, entre outros. Finalmente, a formação de PRP é não associada ao crescimento, o que vai de acordo com o fato de a sua formação não estar envolvida nos processos centrais do metabolismo e não ser essencial para a manutenção dos processos celulares, sendo um produto secundário. Porém, a sua formação sofre inibição pela concentração de acetato, de forma independente à inibição ao crescimento. Esta configuração, onde o ácido orgânico age de forma diferenciada sobre o crescimento e a produção de polissacarídeo é observada na literatura em outros organismos, como por exemplo no caso da inibição do lactato sobre o crescimento de Streptococcus zooepidemicus e produção de ácido hialurônico; interessantemente, essa diferença na forma de inibição pode ser 
utilizada como estratégia de otimização, possibilitando controlar a formação de células em prol da maior produção de polissacarídeo (Liu et al., 2008).

O modelo cinético ajustado a cada caso e os dados experimentais é ilustrado da Figura 6 até a Figura 15 (linha contínua), sendo mostradas também as curvas de biomassa, acetato e PRP total (soma da fração celular e livre no sobrenadante), juntamente com os erros experimentais (pontos e barras).

Figura 6 - Dados experimentais e modelo ajustado para o ensaio $1\left(\mathrm{~T}_{\mathrm{C}}=0 ; \mathrm{pH}_{\mathrm{C}}=0\right)$
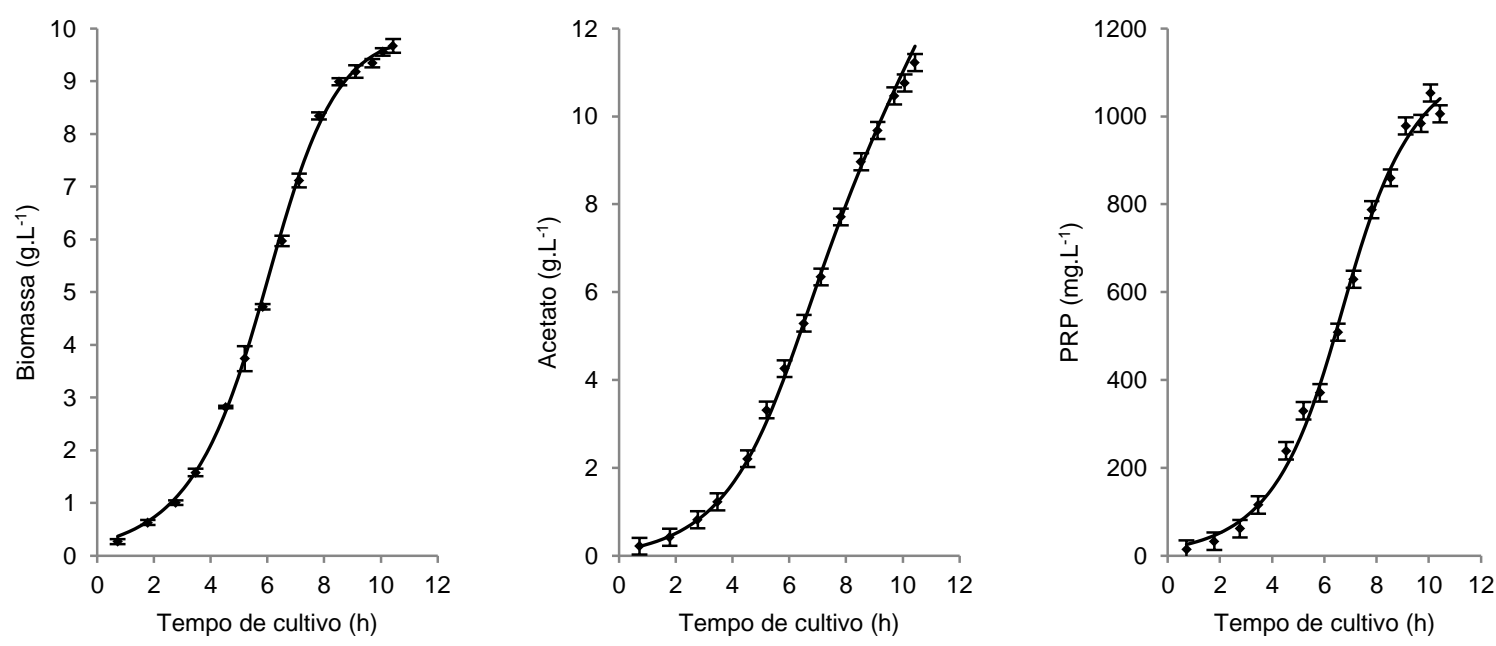

Figura 7 - Dados experimentais e modelo ajustado para o ensaio $2\left(\mathrm{~T}_{\mathrm{C}}=0 ; \mathrm{pH}_{\mathrm{C}}=0\right)$
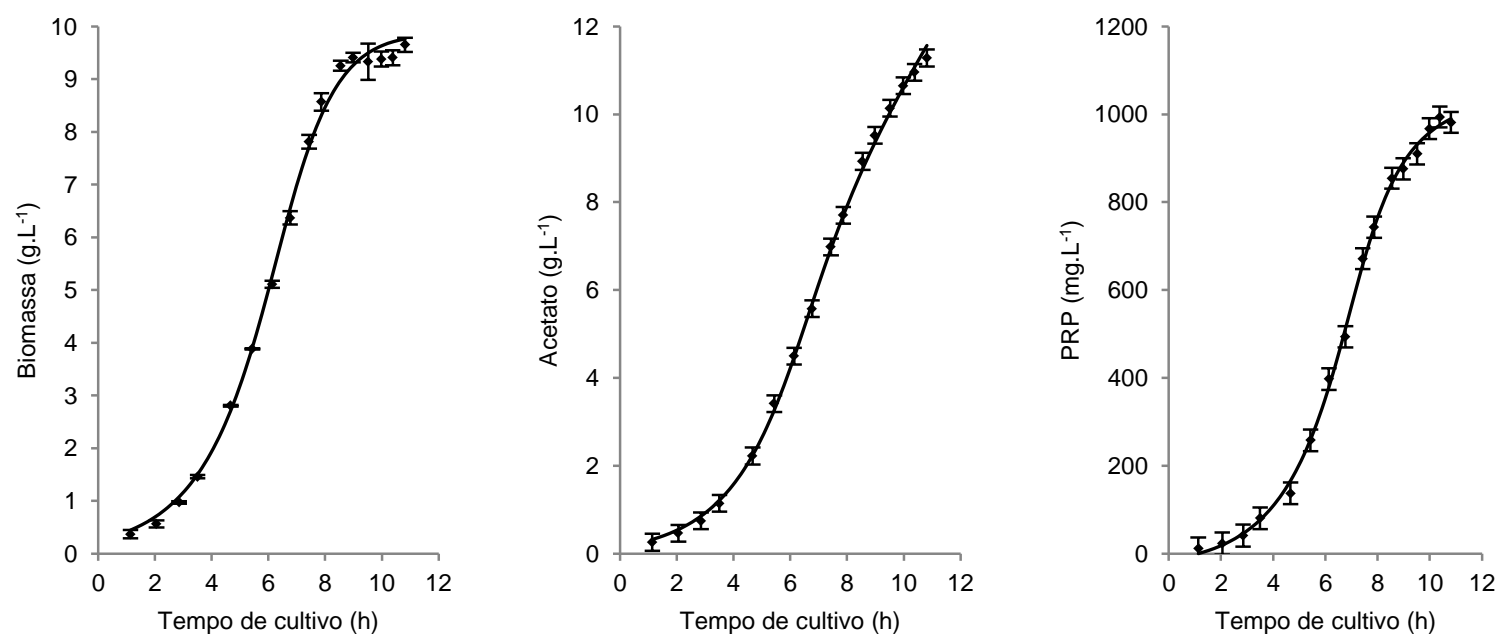
Figura 8 - Dados experimentais e modelo ajustado para o ensaio $3\left(T_{C}=+1 ; \mathrm{pH}_{\mathrm{C}}=+1\right)$
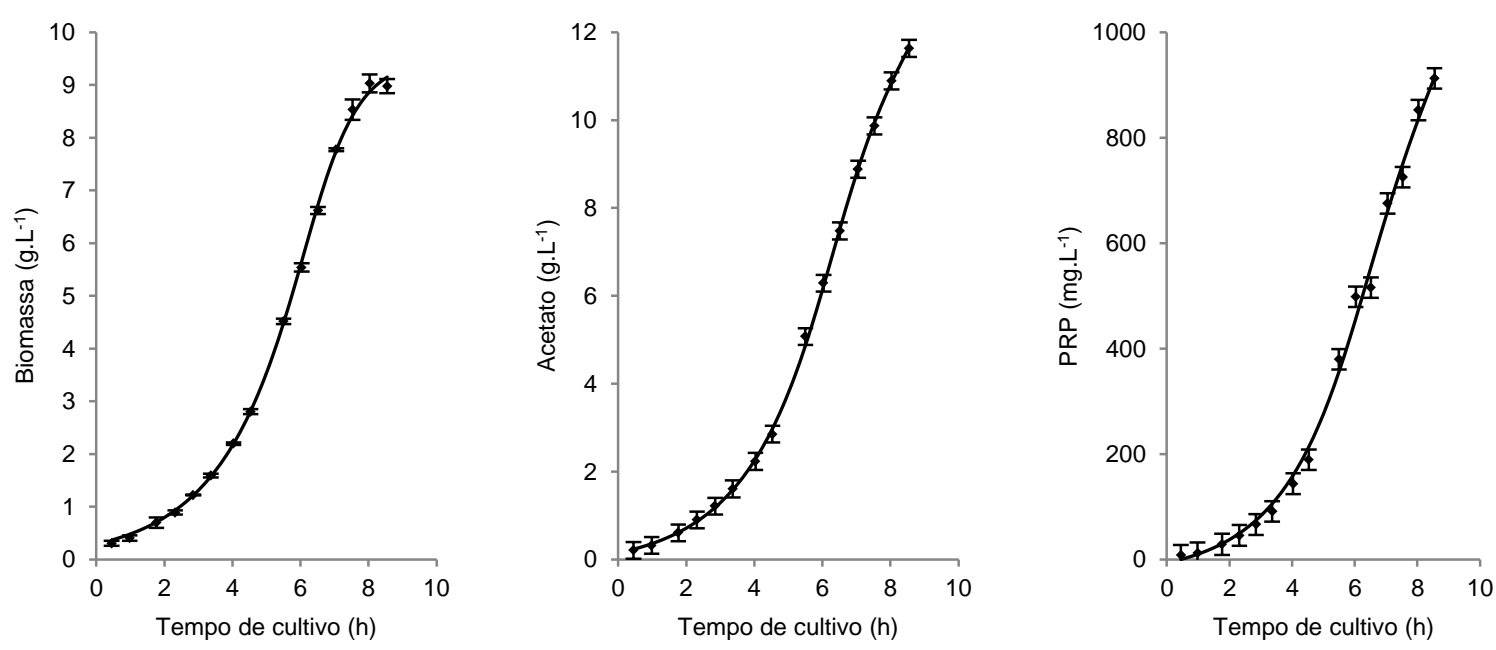

Figura 9 - Dados experimentais e modelo ajustado para o ensaio $4\left(\mathrm{~T}_{\mathrm{C}}=+1 ; \mathrm{pH}_{\mathrm{C}}=-1\right)$
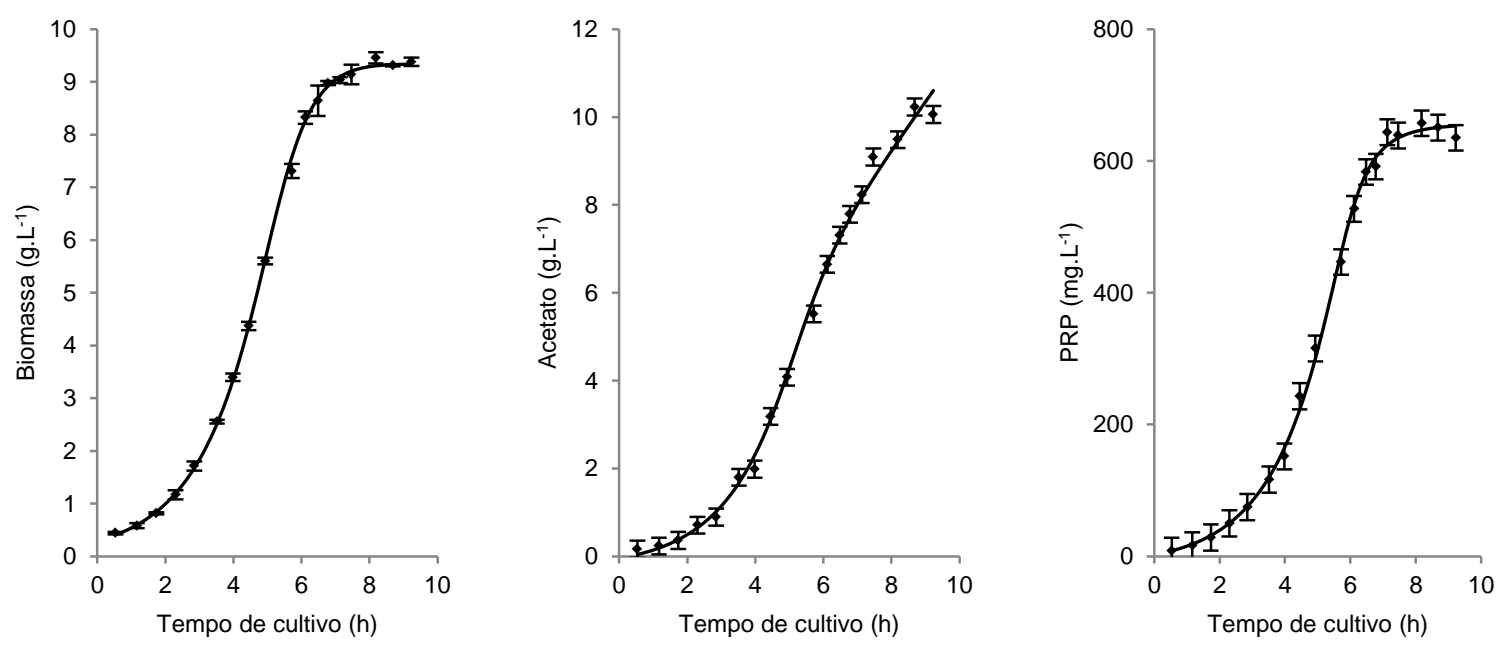

Figura 10 - Dados experimentais e modelo ajustado para o ensaio $5\left(\mathrm{~T}_{\mathrm{C}}=-1 ; \mathrm{pH}_{\mathrm{C}}=+1\right)$
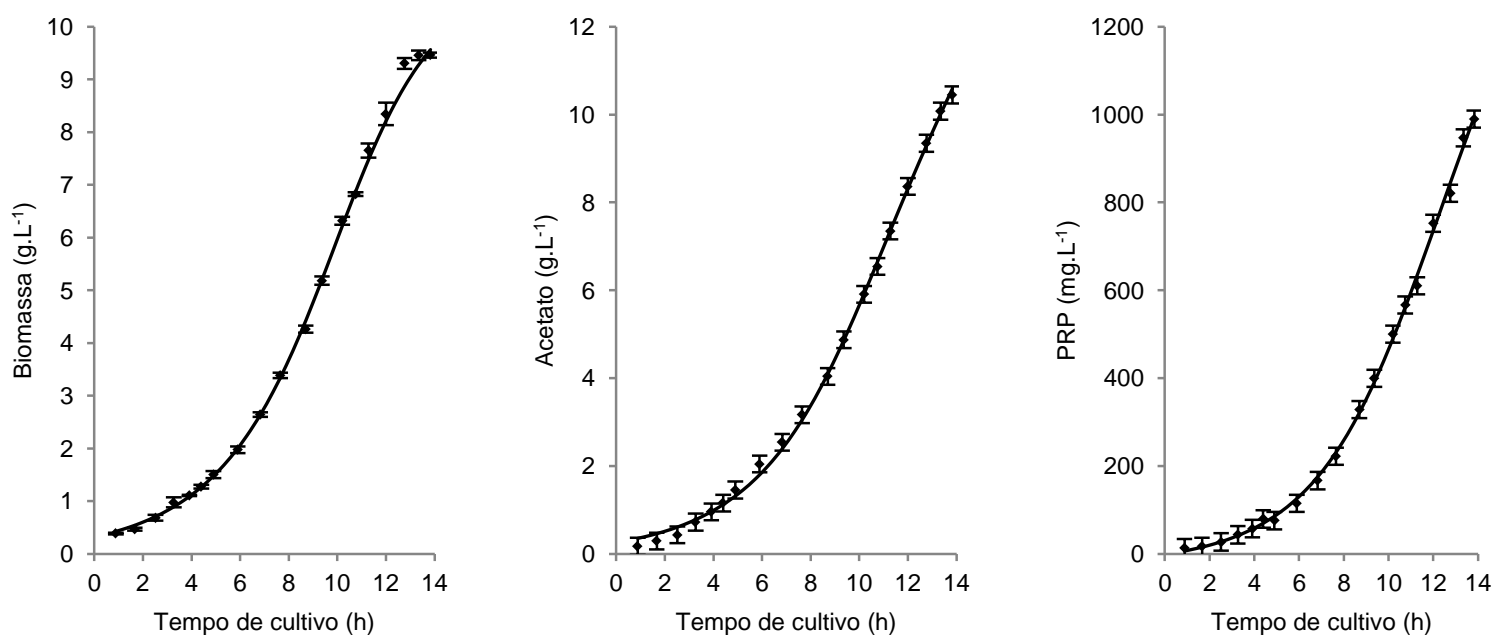
Figura 11 - Dados experimentais e modelo ajustado para o ensaio $6\left(\mathrm{~T}_{\mathrm{C}}=-1 ; \mathrm{pH}_{\mathrm{C}}=-1\right)$
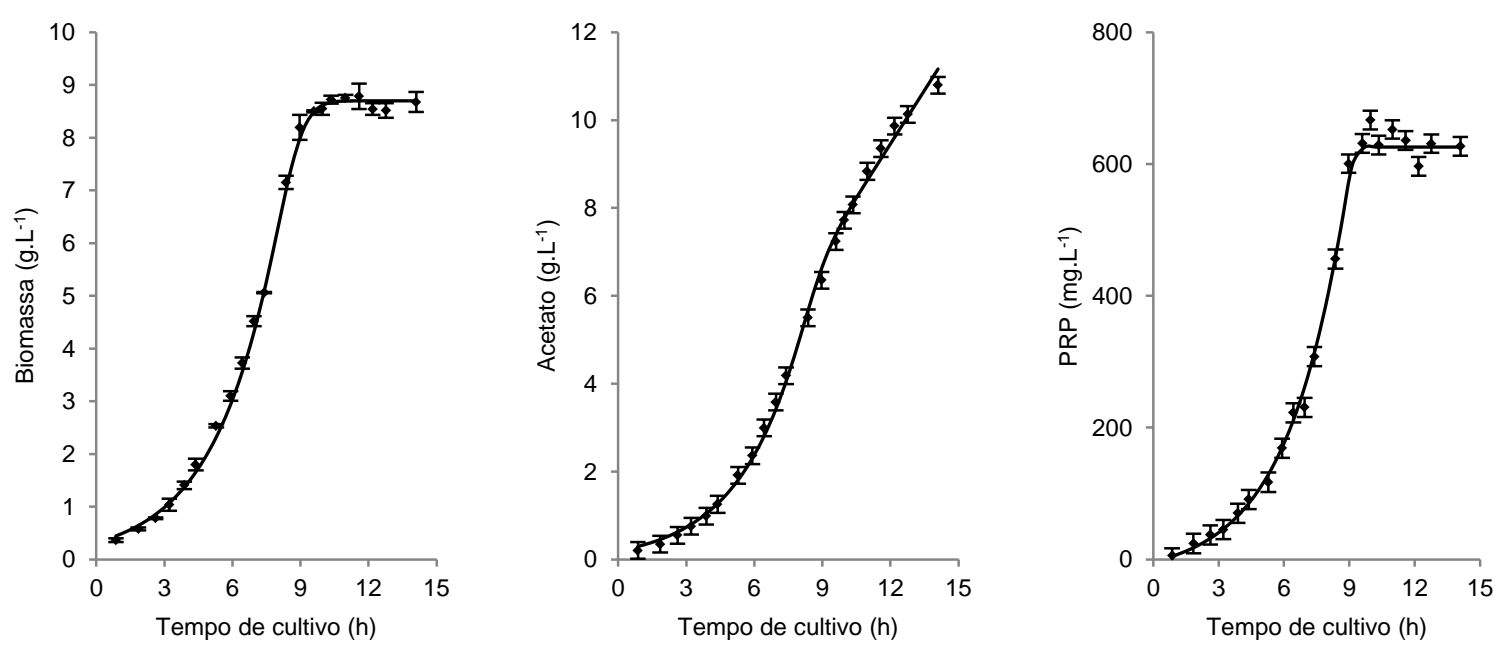

Figura 12 - Dados experimentais e modelo ajustado para o ensaio $7\left(\mathrm{~T}_{\mathrm{C}}=0 ; \mathrm{pH}_{\mathrm{C}}=+1,4\right)$
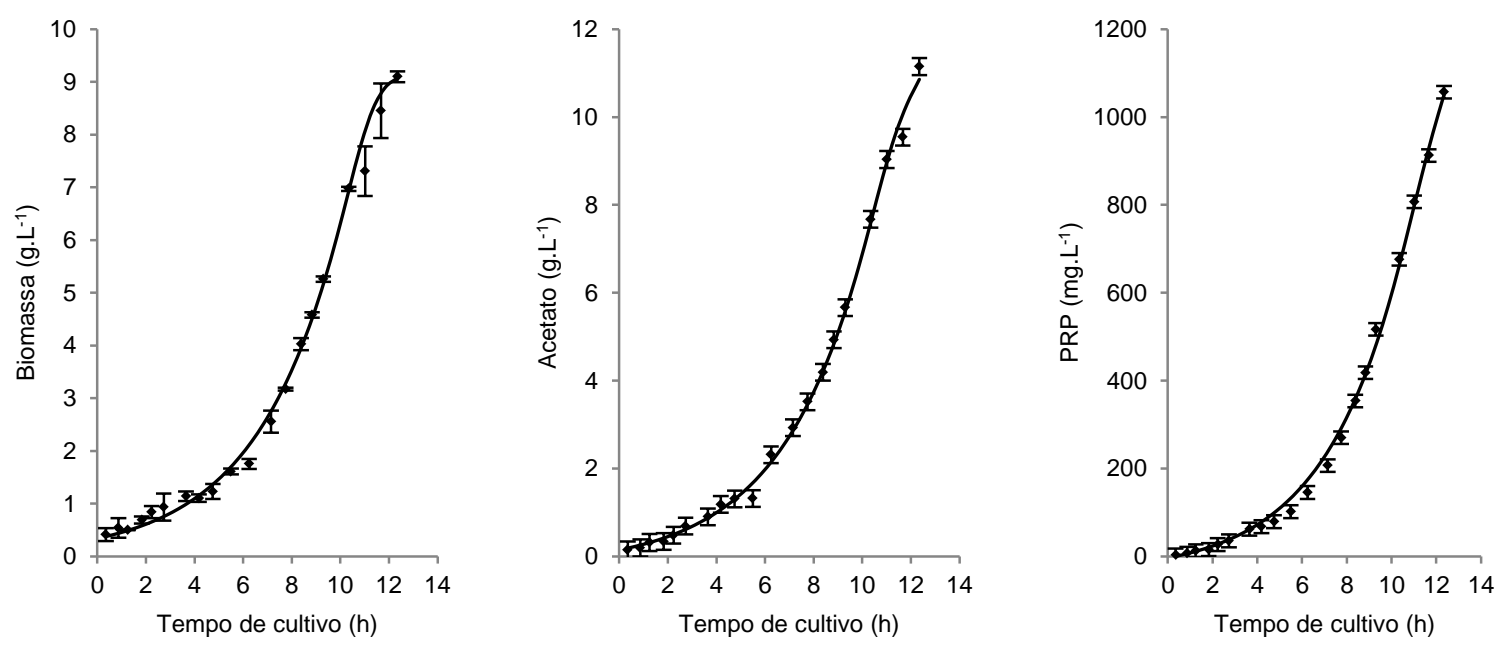

Figura 13 - Dados experimentais e modelo ajustado para o ensaio $8\left(\mathrm{~T}_{\mathrm{C}}=0 ; \mathrm{pH}_{\mathrm{C}}=-1,4\right)$
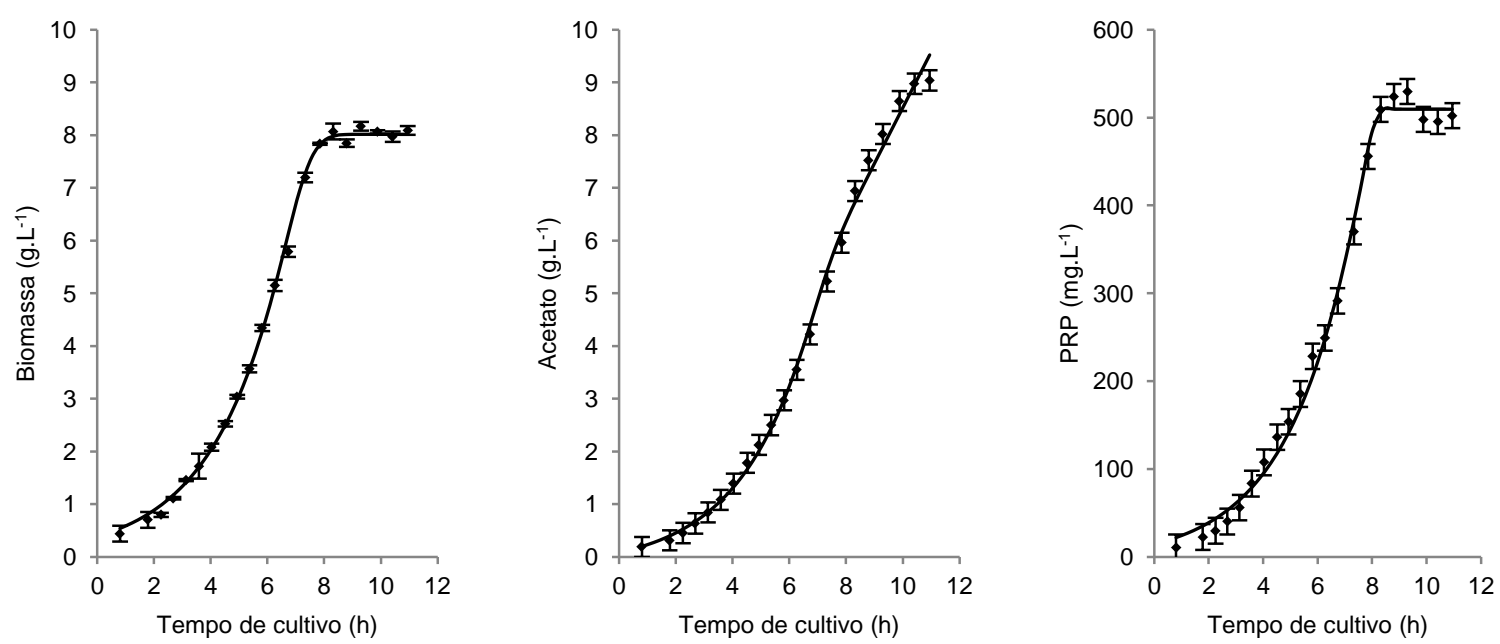
Figura 14 - Dados experimentais e modelo ajustado para o ensaio $9\left(\mathrm{~T}_{\mathrm{C}}=+1,4 ; \mathrm{pH}_{\mathrm{C}}=0\right)$
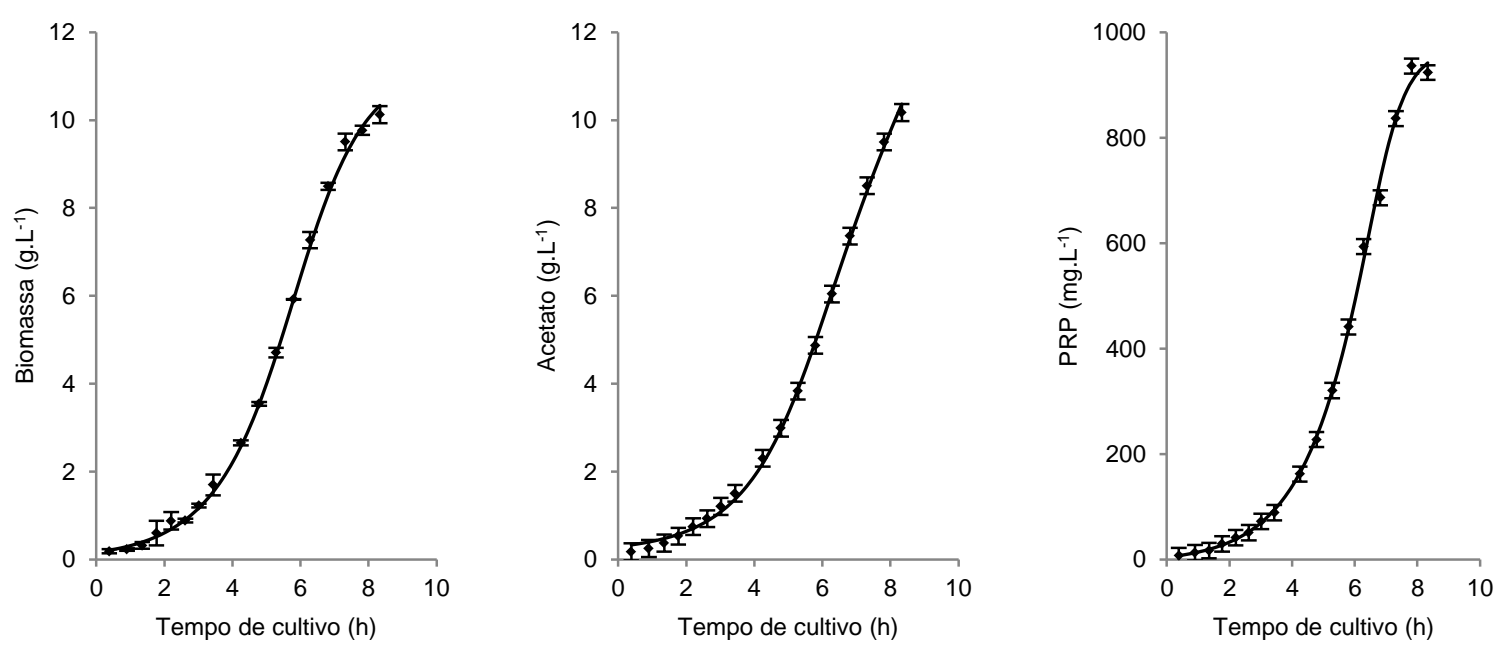

Figura 15 - Dados experimentais e modelo ajustado para o ensaio $10\left(\mathrm{~T}_{\mathrm{C}}=-1,4 ; \mathrm{pH}_{\mathrm{C}}=0\right)$
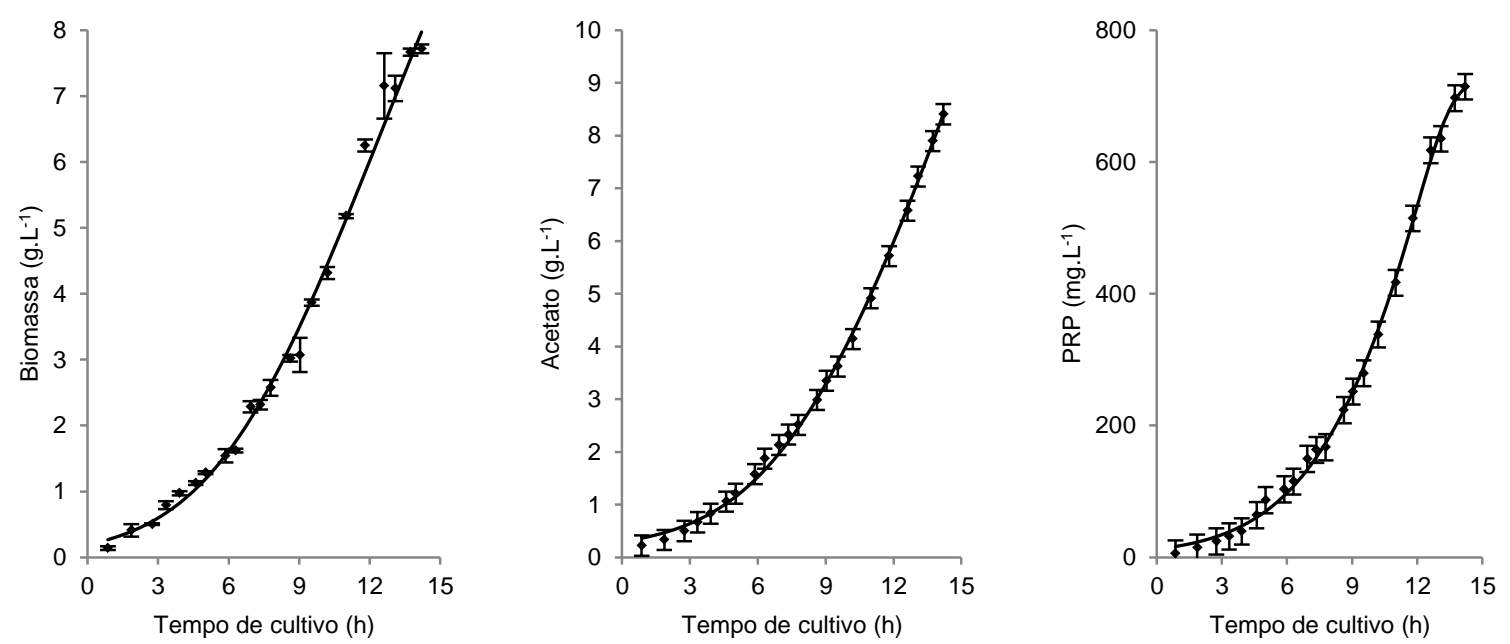

\subsection{Efeitos do pH e temperatura sobre a cinética microbiana}

A partir do modelo cinético selecionado conforme o item anterior, fez-se o estudo dos efeitos do $\mathrm{pH}$ e da temperatura sobre a cinética microbiana. Os parâmetros do modelo, tais como a máxima velocidade específica de crescimento, a constante de inibição pelo acetato, as constantes de formação de produtos, etc., foram utilizados como variável resposta para a construção de superfícies de resposta em função do $\mathrm{pH}$ e da temperatura. Cada parâmetro foi estudado separadamente através de modelos estatísticos, como especificado no item 3.3.2, sendo feitas as interpretações dos resultados, quando apropriado, com a comparação aos modelos formais apresentados nos itens 2.3.2 a 2.3.4. Para melhor 
compreensão, os parâmetros foram divididos em três partes: formação de biomassa, formação de acetato e formação de PRP. Além dos parâmetros cinéticos obtidos dos ajustes dos modelos, foram estudados também a liberação de PRP ao sobrenadante e a massa molecular. Ao final, os resultados obtidos são unificados para a determinação da produtividade final de PRP, durante o processo de crescimento celular, e determinação do ponto ótimo de cultivo.

\subsubsection{Formação de biomassa}

\subsubsection{Máxima velocidade específica de crescimento}

Os valores de $\mu_{\max }$ foram alterados de acordo com a temperatura do cultivo como o esperado, apresentando valores maiores a temperaturas mais elevadas, como se pode verificar na Tabela 11. Quanto ao $\mathrm{pH}$, verifica-se que o crescimento tende a aumentar na região abaixo da neutralidade (ensaio 4 e 9), atingindo cerca de $0,600 \mathrm{~h}^{-1}$.

Tabela 11 - Valores de $\mu_{\max }$ obtidos para as variações de $\mathrm{pH}$ e temperatura

\begin{tabular}{lrrrrr}
\hline \multicolumn{3}{c}{ Valor codificado } & \multicolumn{3}{c}{ Valor real } \\
Ensaio & $\mathrm{T}\left({ }^{\circ} \mathrm{C}\right)$ & $\mathrm{pH}$ & $\mathrm{T}\left({ }^{\circ} \mathrm{C}\right)$ & $\mathrm{pH}$ & $\mu_{\max }\left(\mathrm{h}^{-1}\right)$ \\
\hline 1 & 0,00 & 0,00 & 33,0 & 6,90 & 0,502 \\
2 & 0,00 & 0,00 & 33,0 & 6,90 & 0,490 \\
3 & 1,00 & 1,00 & 35,8 & 7,32 & 0,504 \\
4 & 1,00 & $-1,00$ & 35,8 & 6,48 & 0,600 \\
5 & $-1,00$ & 1,00 & 30,2 & 7,32 & 0,291 \\
6 & $-1,00$ & $-1,00$ & 30,2 & 6,48 & 0,373 \\
7 & 0,00 & 1,43 & 33,0 & 7,50 & 0,335 \\
8 & 0,00 & $-1,43$ & 33,0 & 6,30 & 0,403 \\
9 & 1,43 & 0,00 & 37,0 & 6,90 & 0,607 \\
10 & $-1,43$ & 0,00 & 29,0 & 6,90 & 0,258 \\
\hline
\end{tabular}

A análise de significância do modelo quadrático resultou na escolha de três fatores para a descrição da superfície de resposta, sendo eles os coeficientes lineares $(\mathrm{L})$ para a temperatura e para o $\mathrm{pH}$, além do coeficiente quadrático $(\mathrm{Q})$ para o pH. Na Tabela 12, são listados os efeitos significativos para a descrição de $\mu_{\max } \mathrm{e}$ seus níveis de siginificância.

A superfície descrita pelos coeficientes obtidos possui as formas típicas como previsto pelos modelos de Ratkowsky et al. (1983) e Rosso et al. (1995), como se 
observa na Figura 16. Na dimensão da variável pH, a predição sugere um ponto de máximo ao redor de 6,73. Este ponto de máximo previsto para o pH é muito inferior que os valores tradicionalmente usados para o crescimento da Hib. Quanto à temperatura, não se observou um ponto de máximo na região estudada, mas apenas o aumento linear do crescimento celular acompanhando a elevação da temperatura. No limite de temperatura do ensaio, em $37^{\circ} \mathrm{C}$, e no $\mathrm{pH}$ ótimo de 6,73 , o valor de $\mu_{\max }$ previsto é de $0,644 \mathrm{~h}^{-1}$.

Tabela 12 - Efeitos significativos para a descrição da variável $\mu_{\max }$

\begin{tabular}{lrrrr}
\hline & Coeficiente & Erro padrão & $\mathrm{t}(6)$ & $\mathrm{p}$-valor \\
\hline $\mathrm{T}(\mathrm{L})$ & 0,116 & 0,012 & 9,891 & $<0,001$ \\
$\mathrm{pH}(\mathrm{L})$ & $-0,034$ & 0,012 & 2,915 & 0,027 \\
$\mathrm{pH}(\mathrm{Q})$ & $-0,043$ & 0,014 & 3,131 & 0,020 \\
Média & 0,471 & 0,015 & 30,639 & $<0,001$ \\
\hline
\end{tabular}

Figura 16 - Superfície de resposta para $\mu_{\max }$ com o modelo estatístico ajustado
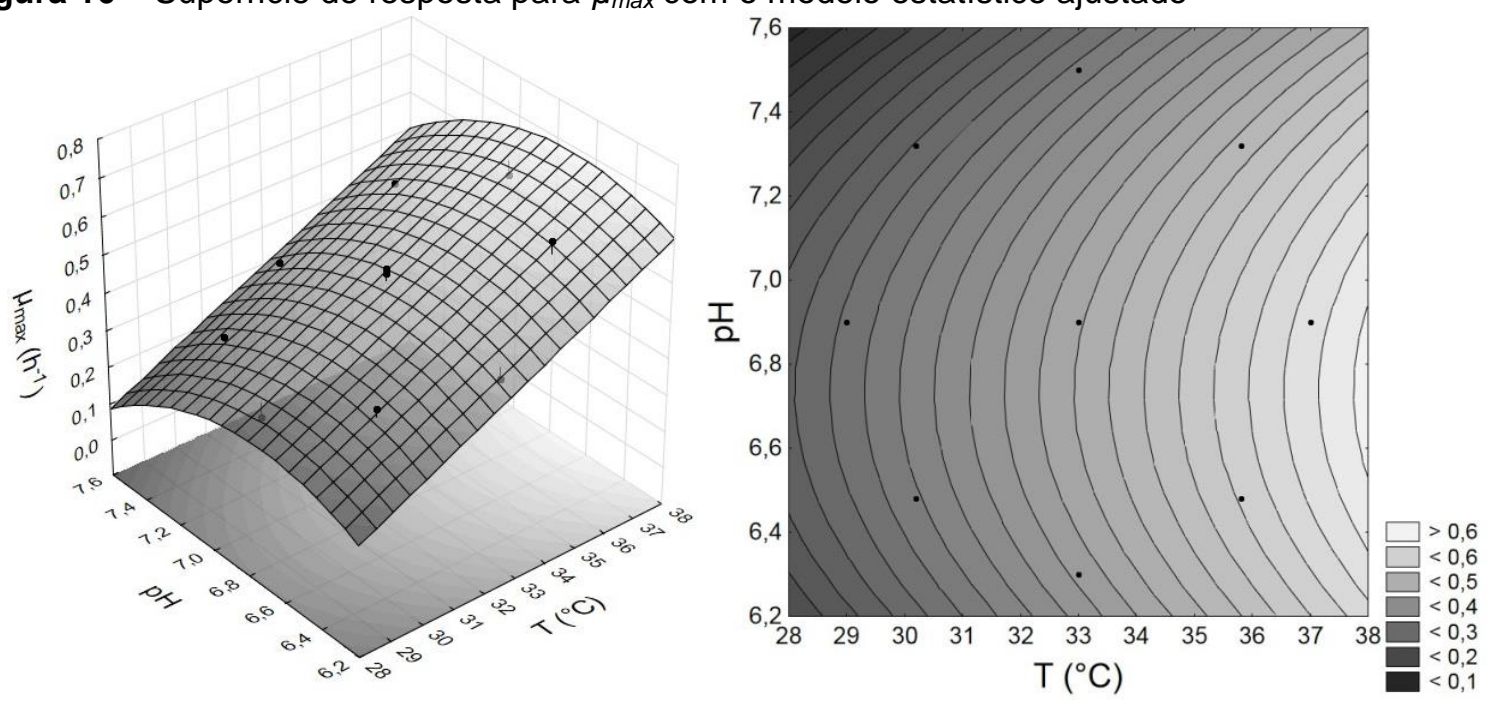

\subsubsection{Fator de inibição pelo acetato sobre o crescimento}

O componente do modelo cinético que prevê a inibição pelo ácido acético possui dois parâmetros que foram estimados para cada cultivo. Foram analisados separadamente os resultados da constante de inibição $k_{X}$ e do expoente do fator de inibição $n_{X}$. O parâmetro $k_{X}$ representa a concentração de ácido acético onde o expoente do fator de inibição se iguala a um e tem relação direta com a concentração de acetato que é suportada pela bactéria. Os resultados da Tabela 13 mostram que a constante de inibição tende a aumentar em pH's mais alcalinos (ensaios 3, 5 e 7), onde atinge valores maiores que $8,5 \mathrm{~g}_{\mathrm{A}} \cdot \mathrm{L}^{-1}$, enquanto na região 
mais ácida do estudo (ensaios 4, 6 e 8) os valores encontrados equivalem a apenas $6,6 \mathrm{~g}_{\mathrm{A}} \cdot \mathrm{L}^{-1}$ ou menores. Na Tabela 14 verifica-se que o $\mathrm{pH}$ é a variável determinante para a constante de inibição, sendo significativa tanto na forma linear quanto na forma quadrática. Além do efeito do $\mathrm{pH}$, existe ainda o efeito de interação entre o pH e a temperatura.

Tabela 13 - Valores de $k_{x}$ obtidos para as variações de $\mathrm{pH}$ e temperatura

\begin{tabular}{lrrrrr}
\hline \multicolumn{3}{c}{ Valor codificado } & \multicolumn{3}{c}{ Valor real } \\
Ensaio & $\mathrm{T}\left({ }^{\circ} \mathrm{C}\right)$ & $\mathrm{pH}$ & $\mathrm{T}\left({ }^{\circ} \mathrm{C}\right)$ & $\mathrm{pH}$ & $k\left(\mathrm{~g}_{\left.\mathrm{A} \cdot \mathrm{L}^{-1}\right)}\right.$ \\
\hline 1 & 0,00 & 0,00 & 33,0 & 6,90 & 7,098 \\
2 & 0,00 & 0,00 & 33,0 & 6,90 & 7,376 \\
3 & 1,00 & 1,00 & 35,8 & 7,32 & 9,248 \\
4 & 1,00 & $-1,00$ & 35,8 & 6,48 & 6,303 \\
5 & $-1,00$ & 1,00 & 30,2 & 7,32 & 8,554 \\
6 & $-1,00$ & $-1,00$ & 30,2 & 6,48 & 6,603 \\
7 & 0,00 & 1,43 & 33,0 & 7,50 & 9,907 \\
8 & 0,00 & $-1,43$ & 33,0 & 6,30 & 5,819 \\
9 & 1,43 & 0,00 & 37,0 & 6,90 & 7,435 \\
10 & $-1,43$ & 0,00 & 29,0 & 6,90 & 7,350 \\
\hline
\end{tabular}

Tabela 14 - Efeitos significativos para a descrição da variável $k_{X}$

\begin{tabular}{lrrrr}
\hline & Coeficiente & Erro padrão & $\mathrm{t}(6)$ & $\mathrm{p}$-valor \\
\hline $\mathrm{pH}(\mathrm{L})$ & 1,328 & 0,066 & 20,095 & $<0,001$ \\
$\mathrm{~T} \times \mathrm{pH}$ & 0,248 & 0,094 & 2,644 & 0,038 \\
$\mathrm{pH}(\mathrm{Q})$ & 0,281 & 0,078 & 3,601 & 0,011 \\
Média & 7,342 & 0,087 & 84,728 & $<0,001$ \\
\hline
\end{tabular}

A superfície de resposta para $k_{X}$ mostra, como se verifica na Figura 17, que seu valor aumenta no sentido de maior $\mathrm{pH}$, com alguma inclinação devido à interação com a temperatura. Valores maiores de $k_{X}$ indicam maior tolerância da bactéria ao ácido. O que se verifica é que a influência do $\mathrm{pH}$ é muito mais relevante que a da temperatura, indicando menor tolerância nos pH's mais ácidos.

O perfil obtido indica que no range de $\mathrm{pH}$ baixo, é necessário menos ácido para causar a inibição, o que entra em concordância com o conhecimento teórico visto no item 2.3.4 de que a inibição causada pela forma não dissociada do ácido é maior, devido à maior permeabilidade da membrana citoplasmática à molécula. 
Figura 17 - Superfície de resposta para $k_{x}$ com o modelo estatístico ajustado
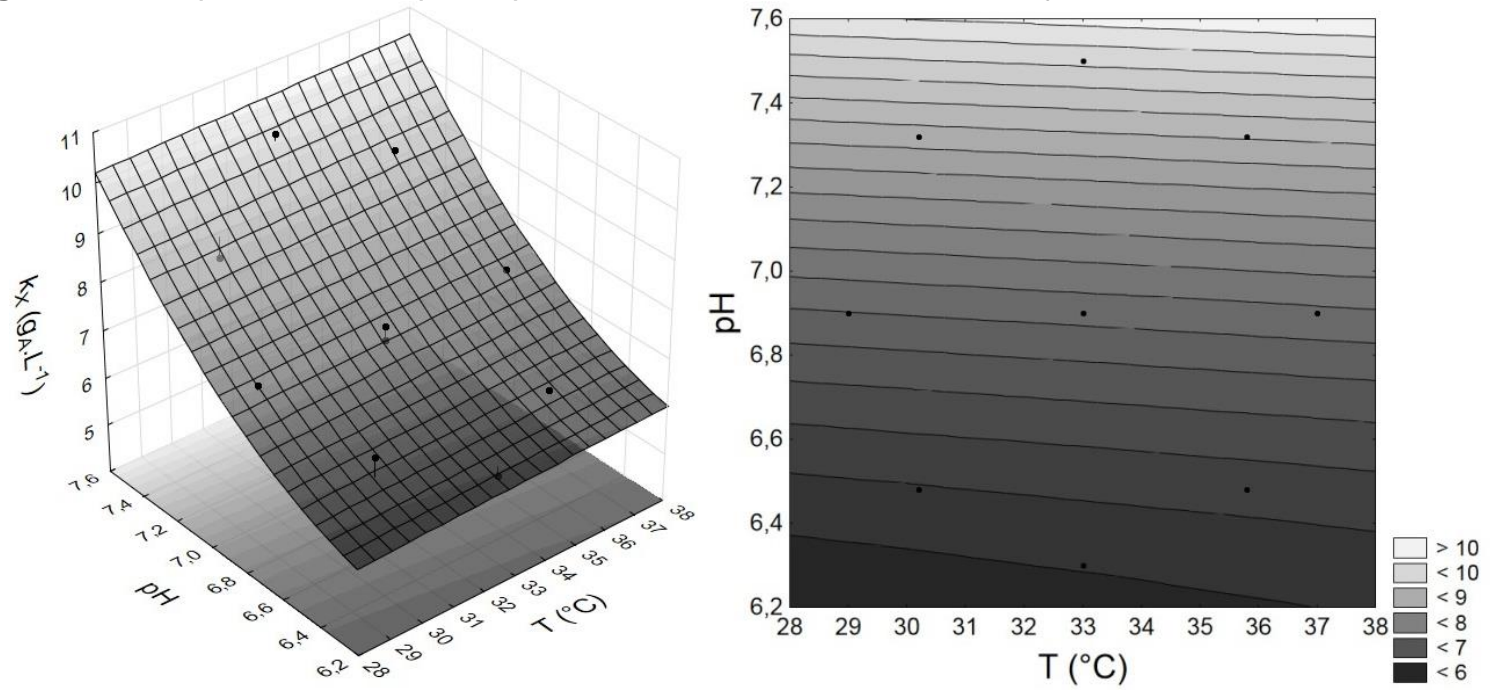

Já para o expoente do fator de inibição $n_{X}$, os resultados mostram que nos cultivos de menor $\mathrm{pH}$ e menor temperatura seu valor é maior, como se verifica na Tabela 15 (ensaios 6 e 8), onde se observa valores acima de 7,5.

Tabela 15 - Valores de $n_{X}$ obtidos para as variações de $\mathrm{pH}$ e temperatura

\begin{tabular}{lrrrrc}
\hline & \multicolumn{3}{c}{ Valor codificado } & \multicolumn{3}{c}{ Valor real } \\
Ensaio & $\mathrm{T}\left({ }^{\circ} \mathrm{C}\right)$ & $\mathrm{pH}$ & $\mathrm{T}\left({ }^{\circ} \mathrm{C}\right)$ & $\mathrm{pH}$ & $n_{X}$ \\
\hline 1 & 0,00 & 0,00 & 33,0 & 6,90 & 2,692 \\
2 & 0,00 & 0,00 & 33,0 & 6,90 & 3,770 \\
3 & 1,00 & 1,00 & 35,8 & 7,32 & 4,092 \\
4 & 1,00 & $-1,00$ & 35,8 & 6,48 & 3,498 \\
5 & $-1,00$ & 1,00 & 30,2 & 7,32 & 3,166 \\
6 & $-1,00$ & $-1,00$ & 30,2 & 6,48 & 7,701 \\
7 & 0,00 & 1,43 & 33,0 & 7,50 & 3,153 \\
8 & 0,00 & $-1,43$ & 33,0 & 6,30 & 7,538 \\
9 & 1,43 & 0,00 & 37,0 & 6,90 & 3,009 \\
10 & $-1,43$ & 0,00 & 29,0 & 6,90 & 4,499 \\
\hline
\end{tabular}

A análise estatística demonstrou que apenas o coeficiente quadrático da temperatura pode ser descondiderado para a descrição de $n_{X}$, como se pode verificar na Tabela 16.

Tabela 16 - Efeitos significativos para a descrição da variável $n_{X}$

\begin{tabular}{lrrrr}
\hline & Coeficiente & Erro padrão & $t(5)$ & $p$-valor \\
\hline $\mathrm{T}(\mathrm{L})$ & $-0,669$ & 0,208 & 3,215 & 0,024 \\
$\mathrm{pH}(\mathrm{L})$ & $-1,263$ & 0,208 & 6,068 & 0,002 \\
$\mathrm{~T} \times \mathrm{pH}$ & 1,282 & 0,296 & 4,334 & 0,007 \\
$\mathrm{pH}(\mathrm{Q})$ & 0,936 & 0,246 & 3,811 & 0,012 \\
Média & 3,555 & 0,273 & 13,033 & $<0,001$ \\
\hline
\end{tabular}


A Figura 18 mostra a superfície de resposta obtida para $n_{X}$. Nela, vê-se que o valor do expoente do fator de inibição se mantém razoavelmente constante, se elevando de forma considerável apenas na região de menor temperatura e $\mathrm{pH}$. O fato de $n_{X}$ aumentar nos valores mais baixos de $\mathrm{pH}$ e temperatura significa que, num ambiente de maior acidez e com o crescimento mais vagaroso, a Hib se desenvolve próxima a velocidade de $\mu_{\max }$ por um período mais longo, até atingir um valor intolerável de acetato e cessando o crescimento abruptamente; isso indica que a curva de crescimento se manterá na forma exponencial, ou próxima a ela, e irá atingir um valor máximo rapidamente, sem que seja possível observar uma faixa de transição entre as fases exponencial e estacionária. Já na região mais alcalina, a célula irá responder aos efeitos da inibição de forma gradativa, ou seja, a velocidade de crescimento irá diminuir de forma menos perceptível e a curva de crescimento deixará de apresentar a forma exponencial mais cedo; porém o valor máximo de biomassa será atingido mais tardiamente, sendo possível observar uma faixa de transição.

Figura 18 - Superfície de resposta para $n_{X}$ com o modelo estatístico ajustado
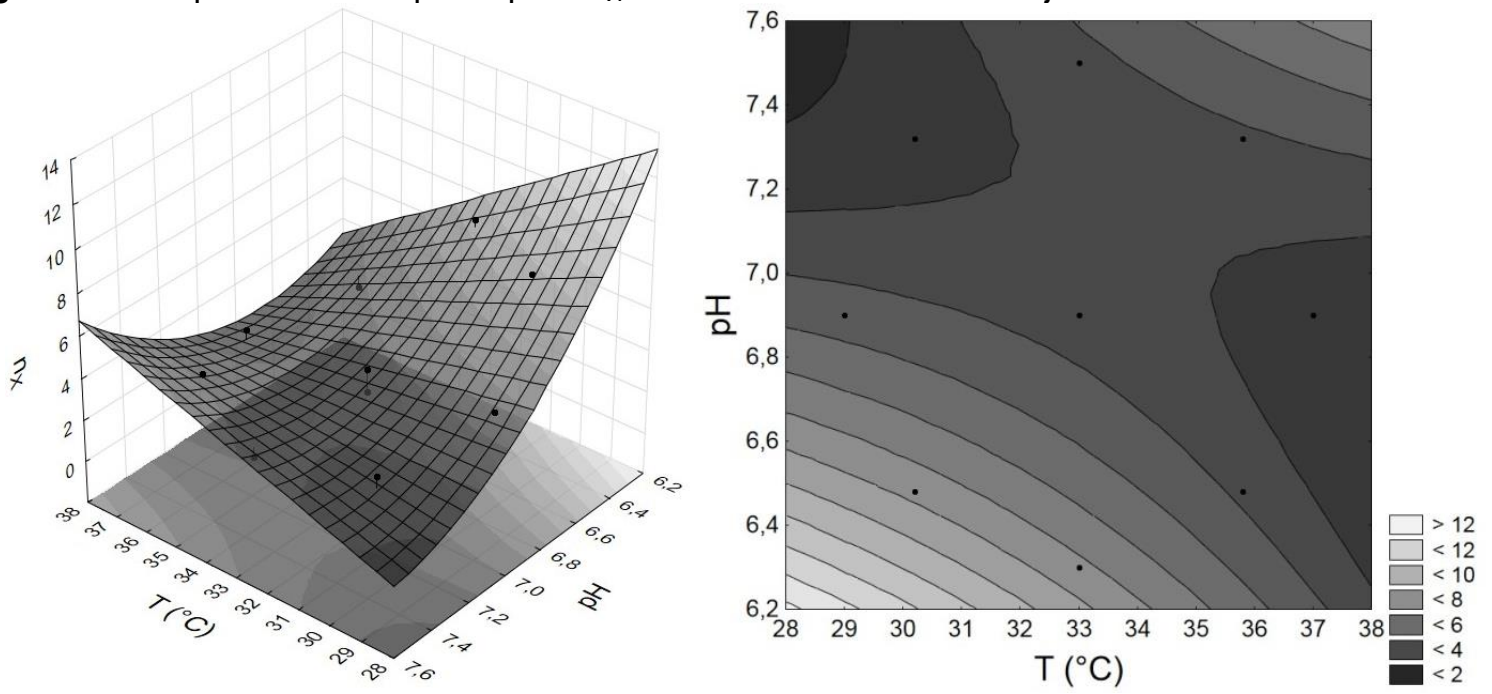

Este fenômeno pode ser observado na Figura 19, onde os valores de biomassa medidos são comparados com uma simulação do modelo cinético onde o efeito da inibição é removido, nos cultivos nos níveis de +1 ( $\mathrm{T}=35,8 ; \mathrm{pH}=7,32)$ e -1 ( $\mathrm{T}=$ $30,2 ; \mathrm{pH}=6,48)$. Os valores simulados representam a forma totalmente exponencial da curva, ignorando-se o fator de inibição. Nos cultivos de pH mais baixo (ensaio 4 e 6), nota-se que os valores medidos de biomassa, quando plotados em escala logarítmica, apresentam uma linearidade ao longo de quase toda a faixa de crescimento, seguindo a simulação onde é desconsiderada a inibição pelo ácido. 
Figura 19 - Comparação dos valores observados de biomassa com a simulação do crescimento sem o efeito de inibição pelo ácido acético
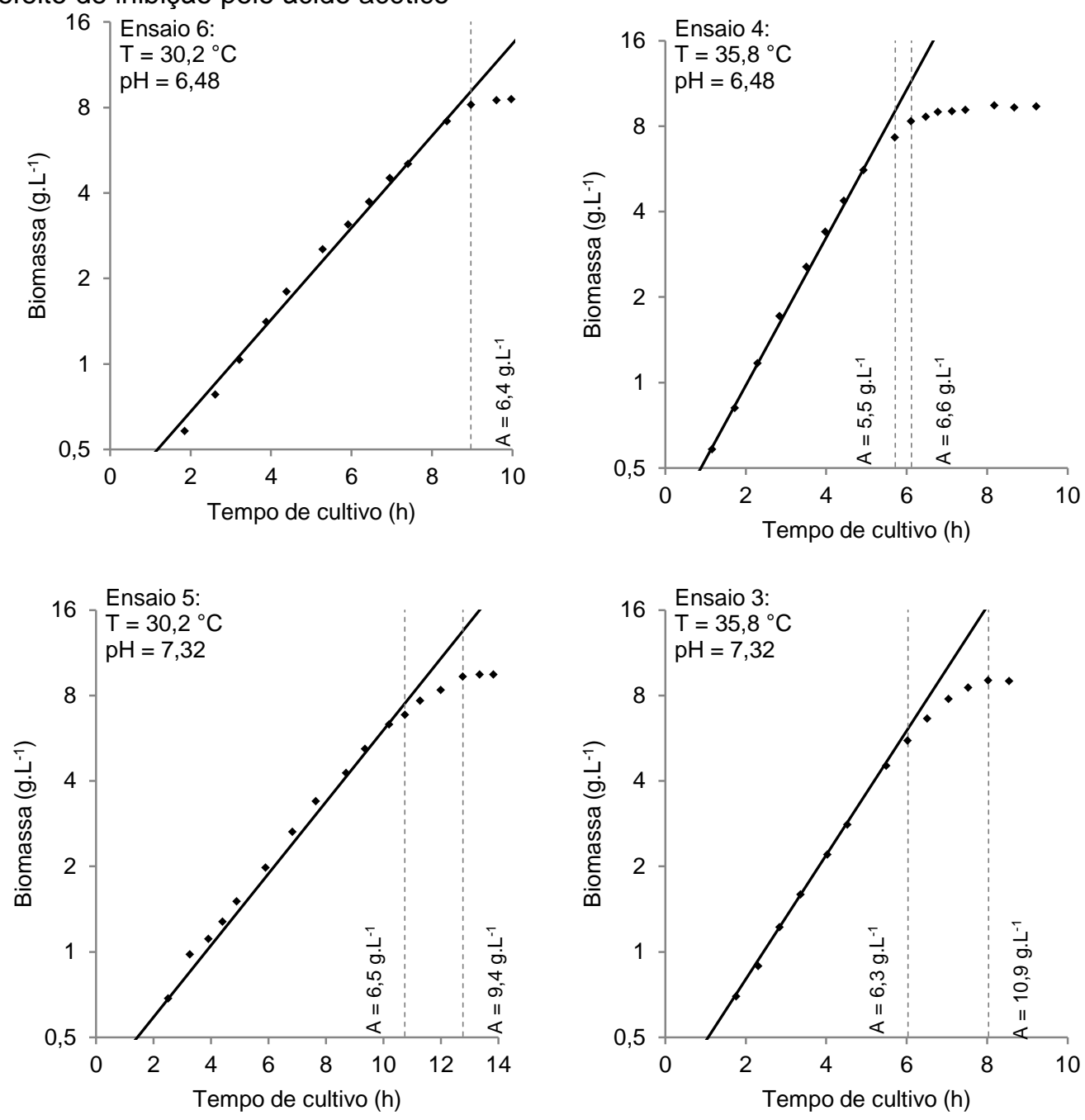

No ensaio 6, no momento em que a concentração de acetato atinge cerca de $6,4 g_{A} \cdot L^{-1}$, a divisão celular é interrompida abruptamente. No ensaio 4 , a célula começa a diminuir a velocidade de crescimento quando a concentração de acetato chega a $5,5 \mathrm{~g}_{\mathrm{A}} \cdot \mathrm{L}^{-1}$, e o crescimento cessa totalmente menos de uma hora depois, com a concentração de ácido em 6,6 g $\mathrm{A} \cdot \mathrm{L}^{-1}$. Já nos ensaios de $\mathrm{pH}$ mais alcalino (3 e 5), é possível observar que entre as fases de crescimento exponencial e estacionária existe uma fase intermediária de quase duas horas de duração, onde a velocidade máxima de crescimento não é atingida. No ensaio 5 , a célula começa a apresentar algum efeito pela inibição do ácido quando a concentração deste atinge 6,5 g $\mathrm{g}_{\mathrm{A}} \mathrm{L}^{-1}$, mas continua se dividindo até que a concentração de ácido atinja cerca de 9,4 $g_{A} \cdot L^{-1}$. O mesmo fenômeno é observado no ensaio 3: o perfil do logaritmo da biomassa se desvia da linearidade a partir do momento em que o acetato ultrapassa 
6,3 $\mathrm{g}_{\mathrm{A}} \cdot \mathrm{L}^{-1}$, mas o crescimento só é interrompido totalmente quando esta concentração chega a um valor de $10,9 \mathrm{~g}_{\mathrm{A}} \mathrm{L}^{-1}$.

Assim, tem-se que o valor máximo tolerável pela bactéria é determinado por $k_{X}$, que, como visto anteriormente e confirmado pela análise da figura acima, sugere maior tolerância na região alcalina. No entanto, o expoente do fator de inibição $n_{X}$ determina que a inibição irá atuar de forma significativa durante a fase de crescimento nas regiões alcalinas; no outro extremo, com o pH reduzido, a célula tolera menor quantidade de ácido, porém o efeito da inibição se mostra apenas no final da fase exponencial, com a cessação do crescimento de forma abrupta.

\subsubsection{Formação de acetato}

A formação de acetato é definida por dois fatores aditivos: a formação associada ao crescimento definida por $\alpha_{A}$, que é proporcional à taxa de crescimento da célula, e a não associada definida por $\beta_{A}$, que é proporcional à concentração instantânea de células. A Tabela 17 resume os valores de $\alpha_{A}$ obtidos para as variações de $\mathrm{pH}$ e temperatura. Os maiores valores foram observados nos cultivos de maior $\mathrm{pH}$ (ensaios 3 e 7), onde a constante apresenta um valor de quase $0,8 \mathrm{gA}_{\mathrm{A}} \cdot \mathrm{gx}^{-1}$ ou maior.

Tabela 17 - Valores de $\alpha_{A}$ obtidos para as variações de $\mathrm{pH}$ e temperatura

\begin{tabular}{lrrrrr}
\hline \multicolumn{3}{c}{ Valor codificado } & \multicolumn{3}{c}{ Valor real } \\
Ensaio & $\mathrm{T}\left({ }^{\circ} \mathrm{C}\right)$ & $\mathrm{pH}$ & $\mathrm{T}\left({ }^{\circ} \mathrm{C}\right)$ & $\mathrm{pH}$ & $\alpha_{A}\left(\mathrm{~g}_{\left.\mathrm{A} \cdot \mathrm{g}^{-1}\right)}\right.$ \\
\hline 1 & 0,00 & 0,00 & 33,0 & 6,90 & 0,623 \\
2 & 0,00 & 0,00 & 33,0 & 6,90 & 0,650 \\
3 & 1,00 & 1,00 & 35,8 & 7,32 & 0,883 \\
4 & 1,00 & $-1,00$ & 35,8 & 6,48 & 0,600 \\
5 & $-1,00$ & 1,00 & 30,2 & 7,32 & 0,661 \\
6 & $-1,00$ & $-1,00$ & 30,2 & 6,48 & 0,542 \\
7 & 0,00 & 1,43 & 33,0 & 7,50 & 0,794 \\
8 & 0,00 & $-1,43$ & 33,0 & 6,30 & 0,444 \\
9 & 1,43 & 0,00 & 37,0 & 6,90 & 0,562 \\
10 & $-1,43$ & 0,00 & 29,0 & 6,90 & 0,608 \\
\hline
\end{tabular}

No caso da constante associada ao crescimento, o parâmetro se mostrou como uma função linear do pH apenas, sendo que todos os outros fatores se mostraram desprezíveis. A Tabela 18 mostra a significância desta variável. 
Tabela 18 - Efeitos significativos para a descrição da variável $\alpha_{A}$

\begin{tabular}{rrrrr}
\hline & Coeficiente & Erro padrão & $\mathrm{t}(8)$ & p-valor \\
\hline $\mathrm{pH}(\mathrm{L})$ & 0,112 & 0,025 & 4,535 & 0,002 \\
Média & 0,637 & 0,022 & 28,743 & $<0,001$ \\
\hline
\end{tabular}

Na Figura 20, é possível observar a tendência geral da dependência linear do modelo obtido, onde a produção de acetato associada ao crescimento é maior quanto maior for o $\mathrm{pH}$ do meio de cultivo. Apesar de a tendência linear do $\mathrm{pH}$ sobre o parâmetro ser significativa, pode-se observar na figura que alguns pontos apresentam grande desvio quando comparado com os valores previstos pela superfície. Isso indica que o perfil de produção de acetato associado ao crescimento deve seguir um modelo mais complexo que não se aproxima do modelo quadrático na região estudada.

Figura 20 - Superfície de resposta para $\alpha_{A}$ com o modelo estatístico ajustado
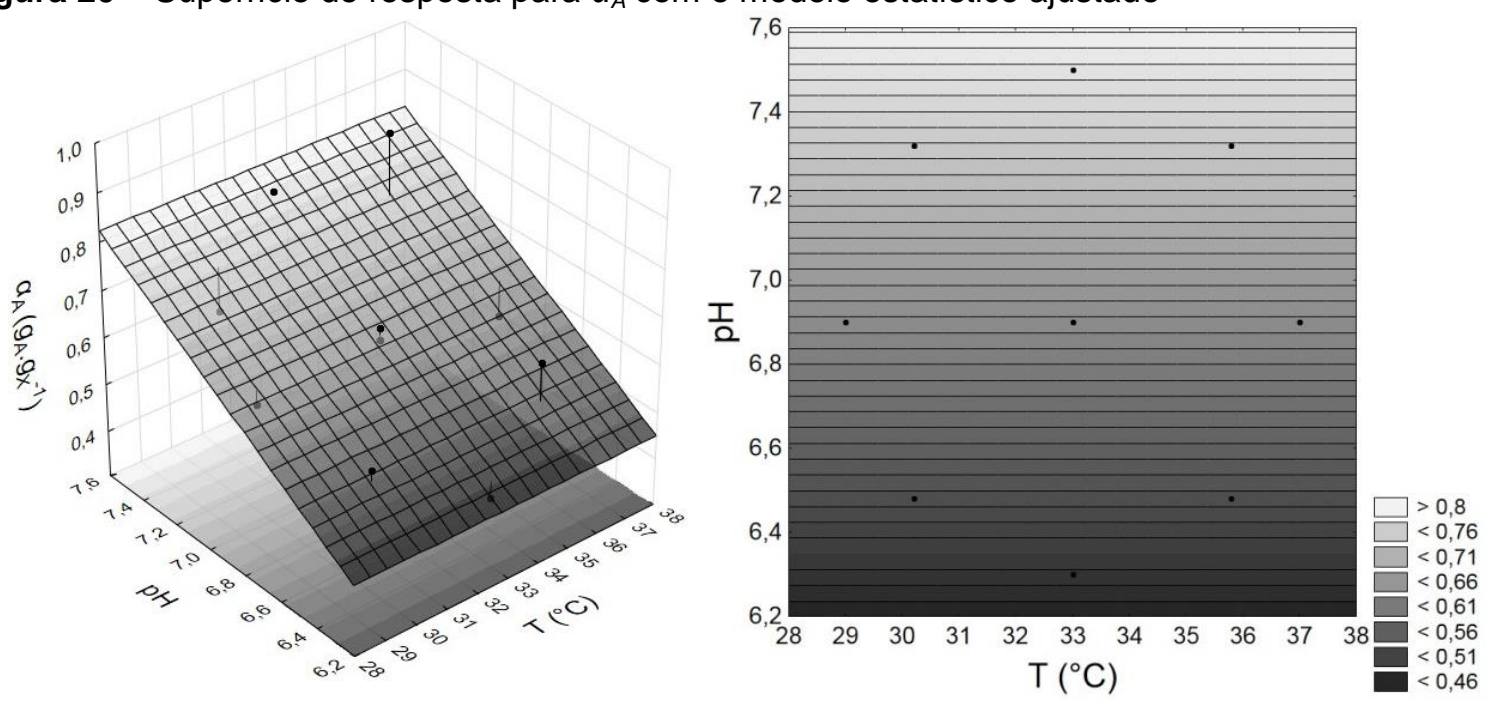

Já a constante não associada ao crescimento, $\beta_{A}$, se mostrou influenciada tanto pelo $\mathrm{pH}$ quanto pela a temperatura, de forma linear. Na Tabela 19 são apresentados os valores obtidos para a variável, e na Tabela 20 a significância para os coeficientes do modelo estatístico. Observa-se que nos cultivos de baixa temperatura (ensaios 5, 6 e 10) os valores da constante são menores, estando abaixo de $0,1 g_{A} \cdot g x^{-1} \cdot h^{-1}$, indicando que a produção não associada é maior em temperaturas mais altas.

Na Figura 21 é mostrado o perfil da superfície obtida para $\beta_{A}$. Observa-se nela que a constante associada ao crescimento é influenciada principalmente pela temperatura, onde a elevação desta significa maior produção de acetato. 
Tabela 19 - Valores de $\beta_{A}$ obtidos para as variações de $\mathrm{pH}$ e temperatura

\begin{tabular}{lrrrrr}
\hline \multicolumn{4}{c}{ Valor codificado } & \multicolumn{3}{c}{ Valor real } \\
Ensaio & $\mathrm{T}\left({ }^{\circ} \mathrm{C}\right)$ & $\mathrm{pH}$ & $\mathrm{T}\left({ }^{\circ} \mathrm{C}\right)$ & $\mathrm{pH}$ & $\beta_{A}\left(\mathrm{~g}_{\mathrm{A}} \cdot \mathrm{gx}^{-1} \cdot \mathrm{h}^{-1}\right)$ \\
\hline 1 & 0,00 & 0,00 & 33,0 & 6,90 & 0,113 \\
2 & 0,00 & 0,00 & 33,0 & 6,90 & 0,106 \\
3 & 1,00 & 1,00 & 35,8 & 7,32 & 0,119 \\
4 & 1,00 & $-1,00$ & 35,8 & 6,48 & 0,113 \\
5 & $-1,00$ & 1,00 & 30,2 & 7,32 & 0,079 \\
6 & $-1,00$ & $-1,00$ & 30,2 & 6,48 & 0,096 \\
7 & 0,00 & 1,43 & 33,0 & 7,50 & 0,101 \\
8 & 0,00 & $-1,43$ & 33,0 & 6,30 & 0,130 \\
9 & 1,43 & 0,00 & 37,0 & 6,90 & 0,136 \\
10 & $-1,43$ & 0,00 & 29,0 & 6,90 & 0,081 \\
\hline
\end{tabular}

Tabela 20 - Efeitos significativos para a descrição da variável $\beta_{A}$

\begin{tabular}{lrrrr}
\hline & Coeficiente & Erro padrão & $\mathrm{t}(7)$ & p-valor \\
\hline $\mathrm{T}(\mathrm{L})$ & 0,017 & 0,003 & 5,048 & 0,001 \\
$\mathrm{pH}(\mathrm{L})$ & $-0,007$ & 0,003 & 1,963 & 0,090 \\
Média & 0,108 & 0,003 & 36,014 & $<0,001$ \\
\hline
\end{tabular}

Novamente em alguns ensaios o valor de $\beta_{A}$ obtido experimentalmente diverge consideravelmente do previsto pelo modelo linear, principalmente na região de menor pH. Isso indica, semelhantemente, que a produção de acetato não associada ao crescimento seja descrita por algum modelo mais complexo nessa região.

Figura 21 - Superfície de resposta para $\beta_{A}$ com o modelo estatístico ajustado
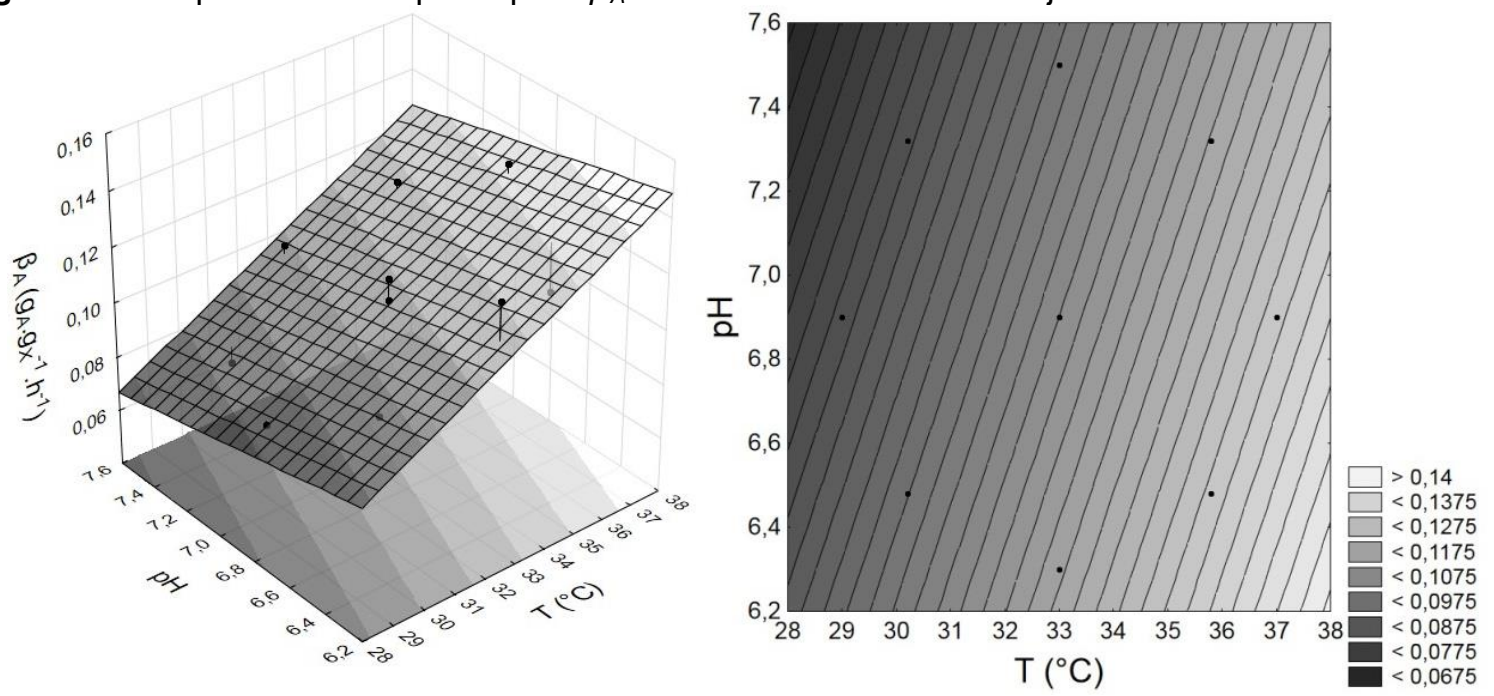

O perfil previsto para a formação de produto, como previsto pela análise do comportamento enzimático com a presença de pontos de máximo descrito no item 2.3.3, não foi observado para o caso do acetato. Isso demonstra que não é 
adequado considerar de que a formação de acetato é determinada por apenas uma etapa enzimática, sendo necessária a utilização de modelos mais complexos.

Esta falta de semelhança pode ser explicada pela regulação dos fluxos metabólicos do microrganismo. Diferentemente de produtos que têm a rede metabólica direcionada especificamente para a sua produção, como os constituintes da biomassa, o acetato é um subproduto do metabolismo energético da bactéria, portanto a sua formação é apenas consequência do balanço eletroquímico para a manutenção dos níveis de ATP na célula. Além disso, por estar correlacionada com a formação de ATP, a formação de acetato pode agir como etapa limitante para diversas reações de biossíntese. Assim, alterações de $\mathrm{pH}$ e temperatura no ambiente de crescimento da bactéria podem exigir diferentes balanços de distribuição metabólica.

Para o caso da formação associada ao crescimento, os dados apresentados evidenciaram uma tendência linear da produção de acetato com o pH do meio. Dentre os mecanismos que podem ser alterados pela elevação do $\mathrm{pH}$, pode-se citar a influência sobre o gradiente de prótons transmembrana. Em meio mais alcalino, 0 potencial de $\mathrm{H}^{+}$presente no espaço periplasmático pode ser reduzido, diminuindo também a atividade da ATPase através da redução da força próton-motora (vide item 2.3.5) e consequentemente a taxa de formação quimiosmótica de ATP. Desta forma, a bactéria é obrigada a utilizar outras vias de produção de ATP, como a via do acetato, explicando assim a maior produção em pH's mais elevados. Já nos casos dos ensaios de $\mathrm{pH}$ mais ácido, outro fator que pode contribuir para a menor produção de acetato é a maior presença da molécula no citosol. Como visto no caso da constante de inibição sobre o crescimento, uma maior quantidade de acetato atravessa a membrana plasmática em pH's menores, devido à constante de dissociação do íon. Com mais moléculas de acetato presentes no citosol, a produção do mesmo pode ser diminuída devido à inibição da enzima produtora pelo próprio produto. 


\subsubsection{Formação de PRP}

\subsubsection{Constante de formação específica de PRP}

O primeiro parâmetro que descreve a formação de PRP é a variável $\beta_{P}$, que é a constante de formação específica não associada ao crescimento. Para o estudo da formação deste parâmetro, levou-se em consideração a quantidade total de polissacarídeo produzido, somando-se a quantidade presente no sobrenadante com aquela associada à célula. Escolheu-se estudar a formação do produto desta forma pois a distribuição do PRP fora da célula, seja organizado na cápsula ou livre no meio de cultura, não deve ter relação direta com as vias bioquímicas de síntese. Os efeitos do $\mathrm{pH}$ e da temperatura sobre essa distribuição foram reservados a avaliação própria adiante.

A constante de formação de PRP $\left(\beta_{P}\right)$ apresentou um valor máximo na região de maior $\mathrm{pH}$ e temperatura (ensaio 3 ), chegando a $44,4 \mathrm{mg}_{\mathrm{p}} \cdot \mathrm{gx}^{-1} \cdot \mathrm{h}^{-1}$, como se verifica na Tabela 21.

Tabela 21 - Valores de $\beta_{P}$ obtidos para as variações de $\mathrm{pH}$ e temperatura

\begin{tabular}{lrrrrr}
\hline \multicolumn{5}{c}{ Valor codificado } & \multicolumn{3}{c}{ Valor real } \\
Ensaio & $\mathrm{T}\left({ }^{\circ} \mathrm{C}\right)$ & $\mathrm{pH}$ & $\mathrm{T}\left({ }^{\circ} \mathrm{C}\right)$ & $\mathrm{pH}$ & $\beta_{P}\left(\mathrm{mg}_{\mathrm{p} .} \mathrm{gx}^{-1} \cdot \mathrm{h}^{-1}\right)$ \\
\hline 1 & 0,00 & 0,00 & 33,0 & 6,90 & 39,966 \\
2 & 0,00 & 0,00 & 33,0 & 6,90 & 37,667 \\
3 & 1,00 & 1,00 & 35,8 & 7,32 & 44,431 \\
4 & 1,00 & $-1,00$ & 35,8 & 6,48 & 32,287 \\
5 & $-1,00$ & 1,00 & 30,2 & 7,32 & 23,597 \\
6 & $-1,00$ & $-1,00$ & 30,2 & 6,48 & 24,253 \\
7 & 0,00 & 1,43 & 33,0 & 7,50 & 31,256 \\
8 & 0,00 & $-1,43$ & 33,0 & 6,30 & 20,522 \\
9 & 1,43 & 0,00 & 37,0 & 6,90 & 41,334 \\
10 & $-1,43$ & 0,00 & 29,0 & 6,90 & 20,628 \\
\hline
\end{tabular}

O modelo estatístico apresentou cinco preditores significativos, ultrapassando consideravelmente o nível de significância para todas as variáveis do modelo quadrático completo, como se verifica na Tabela 22.

A forma da superfície obtida é mostrada na Figura 22, onde se compara os valores preditos aos dados experimentais. A superfície descreve uma região de máximo, num valor de $\mathrm{pH}$ de 7,19 e na temperatura de $37,07^{\circ} \mathrm{C}$, onde a constante de formação de PRP atinge 45,271 mgP.gx ${ }^{-1} \cdot h^{-1}$. 
Como a forma obtida para a superfície se aproxima do que era esperado segundo o item 2.3.3, com pontos de máximo para as variáveis $\mathrm{pH}$ e temperatura, pode-se dizer que a formação de PRP é determinada por uma etapa enzimática limitante.

Tabela 22 - Efeitos significativos para a descrição da variável $\beta_{P}$

\begin{tabular}{rrrrr}
\hline & Coeficiente & Erro padrão & $\mathrm{t}(4)$ & $\mathrm{p}$-valor \\
\hline $\mathrm{T}(\mathrm{L})$ & 7,232 & 0,724 & 9,984 & 0,001 \\
$\mathrm{pH}(\mathrm{L})$ & 3,319 & 0,724 & 4,582 & 0,010 \\
$\mathrm{~T} \times \mathrm{pH}$ & 3,200 & 1,030 & 3,108 & 0,036 \\
$\mathrm{pH}(\mathrm{Q})$ & $-5,748$ & 0,951 & 6,047 & 0,004 \\
$\mathrm{~T}(\mathrm{Q})$ & $-3,252$ & 0,951 & 3,422 & 0,027 \\
Média & 38,868 & 1,456 & 26,697 & 0,000 \\
\hline
\end{tabular}

Figura 22 - Superfície de resposta para $\beta_{P}$ com o modelo estatístico ajustado
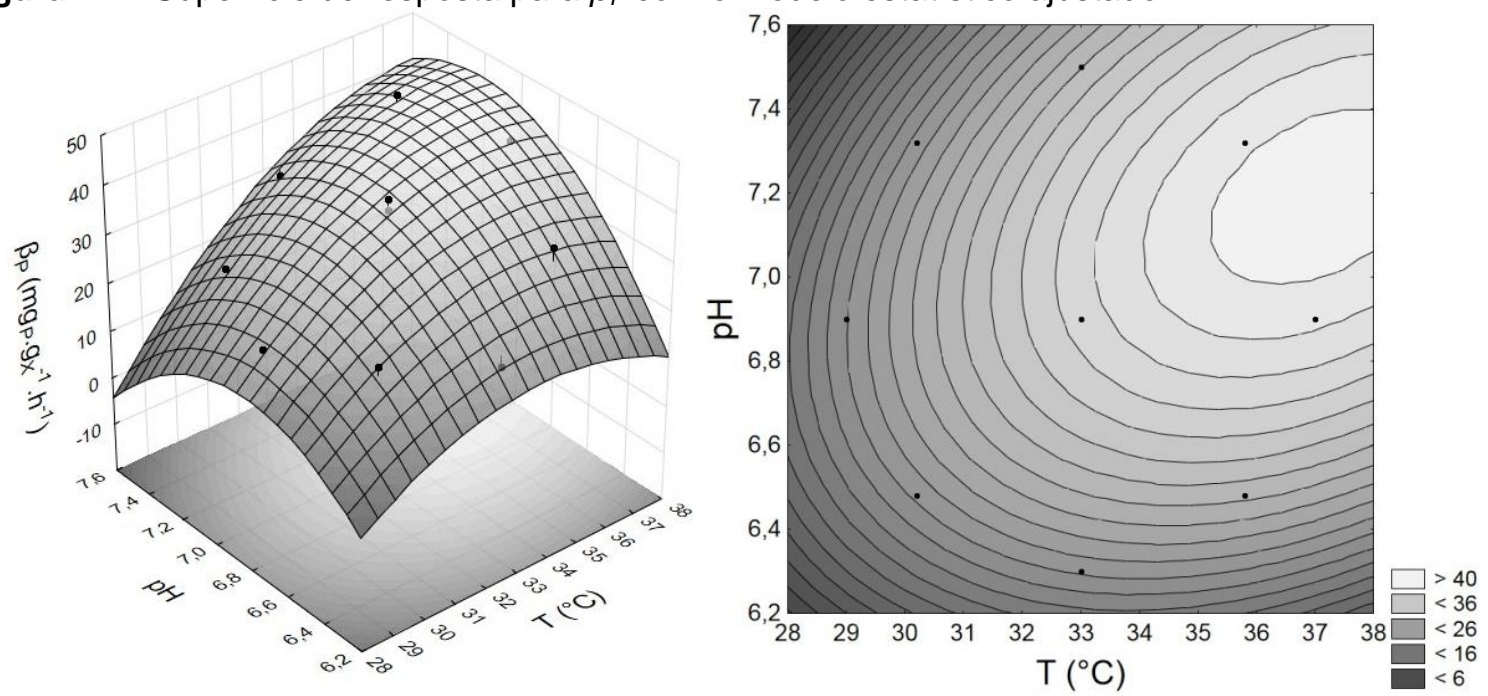

Diferentemente do acetato, o polissacarídeo é um produto especificamente direcionado dentro do mapa metabólico da Hib, ou seja, as etapas intermediárias da via de síntese levam diretamente à sua formação, sem que as etapas enzimáticas sejam utilizadas como forma de criação de ATP ou potencial redutor, como é o caso do acetato. A superfície obtida segue aquilo que é previsto pela teoria. Na dimensão do $\mathrm{pH}$, a velocidade decresce nos sentidos que se afastam do ponto ótimo, provavelmente devido à formação de enzimas cataliticamente inativas. Quanto à temperatura, a inclinação observada na região à esquerda do ponto de máximo é prevista pelo aumento das velocidades moleculares; já no sentido de maiores temperaturas, observa-se a redução da taxa de síntese devido à desnaturação das enzimas envolvidas. 
A formação de PRP sofre inibição pela presença de acetato de forma independente da inibição sobre o crescimento, segundo o modelo cinético escolhido e determinado pela equação (17). O fator de inibição também é definido por dois parâmetros, a constante de inibição, $k_{P}$, e o expoente do fator de inibição, $n_{P}$, que tem o mesmo significado que no caso do crescimento celular. Ou seja, o valor de $k_{P}$ indica a concentração suportada pela célula antes de cessar a produção de PRP, euquanto $n_{P}$ indica se a inibição age de forma repentina.

$\mathrm{Na}$ Tabela 23, se observa que, semelhantemente ao crescimento celular, os maiores valores da contante de inibição sobre a formação de PRP foram obtidos em cultivos de $\mathrm{pH}$ elevado (ensaios 5 e 7), ultrapassando 12,0 $\mathrm{g}_{\mathrm{A}} \cdot \mathrm{L}^{-1}$, enquanto no limite inferior de $\mathrm{pH}$ (ensaio 8) o valor obtido é de apenas 6,5 $\mathrm{g}_{\mathrm{A}} \cdot \mathrm{L}^{-1}$.

Tabela 23 - Valores de $k_{P}$ obtidos para as variações de $\mathrm{pH}$ e temperatura

\begin{tabular}{lrrrrr}
\hline \multicolumn{4}{c}{ Valor codificado } & \multicolumn{3}{c}{ Valor real } \\
Ensaio & $\mathrm{T}\left({ }^{\circ} \mathrm{C}\right)$ & $\mathrm{pH}$ & $\mathrm{T}\left({ }^{\circ} \mathrm{C}\right)$ & $\mathrm{pH}$ & $k_{P}\left(\mathrm{~g}_{\left.\mathrm{A} \cdot \mathrm{L}^{-1}\right)}\right.$ \\
\hline 1 & 0,00 & 0,00 & 33,0 & 6,90 & 7,709 \\
2 & 0,00 & 0,00 & 33,0 & 6,90 & 8,082 \\
3 & 1,00 & 1,00 & 35,8 & 7,32 & 9,641 \\
4 & 1,00 & $-1,00$ & 35,8 & 6,48 & 6,914 \\
5 & $-1,00$ & 1,00 & 30,2 & 7,32 & 12,627 \\
6 & $-1,00$ & $-1,00$ & 30,2 & 6,48 & 6,976 \\
7 & 0,00 & 1,43 & 33,0 & 7,50 & 12,083 \\
8 & 0,00 & $-1,43$ & 33,0 & 6,30 & 6,541 \\
9 & 1,43 & 0,00 & 37,0 & 6,90 & 8,394 \\
10 & $-1,43$ & 0,00 & 29,0 & 6,90 & 7,523 \\
\hline
\end{tabular}

Três variáveis se mostraram significativas para a descrição de $k_{P}$, como se observa na Tabela 24. As variáveis significativas para a constante de inibição sobre a formação de PRP foram as mesmas que as obtidas para a inibição sobre o crescimento: o pH nas formas linear e quadrática, além da interação entre pH e temperatura.

Tabela 24 - Efeitos significativos para a descrição da variável $k_{P}$

\begin{tabular}{lrrrr}
\hline & Coeficiente & Erro padrão & $\mathrm{t}(6)$ & $\mathrm{p}$-valor \\
\hline $\mathrm{pH}(\mathrm{L})$ & 2,016 & 0,259 & 7,781 & 0,000 \\
$\mathrm{~T} \times \mathrm{pH}$ & $-0,731$ & 0,368 & 1,984 & 0,095 \\
$\mathrm{pH}(\mathrm{Q})$ & 0,736 & 0,306 & 2,406 & 0,053 \\
Média & 8,054 & 0,340 & 23,712 & 0,000 \\
\hline
\end{tabular}


A superfície obtida para $k_{P}$ também possui forma semelhante à obtida para a inibição do crescimento celular, como mostrado na Figura 23, com um aumento na tolerância ao ácido em maiores valores de $\mathrm{pH}$. No entanto, os níveis tolerados pela formação de PRP são maiores que os tolerados pelo crescimento, indicando que a produção de PRP pode continuar sendo realizada pela bactéria mesmo após a estagnação da concentração celular.

Já o expoente do fator de inibição sobre a formação de PRP, $n_{P}$, apresenta maiores valores nos ensaios que foram realizados nos valores de $\mathrm{pH}$ mais ácidos (ensaios 6 e 8), como se nota na Tabela 25. Nestes ensaios, o valor do expoente ultrapassa a faixa de 16, o que indica um efeito de inibição abrupto. O ajuste do modelo quadrático sobre este parâmetro não obteve boa qualidade, e apenas o coeficiente linear da variável pH se mostrou significativo. Seu nível de significância é apresentado na Tabela 26.

Figura 23 - Superfície de resposta para $k_{P}$ com o modelo estatístico ajustado
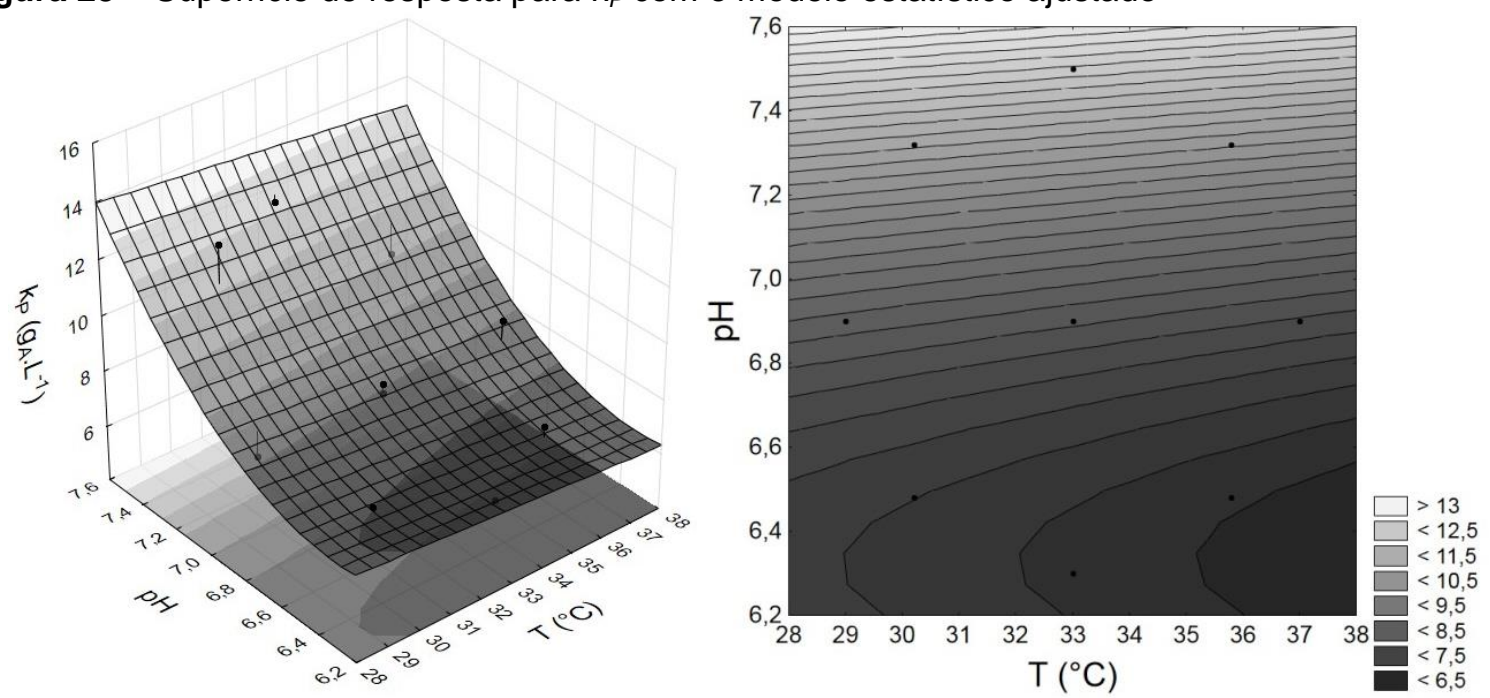

Tabela 25 - Valores de $n_{P}$ obtidos para as variações de $\mathrm{pH}$ e temperatura

\begin{tabular}{lrrrrr}
\hline \multicolumn{3}{c}{ Valor codificado } & \multicolumn{3}{c}{ Valor real } \\
Ensaio & $\mathrm{T}\left({ }^{\circ} \mathrm{C}\right)$ & $\mathrm{pH}$ & $\mathrm{T}\left({ }^{\circ} \mathrm{C}\right)$ & $\mathrm{pH}$ & \multicolumn{1}{c}{$n_{P}$} \\
\hline 1 & 0,00 & 0,00 & 33,0 & 6,90 & 5.115 \\
2 & 0,00 & 0,00 & 33,0 & 6,90 & 7.056 \\
3 & 1,00 & 1,00 & 35,8 & 7,32 & 3.114 \\
4 & 1,00 & $-1,00$ & 35,8 & 6,48 & 11.815 \\
5 & $-1,00$ & 1,00 & 30,2 & 7,32 & 3.073 \\
6 & $-1,00$ & $-1,00$ & 30,2 & 6,48 & 17.425 \\
7 & 0,00 & 1,43 & 33,0 & 7,50 & 5.482 \\
8 & 0,00 & $-1,43$ & 33,0 & 6,30 & 16.292 \\
9 & 1,43 & 0,00 & 37,0 & 6,90 & 11.880 \\
10 & $-1,43$ & 0,00 & 29,0 & 6,90 & 13.434 \\
\hline
\end{tabular}


Tabela 26 - Efeitos significativos para a descrição da variável $n_{P}$

\begin{tabular}{rrrrr}
\hline & Coeficiente & Erro padrão & $\mathrm{t}(8)$ & $\mathrm{p}$-valor \\
\hline $\mathrm{pH}(\mathrm{L})$ & $-4,764$ & 1,081 & 4,408 & 0,002 \\
Média & 9,469 & 0,971 & 9,747 & 0,000 \\
\hline
\end{tabular}

Pela análise da superfície obtida, mostrada na Figura 24, confirma-se a tendência para o aumento do expoente na região de menores valores de $\mathrm{pH}$. $\mathrm{A}$ interpretação deste resultado, juntamente com o coeficiente de inibição $k_{P}$, é a mesma que realizada no item 4.2.1.2 para a inibição sobre o crescimento. Em pH's mais alcalinos, a bactéria é capaz de sintetizar PRP em concentrações elevadas de acetato; contudo, os efeitos da inibição são observados mais cedo durante o cultivo, onde o pouco acetato produzido é capaz de reduzir em algum nível a formação do polissacarídeo. Já em pH's mais ácidos a bactéria mantém a síntese de PRP próximo à velocidade específica máxima até o momento em que o acetato atinge o valor máximo tolerado; este, em contrapartida, é menor

Figura 24 - Superfície de resposta para $n_{P}$ com o modelo estatístico ajustado
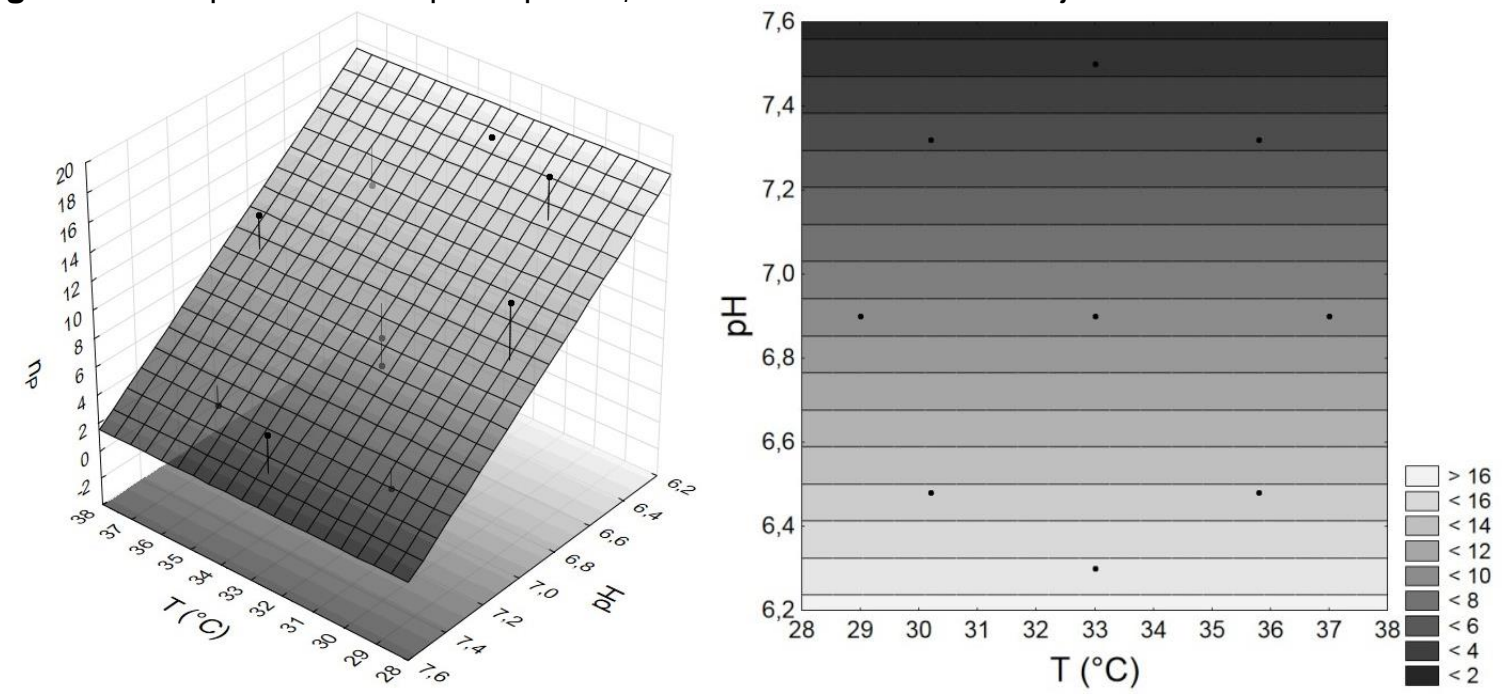

\subsubsection{Polissacarídeo liberado ao sobrenadante}

No item anterior, estudou-se os efeitos do $\mathrm{pH}$ e da temperatura sobre a formação específica de polissacarídeo a partir da quantidade total produzida pela célula. Ficou demonstrado como as condições ambientais alteram as velocidades específicas de síntese de PRP. No entanto, para o processo de produção da vacina interessa apenas a fração de polissacarídeo livre no sobrenadante, que é a fração majoritária, quando a fração celular é descartada. Por isso, faz-se necessário 
determinar como as modificações ambientais atuam sobre a forma como o PRP se organiza fora da célula.

Não existem modelos cinéticos descritos para a liberação de polissacarídeo capsular ao sobrenadante. Por isso, a caracterização deste parâmetro foi realizada de forma mais empírica. Como mostrado na Figura 26, em cada um dos ensaios realizados tomou-se a quantidade total de PRP produzido, plotando-se contra a quantidade presente no sobrenadante, a cada tempo. O coeficiente angular da reta ajustada sobre o gráfico pode dar uma medida média da proporção de polissacarídeo que é liberada ao sobrenadante.

Assim, calculou-se a porcentagem de PRP presente no sobrenadante dado a quantidade total produzida, sendo os resultados apresentados na Tabela 27. Podese notar de pronto que existe alguma correlação entre $\mathrm{o} p \mathrm{pH}$ do cultivo e a quantidade de PRP liberada, observando-se que em pH's mais baixos essa proporção é menor, inferior a 70\% (ensaios 6, 8 e 10), quando comparada às quantidades observadas em pH's mais elevados (ensaios 3 e 7), que atingem valores acima de $90 \%$.

Tabela 27 - Proporção de PRP liberada ao sobrenadante em cada condição de cultivo

\begin{tabular}{lrrrrr}
\hline \multicolumn{4}{c}{ Valor codificado } & \multicolumn{3}{c}{ Valor real } \\
Ensaio & $\mathrm{T}\left({ }^{\circ} \mathrm{C}\right)$ & $\mathrm{pH}$ & $\mathrm{T}\left({ }^{\circ} \mathrm{C}\right)$ & $\mathrm{pH}$ & $\begin{array}{r}\% \text { de PRP liberada } \\
\text { ao sobrenadante }\end{array}$ \\
\hline 1 & 0,00 & 0,00 & 33,0 & 6,90 & $92 \%$ \\
2 & 0,00 & 0,00 & 33,0 & 6,90 & $87 \%$ \\
3 & 1,00 & 1,00 & 35,8 & 7,32 & $90 \%$ \\
4 & 1,00 & $-1,00$ & 35,8 & 6,48 & $68 \%$ \\
5 & $-1,00$ & 1,00 & 30,2 & 7,32 & $86 \%$ \\
6 & $-1,00$ & $-1,00$ & 30,2 & 6,48 & $69 \%$ \\
7 & 0,00 & 1,43 & 33,0 & 7,50 & $88 \%$ \\
8 & 0,00 & $-1,43$ & 33,0 & 6,30 & $55 \%$ \\
9 & 1,43 & 0,00 & 37,0 & 6,90 & $86 \%$ \\
10 & $-1,43$ & 0,00 & 29,0 & 6,90 & $81 \%$ \\
\hline
\end{tabular}

Ao se realizar a análise de significância, foi possível concluir que a proporção de PRP liberado ao sobrenadante é função tanto do $\mathrm{pH}$ quanto da temperatura. Como se observa na Tabela $28,0 \mathrm{pH}$ influencia a liberação tanto na forma linear quanto na forma quadrática, enquanto a temperatura influencia apenas na forma quadrática. 
Tabela 28 - Efeitos significativos para a descrição da proporção de PRP liberada ao sobrenadante

\begin{tabular}{lrrrr}
\hline & Coeficiente & Erro padrão & $\mathrm{t}(6)$ & $\mathrm{p}$-valor \\
\hline $\mathrm{pH}(\mathrm{L})$ & 0,107 & 0,009 & 11,897 & 0,000 \\
$\mathrm{pH}(\mathrm{Q})$ & $-0,086$ & 0,012 & 7,293 & 0,000 \\
$\mathrm{~T}(\mathrm{Q})$ & $-0,028$ & 0,012 & 2,355 & 0,057 \\
Média & 0,895 & 0,018 & 49,413 & 0,000 \\
\hline
\end{tabular}

A superfície de resposta obtida, mostrada na Figura 25, demonstra que em valores de $\mathrm{pH}$ maiores a quantidade de PRP liberada ao sobrenadante é maior, sendo sugerida uma região de máximo ao redor de valores de $\mathrm{pH}$ de 7,16, com algum efeito do aumento de temperatura. Nesta região, a superfície prevê uma liberação de $98 \%$ do total de PRP sintetizado pela bactéria.

Mediante a ausência de informações específicas sobre o mecanismo pelo qual a célula secreta o polissacarídeo no sobrenadante, uma interpretação possível é relacionar este resultado com a superfície de degradação observada no trabalho apresentado no Apêndice B (Cintra, Takagi, 2015). Em pH mais alcalino, a molécula de PRP é mais suscetível à degradação espontânea; por isso, espera-se que com a transesterificação da ligação fosfodiéster, o polissacarídeo organizado na capsula perca a sua ligação física com a célula e seja liberada para o meio de cultura.

Figura 25 - Superfície de resposta para proporção de PRP liberada ao sobrenadante com o modelo estatístico ajustado
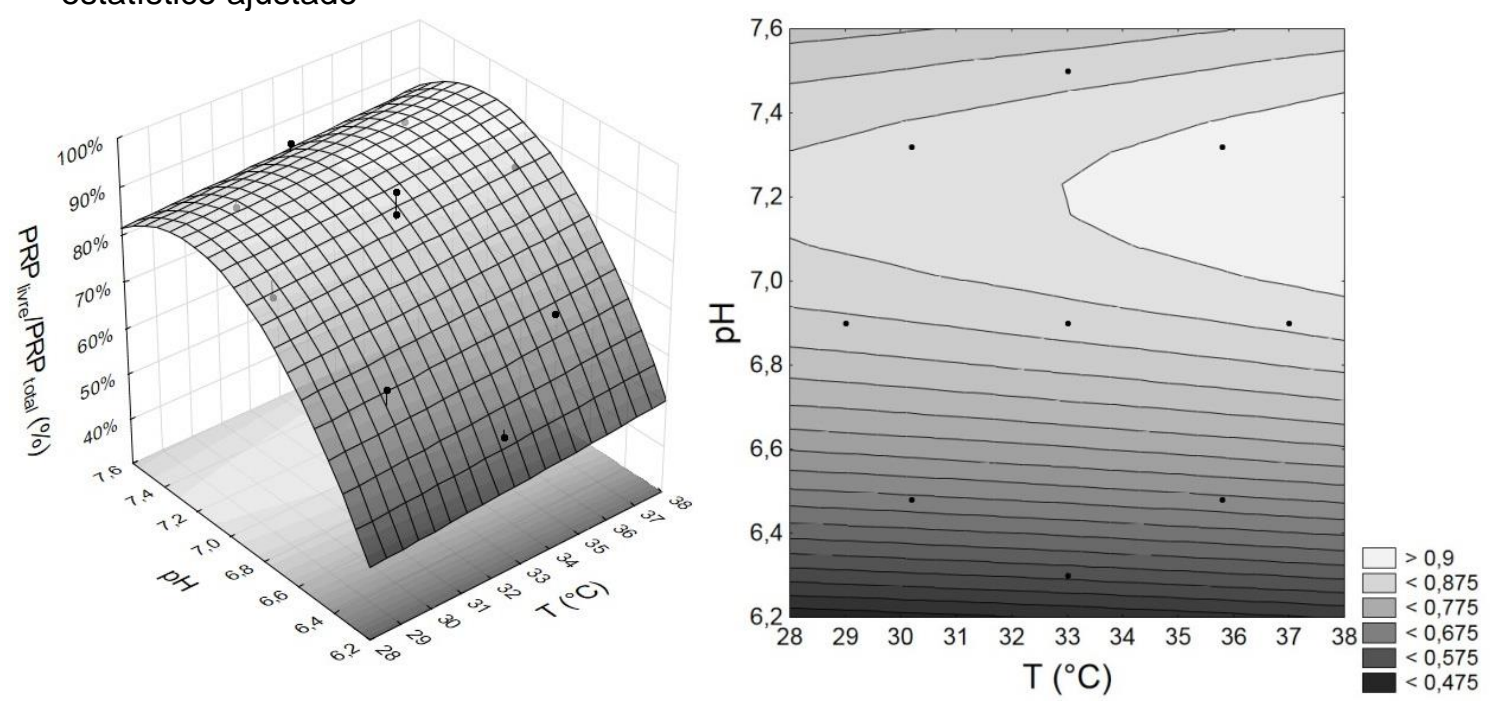
Figura 26 - Perfis de PRP total e livre no sobrenadante em cada condição de cultivo
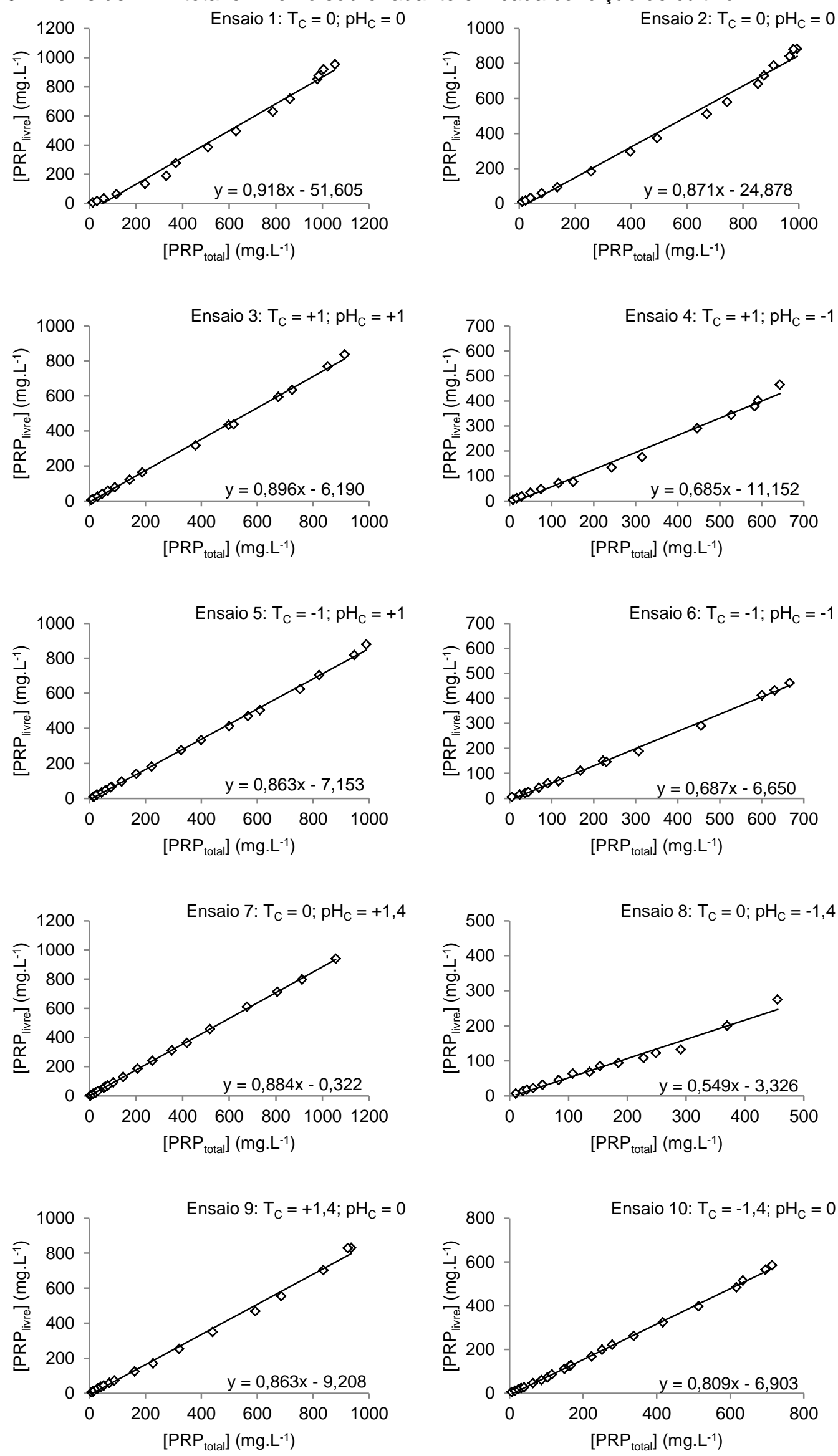


\subsubsection{Produtividade de PRP}

As superfícies encontradas nos itens anteriores permitem avaliar os efeitos das condições de cultivo sobre os parâmetros cinéticos isoladamente. Observou-se que a velocidade específica de crescimento encontra uma região de ótimo em pH 6,73, enquanto a velocidade específica de formação de PRP atinge seu ótimo em $\mathrm{pH} 7,19$, valor próximo do qual onde a liberação de PRP é também maior, em pH 7,16. Já a produção específica de acetato é intensificada em regiões de maior temperatura e pH. A inibição pelo acetato, em contrapartida, é maior em pH's mais ácidos, ou seja, a bactéria é mais tolerante ao acetato em regiões mais alcalinas, balanceando portanto a maior produção do subproduto. Ora, a região de maior produtividade de PRP será atingida no ponto onde todos estes parâmetros estejam regulados para o maior direcionamento do metabolismo à produção do polissacarídeo. Para avaliar qual seria este ponto ótimo, os parâmetros cinéticos obtidos em cada ensaio foram utilizados para realizar a simulação do cultivo e determinar o ponto de máxima produtividade de PRP. A produtividade, definida como $r_{P}$, foi calculada pela razão entre a concentração instantânea de PRP e o tempo de cultivo decorrido. Em cada condição de cultivo foi encontrado um valor máximo para $r_{P}$. Como a simulação cinética considera apenas o valor total de PRP obtido, a produtividade máxima foi multiplicada pela porcentagem de PRP liberado em cada cultivo (valores da Tabela 27), definindo-se assim um valor de produtividade de PRP liberado ao sobrenadante, $r_{P}^{\prime}$. Os valores obtidos são apresentados na Tabela 29.

Tabela 29 - Produtividade máxima de PRP liberada ao sobrenadante em cada condição de cultivo

\begin{tabular}{lrrrrr}
\hline \multicolumn{4}{c}{ Valor codificado } & \multicolumn{3}{c}{ Valor real } \\
Ensaio & $\mathrm{T}\left({ }^{\circ} \mathrm{C}\right)$ & $\mathrm{pH}$ & $\mathrm{T}\left({ }^{\circ} \mathrm{C}\right)$ & $\mathrm{pH}$ & $r_{P}^{\prime}\left(\mathrm{mg}_{\left.\mathrm{p} . \mathrm{L}^{-1} \cdot \mathrm{h}^{-1}\right)}\right.$ \\
\hline 1 & 0,00 & 0,00 & 33,0 & 6,90 & 98,54 \\
2 & 0,00 & 0,00 & 33,0 & 6,90 & 93,06 \\
3 & 1,00 & 1,00 & 35,8 & 7,32 & 100,80 \\
4 & 1,00 & $-1,00$ & 35,8 & 6,48 & 61,23 \\
5 & $-1,00$ & 1,00 & 30,2 & 7,32 & 73,21 \\
6 & $-1,00$ & $-1,00$ & 30,2 & 6,48 & 45,71 \\
7 & 0,00 & 1,43 & 33,0 & 7,50 & 79,25 \\
8 & 0,00 & $-1,43$ & 33,0 & 6,30 & 30,80 \\
9 & 1,43 & 0,00 & 37,0 & 6,90 & 117,21 \\
10 & $-1,43$ & 0,00 & 29,0 & 6,90 & 47,11 \\
\hline
\end{tabular}


Se observa que a diferença de produtividade em cada condição varia mais de $50 \%$ no intervalo estudado, apresentando valores menores que $50 \mathrm{mg} \cdot \mathrm{L}^{-1} \cdot \mathrm{h}^{-1} \mathrm{em}$ cultivos de menor temperatura e $\mathrm{pH}$ (ensaios 6 e 10) e iguais ou maiores que 100 $m g_{p} \cdot L^{-1} \cdot h^{-1}$ em temperaturas maiores e pH's próximos ou pouco acima da neutralidade (ensaios 3 e 9). A análise de significância estatística, realizada da mesma forma que no caso dos parâmetros cinéticos e apresentada na Tabela 30, mostrou que a produtividade cresce linearmente com o aumento de temperatura, e que sofre influencia do $\mathrm{pH}$ de forma tanto linear quanto quadrática.

Tabela 30 - Efeitos significativos para a descrição da proporção de PRP liberada ao sobrenadante

\begin{tabular}{lrrrr}
\hline & Coeficiente & Erro padrão & $\mathrm{t}(6)$ & $\mathrm{p}$-valor \\
\hline $\mathrm{T}(\mathrm{L})$ & 17,726 & 3,605 & 4,917 & 0,003 \\
$\mathrm{pH}(\mathrm{L})$ & 16,865 & 3,605 & 4,678 & 0,003 \\
$\mathrm{pH}(\mathrm{Q})$ & $-16,918$ & 4,256 & 3,975 & 0,007 \\
Média & 88,364 & 4,726 & 18,698 & $<0,001$ \\
\hline
\end{tabular}

A Figura 27 mostra o valor máximo de produtividade como função do $\mathrm{pH}$ e temperatura do cultivo obtido pela análise de significância. Os valores máximos previsto pela superfície, considerando-se a dimensão do $\mathrm{pH}$, são observados num num valor de 7,11 , pouco acima da neutralidade. Já quanto à temperatura, a produtividade cresce linearmente e não apresenta um ponto de máximo no intervalo estudado; contudo pode-se calcular que no limite do desenho experimental, num valor de $37^{\circ} \mathrm{C}$, e no $\mathrm{pH}$ de 7,11 , o valor de $r_{P}^{\prime}$ atinge $117,9 \mathrm{mg} \cdot \mathrm{L}^{-1} \cdot \mathrm{h}^{-1}$.

Figura 27 - Perfil da máxima produtividade de PRP em relação aos valores de pH e temperatura.
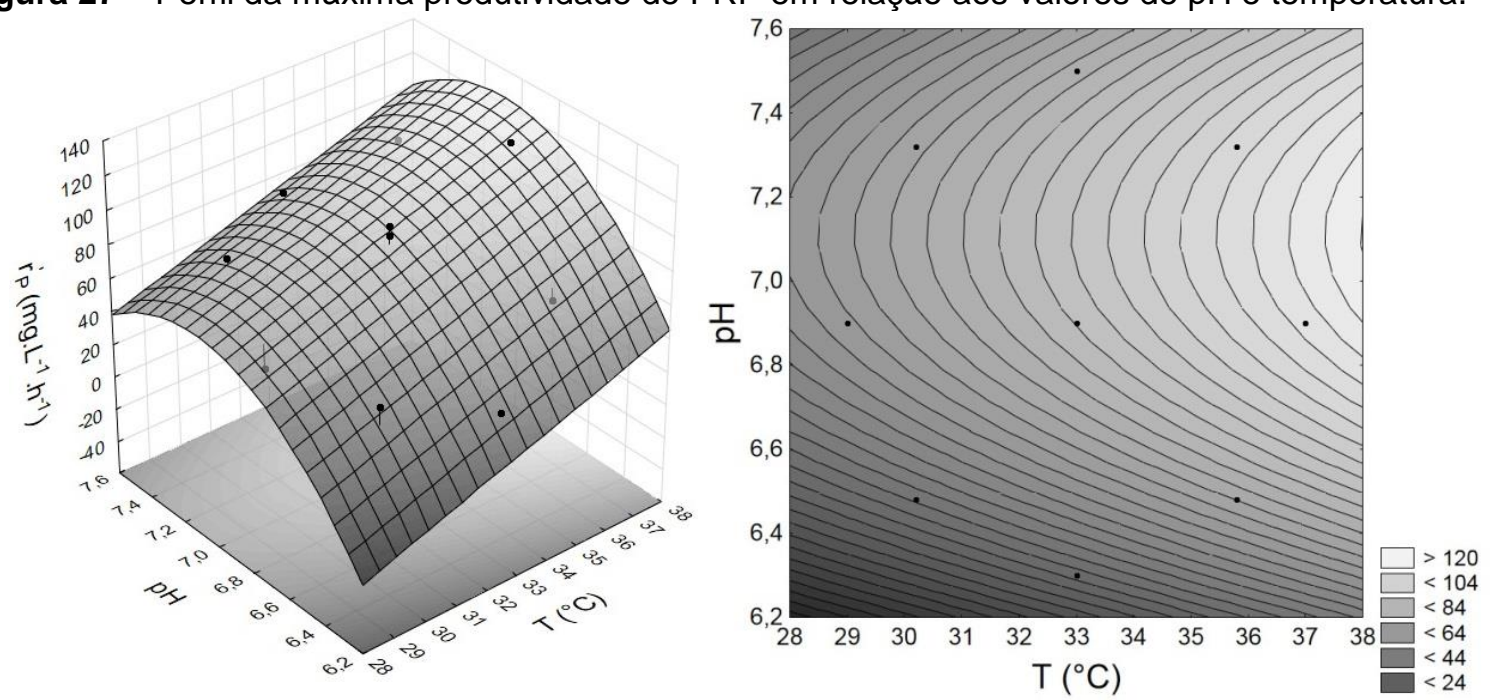

A condição de máxima produtividade se assemelha com a melhor condição de máxima velocidade específica de formação de PRP (item 4.2.3.1), estando ambas 
em temperaturas fisiológicas e próximas da neutralidade. Em trabalhos anteriores, a produção de PRP ocorreu em valores de pH mais elevados, como 7,30 (Merritt et al., 2000) e 7,50 (Silva, 2010). No primeiro caso, atingiu-se valores de aproximadamente 90 mg $g_{\text {PRP.L. }}{ }^{-1} \cdot \mathrm{h}^{-1}$, enquanto no segundo observou-se até $129 \mathrm{mg}$ PRP.L. ${ }^{-1} \cdot \mathrm{h}^{-1}$. Contudo, estes autores fazem o uso da alimentação para atingir tais valores, enquanto os valores previstos aqui são obtidos de simulações de batelada simples.

A produtividade máxima prevista pelo modelo aqui apresentado leva em conta apenas a etapa de crescimento celular. Como argumentado anteriormente, para a otimização global do processo deve-se levar em consideração também a etapa de purificação, prevendo as perdas que ocorrem devido à qualidade da molécula de PRP, que é afetada pelas condições de cultivo como visto anteriormente (Cintra, Takagi, 2015). Com o propósito de aumentar recuperação durante as etapas de ultrafiltração utilizadas na purificação, a massa molecular do PRP sintetizado ao longo dos cultivos em diferentes condições será estudada como um parâmetro adicional no item a seguir.

\subsubsection{Perfil de massa molecular}

Em cada um dos ensaios realizados, as amostras retiradas durante os cultivos foram submetidas à medição de massa molecular conforme descrito no item 3.2.2.4. Para a comparação dos perfis de massa molecular entre os ensaios, os valores de $M_{w}$ instantâneos foram plotados contra o valor instantâneo da concentração de PRP livre no sobrenadante, como mostrado na Figura 28. Esta comparação permite avaliar melhor as diferenças entre os ensaios de forma a obter uma condição de cultivo onde se maximize tanto a concentração de PRP quanto a sua massa molecular. Assim, a interpretação dos gráficos permitirá avaliar como a evolução na concentração de PRP livre se correlaciona com a queda de massa molecular durante o cultivo; permite também comparar as condições de cultivo sem a influencia da velocidade de produção de PRP, que varia consideravelmente entre os ensaios. Com os gráficos obtidos, foram ajustadas linhas de tendência para correlacionar as duas variáveis, $M_{w}$ e concentração de PRP.

Pelos perfis das correlações ilustradas na Figura 28, se verifica que houve uma grande diferença nos valores de $M_{w}$ entre os cultivos desde o início da produção de $\mathrm{PRP}$, e que em todas as condições existe alguma diminuição de $M_{w}$ ao longo do 
tempo de cultivo e de produção de PRP. Para a comparação das tendências da relação entre $M_{w}$ e concentração, parte-se do ponto central (ensaios 1 e 2). Neles se observa que a concentração de PRP na faixa de 900 a $1000 \mathrm{mg}_{\mathrm{P}} \cdot \mathrm{L}^{-1}$, enquanto $M_{w}$ varia de aproximadamente 550 a $450 \mathrm{kDa}$. Seguindo a partir do ponto central para a região de menor $\mathrm{pH}$ (ensaio 8 ), a concentração de PRP atingida reduz para menos de $500 \mathrm{mg}_{\mathrm{P}} \mathrm{L}^{-1}$, enquanto a variação de $M_{w}$ reduz ligeiramente, variando entre $500 \mathrm{e}$ $450 \mathrm{kDa}$. Seguindo do ensaio 8 para o ensaio 4, região de maior temperatura e $\mathrm{pH}$ ainda baixo, se observa também baixa concentração de PRP (menos que $600 \mathrm{mg}_{\mathrm{p}} \mathrm{L}^{-1}$ ) e uma variação de $M_{w}$ semelhante ao ponto central. Continuando na direção de maior temperatura e elevando-se $0 \mathrm{pH}$ para próximo da neutralidade (ensaio 9), verifica-se um aumento na concentração de PRP, que atinge até $800 \mathrm{mg}_{\mathrm{p} . \mathrm{L}^{-1}}$, enquanto $M_{w}$ se mantém variando próxima ao ponto central e ao ensaio 8. Elevando-se agora o pH e mantendo-se a temperatura elevada, no ensaio 3, aumenta-se a produção de PRP para cerca de $900 \mathrm{mg}_{\mathrm{P}} \mathrm{L}^{-1}$, porém $M_{w}$ continua no mesmo patamar. Reduzindo a temperatura para aquela do ponto central e elevando o pH para o valor máximo (ensaio 7), observa-se o mesmo nível de concentração de PRP, com um ligeiro aumento de $M_{w}$, que agora varia entre 600 e $500 \mathrm{kDa}$. Reduzindo a temperatura e mantendo-se o pH acima da neutralidade, no ensaio 5, observa-se ainda uma boa produção de PRP, que atinge até $900 \mathrm{mg}_{\mathrm{P}} \mathrm{L}^{-1}$, e um aumento na variação de $M_{w}$, que apresenta valores entre 700 e 550 kDa. Continuando na direção de menor temperatura e reduzindo-se $0 \mathrm{pH}$ para a neutralidade (ensaio 10), observa-se que $M_{w}$ continua numa faixa de variação mais elevada, entre 700 e 600 kDa, porém a concetração de PRP volta a cair, atingindo até $600 \mathrm{mg} \cdot \mathrm{L}^{-1}$. Finalmente, na região de menor temperatura e $\mathrm{pH}$ (ensaio 6), a concentração de PRP dimunui ainda mais, chegando a apenas $500 \mathrm{mg} \cdot \mathrm{L}^{-1}$, enquanto $M_{w}$ volta a variar entre 700 e 550 kDa. Nestas considerações, pode-se já perceber que a região de menor temperatura tem grande influencia sobre o tamanho da molécula, rendendo os maiores valores observados, enquanto a manutenção do $\mathrm{pH}$ acima da neutralidade permite manter a produção de PRP em concentrações mais altas. Dentre os ensaios realizados, pode-se concluir que o ensaio 5 , realizado a $30,2^{\circ} \mathrm{C}$ e com $\mathrm{pH}$ de 7,32 , configura a condição mais adequada, permitindo ao mesmo tempo que se atinja altos valores de concentração de PRP e de $M_{w}$. 
Figura 28- Perfis de massa molecular em relação à evolução da concentração de PRP livre nos diferentes ensaios
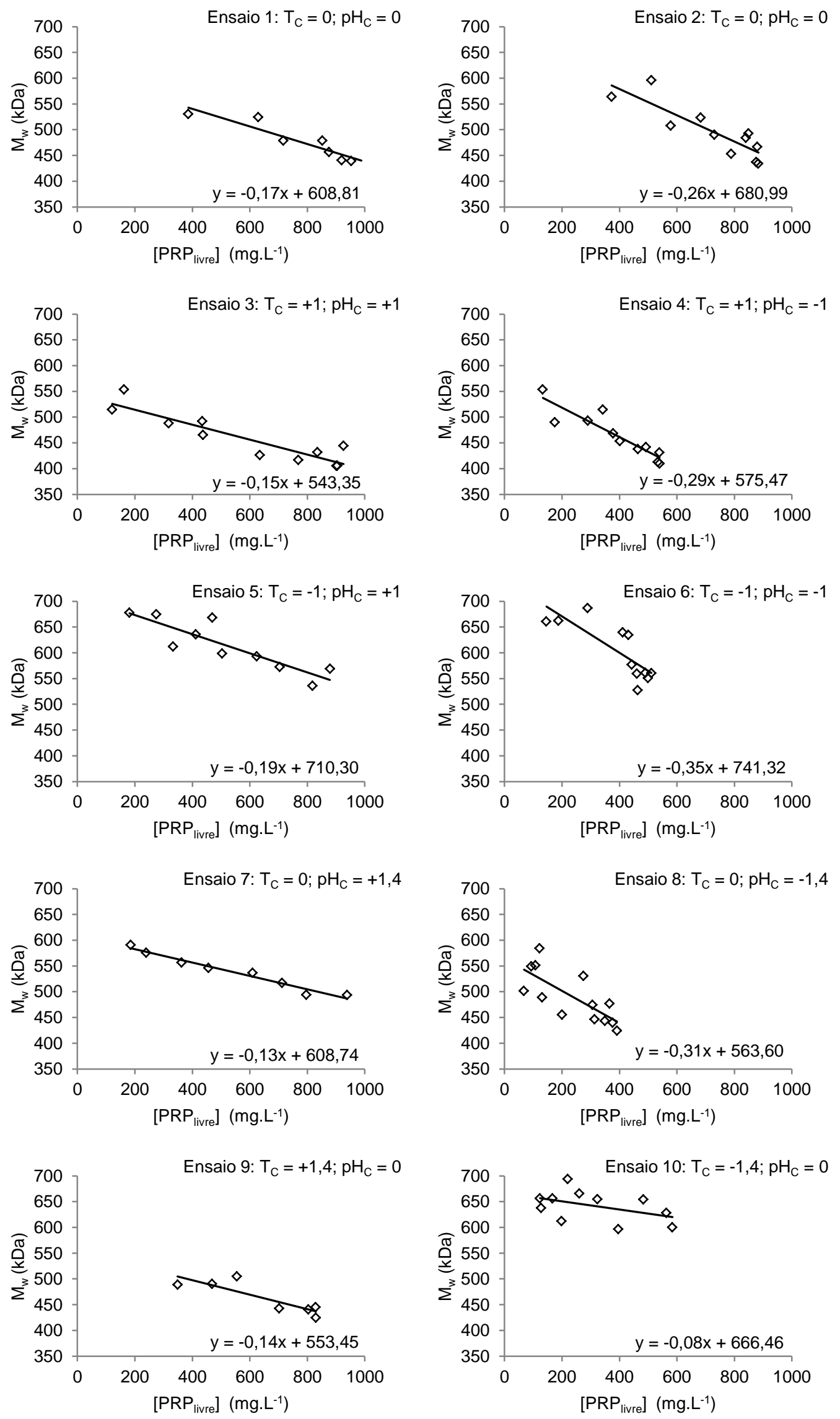
Para realizar uma análise mais completa do perfil de variação, tomou-se a partir das linhas de tendência de cada ensaio o valor de $M_{w}$ quando a concentração de PRP livre equivaleria a $500 \mathrm{mg}_{\mathrm{P}} \mathrm{L}^{-1}$. Este valor foi escolhido por ser um valor encontrado na literatura para a produção de PRP (Hamidi, Beurret, 2009) e que foi atingido por todos os cultivos realizados no ensaio, exceto um (ensaio 8). Neste ensaio, extrapolou-se a curva de tendência.

Tabela 31 - Massa molecular do PRP livre no instante onde a concentração equivale a $500 \mathrm{mg}_{\mathrm{P} . \mathrm{L}^{-1}}$ em cada condição de cultivo

\begin{tabular}{lrrrrr}
\hline \multicolumn{4}{c}{ Valor codificado } & \multicolumn{3}{c}{ Valor real } \\
Ensaio & $\mathrm{T}\left({ }^{\circ} \mathrm{C}\right)$ & $\mathrm{pH}$ & $\mathrm{T}\left({ }^{\circ} \mathrm{C}\right)$ & $\mathrm{pH}$ & $M_{w}(\mathrm{kDa})$ \\
\hline 1 & 0,00 & 0,00 & 33,0 & 6,90 & 518,23 \\
2 & 0,00 & 0,00 & 33,0 & 6,90 & 553,39 \\
3 & 1,00 & 1,00 & 35,8 & 7,32 & 470,85 \\
4 & 1,00 & $-1,00$ & 35,8 & 6,48 & 432,92 \\
5 & $-1,00$ & 1,00 & 30,2 & 7,32 & 617,55 \\
6 & $-1,00$ & $-1,00$ & 30,2 & 6,48 & 564,77 \\
7 & 0,00 & 1,43 & 33,0 & 7,50 & 543,64 \\
8 & 0,00 & $-1,43$ & 33,0 & 6,30 & 412,96 \\
9 & 1,43 & 0,00 & 37,0 & 6,90 & 483,25 \\
10 & $-1,43$ & 0,00 & 29,0 & 6,90 & 626,81 \\
\hline
\end{tabular}

Com os valores estimados de $M_{w}$ apresentados na Tabela 31, foi realizada uma análise de significância estatística da mesma forma que apresentado anteriormente para os parâmetros cinéticos. As variáveis significativas obtidas, apresentadas na Tabela 32, foram o pH nas formas linear e quadrática e a temperatura apenas na forma linear, semelhantemente ao caso da produtividade de PRP visto no item anterior.

Tabela 32 - Efeitos significativos para a descrição da massa molecular de PRP liberada ao sobrenadante na concentração de $500 \mathrm{mg}_{\mathrm{P}} \mathrm{L}^{-1}$

\begin{tabular}{lrrrr}
\hline & Coeficiente & Erro padrão & $\mathrm{t}(6)$ & $\mathrm{p}$-valor \\
\hline $\mathrm{T}(\mathrm{L})$ & $-59,844$ & 7,947 & 7,530 & $<0,001$ \\
$\mathrm{pH}(\mathrm{L})$ & 34,324 & 7,947 & 4,319 & 0,005 \\
$\mathrm{pH}(\mathrm{Q})$ & $-31,699$ & 9,382 & 3,379 & 0,015 \\
Média & 548,055 & 10,418 & 52,608 & $<0,001$ \\
\hline
\end{tabular}

A superfície obtida com os preditores obtidos é mostrada na Figura 29. Nela, se observa que na dimensão da variável $\mathrm{pH}$ os maiores valores de $M_{w}$ são atingidos no valor de 7,13, um valor muito próximo ao valor ótimo para a produtividade de PRP, vista no item 4.2.5. No entanto, diferentemente daquele caso, os valores de $M_{w}$ 
aumentam na direção de menor temperatura. Fixando-se $\mathrm{o} \mathrm{pH}$ no valor ótimo de 7,13 e considerando a temperatura num valor de $29^{\circ} \mathrm{C}$, que é o limite inferior da região estudada, a $M_{w}$ atingida com a concentração de $500 \mathrm{mg}_{\mathrm{P}} \mathrm{L}^{-1}$ equivale a 642 $\mathrm{kDa}$, enquanto que no extremo superior de $37^{\circ} \mathrm{C}$ este valor é de $471 \mathrm{kDa}$.

Figura 29 - Perfil da massa molecular de PRP na concentração de $500 \mathrm{mg}_{\mathrm{P}} \mathrm{L}^{-1}$ em relação aos valores de $\mathrm{pH}$ e temperatura.
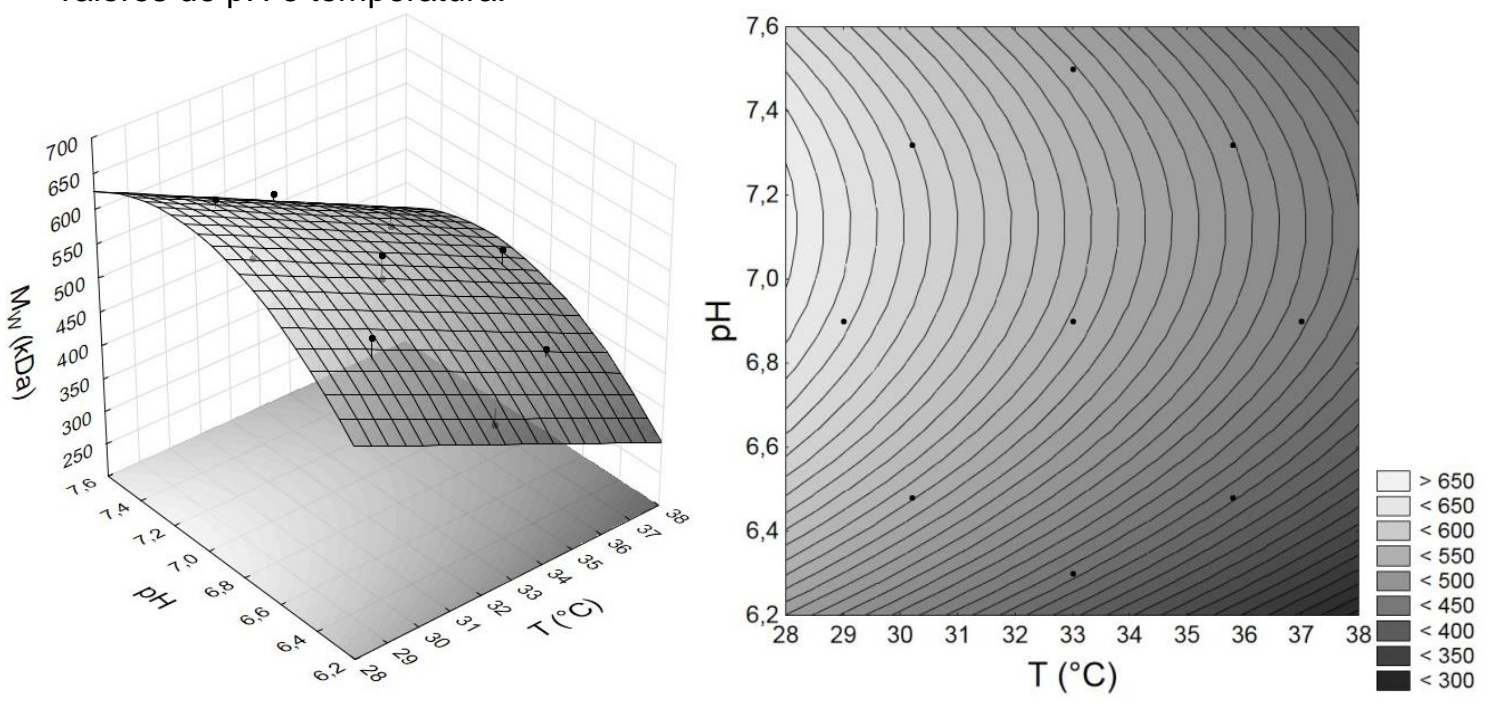

A obtenção de altos valores de $M_{w}$ na região de pH próximo a 7,10 desde 0 início do cultivo mostra que a redução da alcalinidade do meio não age apenas por manter a estabilidade da molécula de PRP, mas também tem influencia direta sobre a massa molecular de síntese do PRP. Em cultivos de baixo pH, onde a estabilidade da molécula é maior, observou-se o mesmo perfil de queda que nos cultivos de alto $\mathrm{pH}$. Isso sugere que a determinação da $M_{w}$ atingida durante o cultivo é mais relacionada com a síntese da molécula do que com as velocidades de degradação no meio extracelular. Pela análise da Figura 28 e da Figura 29, conclui-se que pH's inferiores à neutralidade não são interessantes para a realização do cultivo, pois além de reduzir a concentração de PRP também ocasionam a produção de polissacarídeo de baixa $M_{w}$. Este resultado pode ser correlacionado com aqueles obtidos para a velocidade específica de crescimento celular (item 4.2.1.1) e para a constante de formação específica de PRP (item 4.2.3.1): o crescimento celular apresentou uma região de máximo em pH ácido, no valor de 6,73, implicando que nesta região a célula está mais dedicada à síntese de componentes da célula e portanto compete com a via de formação de PRP diminuindo a disponibilidade de substrato para a formação do polissacarídeo; na região de $\mathrm{pH} 7,1$, a célula está mais dedicada à formação de PRP e existe menos competição com a formação de 
biomassa, disponibilizando maior quantidade de substrato às enzimas polimerizadoras e aumentando a processividade das mesmas.

Quanto à temperatura, os dados evidenciam que baixos valores desta variável foram determinantes na obtenção de maiores valores de $M_{w}$, independentemente do $\mathrm{pH}$ utilizado. As temperaturas mais baixas podem ter apresentado este efeito positivo através da redução das velocidades de reação, o que deve contribuir para a melhor qualidade da molécula. Com a menor movimentação molecular dos substratos e das enzimas envolvidas, a processividade da enzima que efetua a polimerização do PRP pode ter sido aumentada ao garantir que a proteína esteja acoplada ao polímero sintetizado por mais tempo, com menor estresse estérico. No entanto, a falta de descrição e detalhamento na literatura sobre os mecanismos de síntese do PRP impossibilitam a discussão mais aprofundada deste fenômeno.

Estes resultados demonstram que a região de $\mathrm{pH} 7,10$ seria, dentro desta dimensão, a condição ótima para atingir tanto o máximo de produtividade de PRP quanto de massa molecular do polissacarídeo. Já no que diz respeito à temperatura, é necessário encontrar um balanço otimizado para que se obtenha altos valores de $M_{w}$, através da redução da temperatura, mas mantendo-se um bom nível de produtividade. Na avaliação da Figura 28, ficou demonstrado que o ensaio 5, realizado a $30,2^{\circ} \mathrm{C}$, atingiu altas concentrações de PRP, comparáveis aos cultivos realizados em temperaturas mais altas. Por isso, conclui-se esta etapa do trabalho com a determinação do valor de $30{ }^{\circ} \mathrm{C}$ como um valor otimizado para a temperatura do cultivo, combinado com o valor de $\mathrm{pH}$ de 7,10. Nesta condição, o modelo obtido indica que será possível atingir um valor de $M_{w}$ de $621 \mathrm{kDa}$ com uma concentração de PRP de $500 \mathrm{mg}$. $\mathrm{L}^{-1}$. Já na condição de cultivo descrito na literatura por Silva (2010), de $\mathrm{pH} 7,50$ e $37^{\circ} \mathrm{C}$, este valor equivaleria a $447 \mathrm{kDa}$. A mudança de condição de cultivo significaria um incremento de 39,0 \% no valor de $M_{w}$. No item a seguir, serão abordados os resultados dos cultivos nas condições padrão e na condição otimizada definida aqui, a fim de comparação e validação dos resultados obtidos. 


\subsection{Comparação entre os processos padrão e otimizado}

\subsubsection{Etapa de crescimento celular}

Para avaliar a real contribuição da mudança das condições de cultivo para os valores de $\mathrm{pH}$ de 7,10 e temperatura de $30^{\circ} \mathrm{C}$, dois cultivos em batelada alimentada foram realizados. A batelada alimentada foi escolhida por ter sido caracterizada em outros trabalhos como o regime de processo mais adequado que permitiu a obtenção das mais altas concentrações de PRP (Silva, 2010). O primeiro cultivo foi realizado seguindo as condições descritas originalmente e denominadas aqui como "padrão": pH 7,50 e temperatura de $37^{\circ} \mathrm{C}$. A alimentação com o meio concentrado em substrato (vide item 3.2.1.3) foi iniciada em 9,2 horas de cultivo, numa vazão específica de $21,2 \mathrm{~mL} \cdot \mathrm{L}^{-1} \cdot \mathrm{h}^{-1}$. O cultivo se estendeu até 20,6 horas, quando se totalizou a produção de 10,90 $\mathrm{gx} \cdot \mathrm{L}^{-1}$ de células, $19,9 \mathrm{~g}_{\mathrm{A}} \cdot \mathrm{L}^{-1}$ de acetato, 1500,6 mgp. $\mathrm{L}^{-1}$ de PRP total e $1435,4 \mathrm{mg}_{\mathrm{P}} \mathrm{L}^{-1}$ de PRP livre no sobrenadante; os perfis cinéticos obtidos são apresentados na Figura 30. O segundo cultivo foi realizado nas condições otimizadas de $\mathrm{pH} 7,10$ e $30^{\circ} \mathrm{C}$. Neste caso, a alimentação foi iniciada em 8,26 horas de cultivo, numa vazão específica de $17,0 \mathrm{~mL} \cdot \mathrm{L}^{-1} \cdot \mathrm{h}^{-1}$. A definição desta taxa de alimentação foi feita através da medição instantânea da concentração de glicose (vide item 3.2.2.2), e a vazão foi então mantida acima da taxa de consumo deste substrato. A finalização do cultivo se deu em 21,3 horas, com a obtenção de $12,9 \mathrm{gx} \cdot \mathrm{L}^{-1}$ de células, 18,3 $\mathrm{g}_{\mathrm{A}} \cdot \mathrm{L}^{-1}$ de acetato $1585,0 \mathrm{mg} \cdot \mathrm{L}^{-1}$ de PRP total e 1423,7 mg. $\mathrm{L}^{-1}$ de PRP livre no sobrenadante; os dados são mostrados na Figura 31. Em cada cultivo, foi ajustado o melhor modelo cinético utilizado anteriormente e descrito pelas equações (15), (16) e (17). Para o ajuste, considerouse a taxa de diluição específica de cada ensaio.

Para caracterizar melhor as diferenças entre as duas condições de cultivo, os parâmetros obtidos a partir do ajuste do modelo cinético são comparados um a um na Tabela 33. Os valores de $M_{w}$ apresentados equivalem à tendência no momento em que a concentração de PRP livre atinge $1400 \mathrm{mg} \cdot \mathrm{L}^{-1}$. Os perfis obtidos para $M_{w}$ e as linhas de tendência obtidas são mostradas na Figura 32. Já os valores de produtividade $\left(r_{p}^{\prime}\right)$ foram calculados como no item 4.2 .5 , considerando-se a fração de PRP liberada ao sobrenadante. 
Figura 30 - Perfil cinético para o cultivo em batelada alimentada nas condições de $\mathrm{pH}$ de 7,50 e temperatura de $37^{\circ} \mathrm{C}$ (Condições padrão)
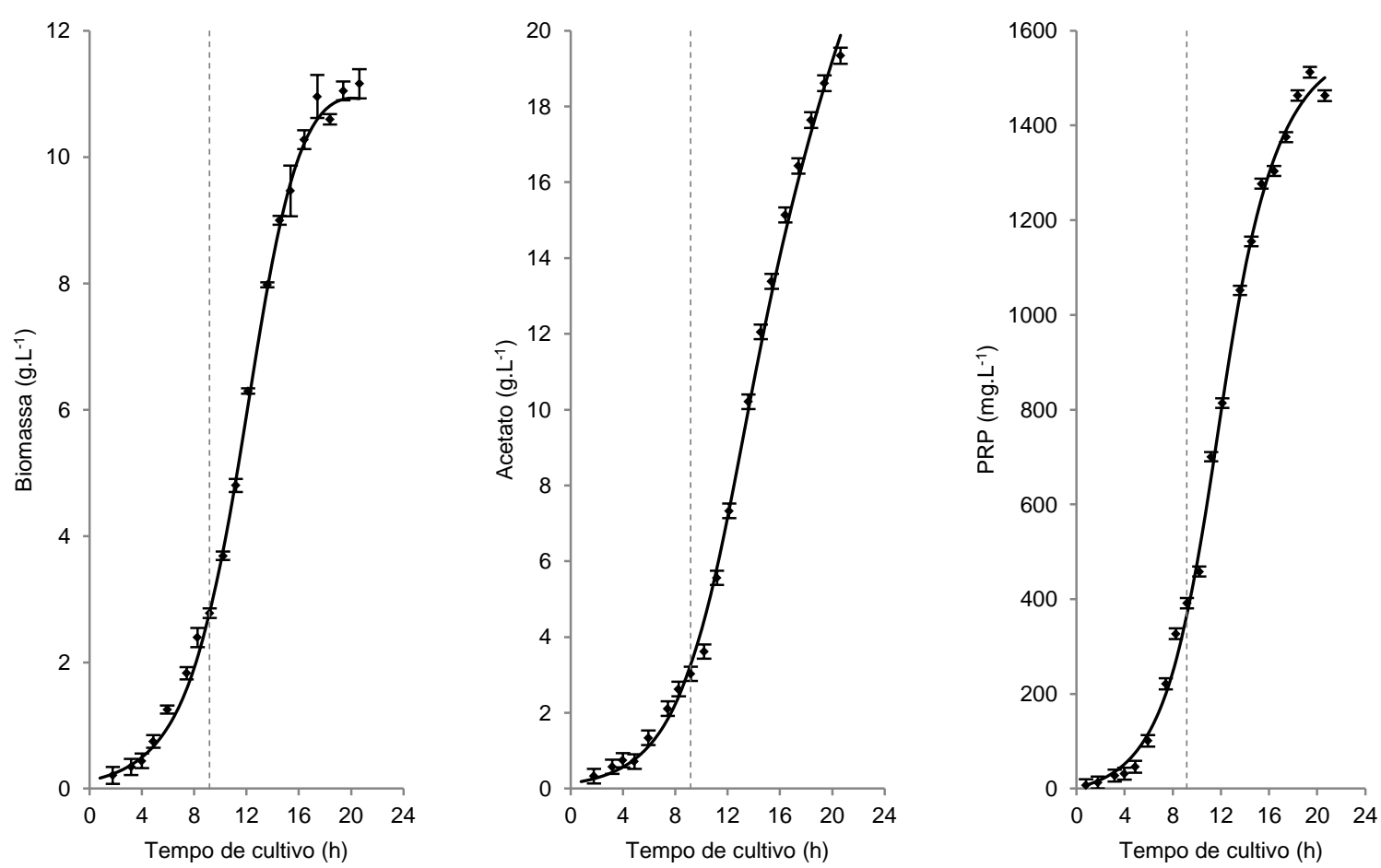

Linhas tracejadas indicam o início da alimentação; linhas contínuas representam o modelo cinético ajustado

Figura 31 - Perfil cinético para o cultivo em batelada alimentada nas condições de $\mathrm{pH}$ de 7,10 e temperatura de $30^{\circ} \mathrm{C}$ (Condições otimizadas)
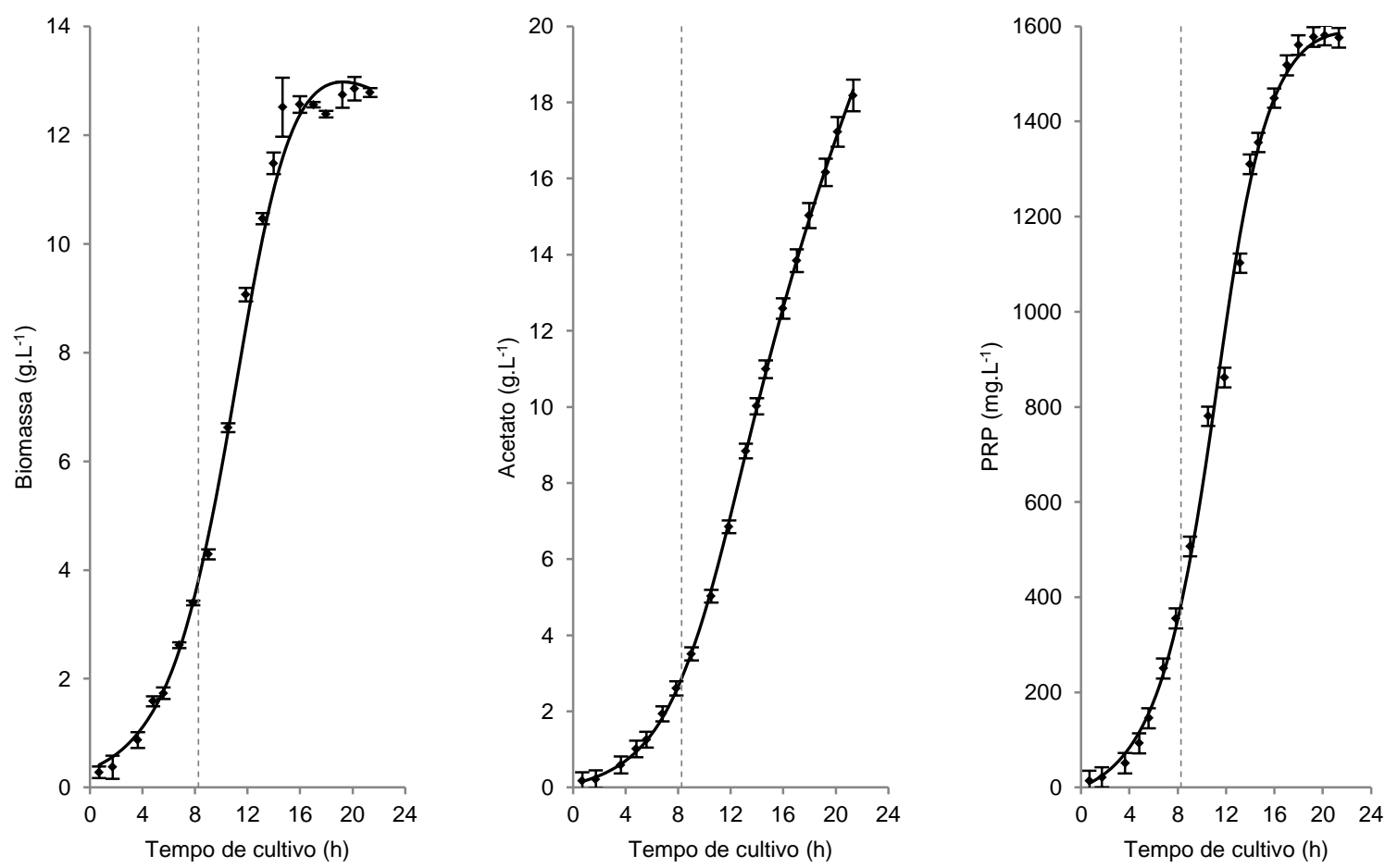

Linhas tracejadas indicam o início da alimentação; linhas contínuas representam o modelo cinético ajustado 
Tabela 33 - Parâmetros cinéticos ajustados aos cultivos em batelada alimentada

\begin{tabular}{lrr}
\hline Parâmetro & $\begin{array}{r}\text { Condição Padrão } \\
\left(\mathrm{pH}=7,50 ; \mathrm{T}=37^{\circ} \mathrm{C}\right)\end{array}$ & $\begin{array}{r}\text { Condição Otimizada } \\
\left(\mathrm{pH}=7,10 ; \mathrm{T}=30^{\circ} \mathrm{C}\right)\end{array}$ \\
\hline$\mu_{\max }\left(\mathrm{h}^{-1}\right)$ & 0,320 & 0,278 \\
$k_{X}\left(\mathrm{~g}_{\mathrm{A}} \cdot \mathrm{L}^{-1}\right)$ & 12,404 & 9,861 \\
$n_{X}$ & 2,702 & 2,817 \\
$\alpha_{A}\left(\mathrm{~g}_{\mathrm{A}} \cdot \mathrm{g}_{\mathrm{x}}^{-1}\right)$ & 0,873 & 0,434 \\
$\beta_{A}\left(\mathrm{~g}_{\mathrm{A}} \cdot \mathrm{g}_{\mathrm{x}}^{-1} \cdot \mathrm{h}^{-1}\right)$ & 0,109 & 0,095 \\
$\beta_{P}\left(\mathrm{mg}_{\mathrm{PRP}} \cdot \mathrm{gx}_{\mathrm{X}}^{-1} \cdot \mathrm{h}^{-1}\right)$ & 48,616 & 31,348 \\
$k_{P}\left(\mathrm{~g}_{\mathrm{A}} \cdot \mathrm{L}^{-1}\right)$ & 8,908 & 8,768 \\
$n_{P}$ & 2,909 & 3,497 \\
$r_{p}^{\prime}\left(\mathrm{mg} \mathrm{PRP}_{\mathrm{PR}} \mathrm{L}^{-1} \cdot \mathrm{h}^{-1}\right)$ & 77,433 & 83,308 \\
$M_{W}(\mathrm{kDa})$ & 360,73 & 642,76 \\
\hline
\end{tabular}

Figura 32 - Perfil de massa molecular em relação à concentração de PRP livre para os cultivos em batelada alimentada
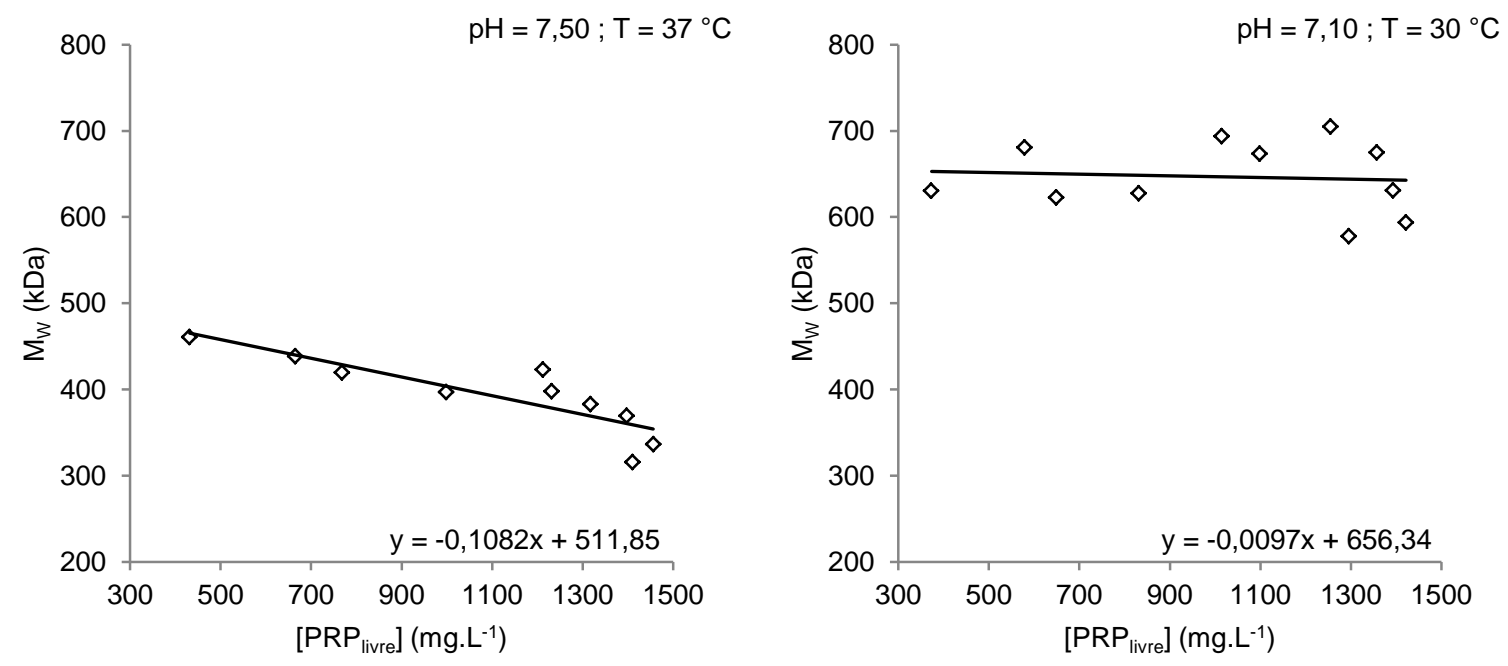

Com os valores parametrizados, é possível realizar algumas análises a respeito dos efeitos da alteração das condições de cultivo sobre o metabolismo. Quanto à máxima velocidade específica de crescimento, observa-se uma variação de 0,320 a $0,278 \mathrm{~h}^{-1}$, demonstrando que o desenvolvimento celular foi mantido razoavelmente constante. Quanto à constante de inibição sobre o crescimento, observa-se que nas condições padrão a célula tolera maior concentração de ácido, já que nas condições otimizadas $k_{X}$ é reduzida em cerca de $20,5 \%$. No entanto, a produção específica de acetato, na forma associada ao crescimento, é 50,3 \% menor nas condições otimizadas, e 12,8 \% menor na forma não associada. Portanto, nas condições otimizadas a bactéria é menos tolerante ao ácido, mas em contrapartida existe uma menor produção do mesmo, permitindo assim o crescimento de forma semelhante nas duas condições. Estes resultados coincidem com aqueles encontrados nos itens 
4.2.1.2 e 4.2.2. Em pH's mais alcalinos (condição padrão), a bactéria tolera maiores concentrações de acetato, pois este se encontra na forma dissociada e tem mais dificuldade em atravessar a membrana plasmática. No entanto, com a acidificação do meio (condições otimizadas), a produção de acetato é reduzida, provavelmente devido à maior eficiência na produção de ATP pela via quimiosmótica. A produção específica de PRP é cerca de 35,5 \% menor nas condições otimizadas do que nas condições padrão, concordando com os resultados obtidos no item 4.2.3.1, onde o ponto de máximo do parâmetro se aproxima mais da condição padrão do que da condição otimizada. No entanto, a combinação de todos os parâmetros cinéticos permitiu que a produtividade de PRP liberada ao sobrenadante fosse muito parecida, chegando a ser 7,6 \% maior nas condições otimizadas. No item 4.2.6. havia sido previsto que a mudança de condição de cultivo possibilitaria a elevação dos valores de $M_{w}$, o que de fato foi observado: nas condições otimizadas foi possível atingir no final do cultivo um valor maior que $640 \mathrm{kDa}$, um incremento de cerca de 78,0 \% em relação às condições padrões, onde se chegou ao final do cultivo com um valor de $M_{w}$ de apenas $360 \mathrm{kDa}$.

\subsubsection{Primeira etapa de purificação e projeções do processo global}

As duas condições de cultivo permitiram atingir valores semelhantes de concentração de PRP, assim como de produtividade. Para avaliar e mensurar como o aumento de massa molecular obtido nas condições otimizadas poderá contribuir para o rendimento global do processo de produção da vacina, foi realizada a primeira etapa de purificação, seguindo o protocolo descrito por Albani et al. (2015). Esta etapa é constituída por uma ultrafiltração tangencial em membrana de corte nominal de $100 \mathrm{kDa}$, onde o sobrenadante do cultivo é concentrado para um volume menor e lavado com uma série de tampões para a remoção de impurezas. A recuperação dessa etapa (a quantidade de PRP que se mantém na fração do retentado da ultrafiltração) é de cerca de $44 \%$, para o cultivo realizado nas condições padrão de pH 7,50 e $37^{\circ} \mathrm{C}$; a recuperação final após todas as etapas de purificação, que incluem precipitações fracionadas com etanol, microfiltrações em corte de 0,22 $\mu \mathrm{m}$, hidrólises enzimáticas e outras ultrafiltrações, é reportada como cerca de $14 \%$ (Albani et al., 2015). Com o cultivo realizado nas condições otimizadas de $\mathrm{pH} 7,10$ e $30^{\circ} \mathrm{C}$, a recuperação do polissacarídeo na fração do 
retentado na primeira etapa de ultrafiltração foi de cerca de $75 \%$. Considerando que as demais etapas de purificação continuem com os mesmos níveis de recuperação, foi feita uma projeção da recuperação final para o processo nas condições otimizadas, sendo obtido um valor de $24 \%$. A comparação deste resultado e as projeções entre as duas condições são mostradas na Tabela 34.

Tabela 34 - Rendimentos do processo e projeções entre as condições padrão e otimizada

\begin{tabular}{|c|c|c|}
\hline & $\begin{array}{r}\text { Condição Padrão } \\
\left(\mathrm{pH}=7,50 ; \mathrm{T}=37^{\circ} \mathrm{C}\right)\end{array}$ & $\begin{array}{r}\text { Condição Melhorada } \\
\left(\mathrm{pH}=7,10 ; \mathrm{T}=30^{\circ} \mathrm{C}\right)\end{array}$ \\
\hline$\left[\mathrm{PRP}_{\text {livre }}\right]\left(\mathrm{mg}_{\mathrm{P} .} \mathrm{L}^{-1}\right)$ & 1435,4 & 1423,7 \\
\hline Rendimento da $1^{\text {a }}$ etapa de purificação (\%) & $44 \%$ & $75 \%$ \\
\hline Rendimento global da purificação (\%) & $14 \%$ & $24 \%$ \\
\hline$\left[\mathrm{PRP}_{\text {purificado }}\right]\left(\mathrm{mg}_{\left.\mathrm{P} . \mathrm{L}^{-1}\right)}\right.$ & 201,0 & 339,7 \\
\hline Rendimento da conjugação (\%) & $30 \%$ & $30 \%$ \\
\hline$\left[\mathrm{PRP}_{\text {conjugado }}\right]\left(\mathrm{mg}_{\mathrm{P}} . \mathrm{L}^{-1}\right)$ & 60,29 & 101,92 \\
\hline Rendimento final (doses. $\mathrm{L}^{-1}$ ) & 6.029 & 10.192 \\
\hline Demanda nacional (L.ano $\left.{ }^{-1}\right)$ & 1.344 & 795 \\
\hline Demanda mundial $\left(\right.$ L.ano $\left.^{-1}\right)$ & 29.409 & 17.395 \\
\hline
\end{tabular}

O baixo rendimento durante a purificação do polissacarídeo obtido nas condições padrão, numa concentração de PRP de $1400 \mathrm{mg}_{\mathrm{P}} \mathrm{L}^{-1}$, implica que apenas cerca de $200 \mathrm{mg}_{\mathrm{p}} \mathrm{L}^{-1}$ seriam efetivamente recuperados e destinados à conjugação. Com o aumento de 44 para $75 \%$ na primeira etapa de purificação conseguido com as mudanças nas condições de cultivo e o mesmo nível de concentração de PRP atingida, seriam obtidos no final da purificação quase $340 \mathrm{mg}_{\mathrm{P}} \mathrm{L}^{-1}$, um aumento efetivo de cerca de $70 \%$. Este aumento pode entretanto estar subestimado, já que não foram avaliadas as outras etapas de ultrafiltração onde o incremento em massa molecular pode contribuir positivamente para a recuperação do polissacarídeo.

Avaliando-se que durante o processo de conjugação existe cerca de $70 \%$ de perdas em PRP (Barazzone, 2014, comunicação pessoal)*, e ainda que uma dose da vacina de Hib contenha $10 \mu \mathrm{g}$ de PRP (WHO, 2000), a mudança das condições de cultivo implicaria que cada litro de cultivo renderia uma quantidade excedente de cerca de 4000 doses, chegando até mais de 10 mil doses por litro de cultivo.

Para avaliar o efeito final desta modificação sobre a escala de produção, considera-se por fim a demanda real de vacinas de Hib. A campanha de vacinação prevê a utilização de três doses por indivíduo (WHO, 2000). Considerando que a projeção de nascimentos no Brasil em 2014 seja de 2,7 milhões (Instituto Brasileiro de Geografia e Estatística, 2008), a demanda nacional equivale a 8,1 milhões de

* Informação fornecida por Giovana Barazzone em seminários internos do Centro de Biotecnologia do Instituto 
doses, equivalente a mais de 1300 litros de cultivo ao ano nas condições padrão, e a menos de 800 nas condições otimizadas. Já para a demanda mundial, considera-se que em 2013 a UNICEF adquiriu 177,3 milhões de doses (UNICEF, 2013). Isso demandaria a realização de 29,4 mil litros de cultivo ao ano nas condições padrão; porém nas condições otimizadas esta demanda reduziria para menos de 17,4 mil litros ao ano, reduzindo em cerca de $40 \%$ a escala de produção,

É importante notar, entretanto, que estas projeções foram realizadas considerando-se apenas a primeira etapa de purificação, podendo estar subestimadas. Durante os processos de purificação e conjugação existem mais etapas onde se utiliza a ultrafiltração tangencial e onde se verifica perdas significativas; com um polissacarídeo de massa molecular maior obtido nas condições otimizadas, é de se esperar que o rendimento final do processo global seja também maior.

Assim, fica demonstrado que o melhoramento da qualidade do polissacarídeo obtido durante o crescimento celular irá refletir na produção como um todo, contribuindo com a redução da escala, das instalações, materiais e equipamentos utilizados e com a minimização da demanda por recursos humanos, impactando diretamente no custo final do produto. 


\section{CONCLUSÕES E PERSPECTIVAS}

A diretriz principal deste trabalho foi a criação de modelos cinéticos e estatísticos para a otimização do processo de produção do polissacarídeo capsular de Hib, considerando-se a produtividade global obtida através da consideração da interface entre o crescimento celular e a purificação. Em trabalhos anteriores, ficou demonstrado o decréscimo dos valores de massa molecular do PRP durante o cultivo, e que estes baixos valores resultavam em altas perdas de polissacarídeo durante as etapas de UFT realizadas no processo de purificação; demonstrou-se também que o PRP é inerentemente instável, sofrendo clivagem espontânea em determinadas condições de $\mathrm{pH}$, temperatura e concentração de sais. Pode-se dizer com isso que os pH's elevados usados nos cultivos descritos na literatura e o aumento da concentração de íons sódio devido ao controle de pH são alguns dos fatores responsáveis pela degradação observada, e ficou evidente que estas condições deveriam ser modificadas durante a etapa de crescimento celular para evitar as perdas observadas na purificação.

Para contornar esta problemática, foram realizados cultivos em diferentes condições de $\mathrm{pH}$ e temperatura, com o objetivo de avaliar como a bactéria se comportaria em relação ao seu metabolismo e à qualidade do polissacarídeo obtido ao final do processo.

Para realizar estas avaliações, fez-se necessária a escolha de um modelo cinético. Vários modelos descritos na literatura foram testados, e através do critério de informação de Akaike foi possível escolher um modelo entre o conjunto de modelos sugeridos, sendo que ficou demonstrada a robustez do modelo ao descrever eficientemente a cinética microbiana em diversas condições.

O estudo dos parâmetros cinéticos dos modelos obtidos foi feito através de ferramentas estatísticas, que possibilitaram evidenciar a importância e a forma de atuação do $\mathrm{pH}$ e da temperatura sobre as velocidades de crescimento celular e formação de produtos, como o acetato e o PRP, além de fornecer informações sobre os efeitos de inibição por metabólitos tóxicos. A combinação dos modelos cinéticos obtidos permitiu encontrar uma condição ótima para a produtividade de PRP durante o cultivo. Esta condição é diferente da descrita em várias fontes, fornecendo assim por si só uma informação relevante. 
A medição da massa molecular durante os cultivos evidenciou que existe relação direta entre este parâmetro e as condições de $\mathrm{pH}$ e temperatura mantidas durante o crescimento celular. Ficou claro também que, além de influenciar nas velocidades de degradação da molécula, estes parâmetros tem influência direta sobre a massa molecular de síntese do polissacarídeo. O fato de os cultivos realizados a menores temperaturas apresentarem PRP de maiores massas moleculares indicou que a redução da taxa metabólica permite a ação mais controlada da síntese do polímero, provavelmente pela maior processividade das enzimas envolvidas.

Com a comparação entre os perfis de produtividade e de massa molecular obtidos, foi sugerida uma nova condição de cultivo que otimizasse a relação entre estes dois parâmetros. A replicação do cultivo nessas condições em regimes de alta produção observados na literatura resultou em valores muito semelhantes quanto às concentrações dos metabólitos. No entanto, o aumento da massa molecular do polissacarídeo obtido foi marcante.

Com o estudo da primeira etapa de purificação, ficou demonstrado que a simples mudança na condição de cultivo foi um fator importantíssimo para a produtividade global do processo, já que o rendimento inicial foi grandemente aumentado. A projeção dos resultados obtidos sobre todo o processo de produção, até a vacina final, demonstrou que a escala de produção pode ser reduzida consideravelmente.

O fato de a massa molecular ter influído fortemente sobre uma única etapa da purificação evidencia que este parâmetro deve ser acompanhado durante os estudos de desenvolvimento de processo para a vacina Hib e utilizado como ferramenta de otimização. Os dados obtidos aqui deixam uma série de possibilidades para continuação, tanto nas etapas de upstream quanto de downstream. Entre elas, pode-se citar:

- Acompanhar a evolução da massa molecular do PRP durante os processos de purificação e conjugação, a fim de evidenciar outras etapas de perda de estabilidade;

- Estudar como o aumento da massa molecular pode influir sobre as outras etapas de purificação e conjugação, sendo possível encontrar maiores rendimentos em cada uma delas; 
- Criar modelos para correlacionar a massa molecular do polissacarídeo com a permeabilidade nas membranas de ultrafiltração, a fim de unir os modelos de produtividade das etapas de crescimento celular e de purificação, permitindo encontrar uma condição ótima global;

- Otimizar outros parâmetros do cultivo celular com base nos modelos cinéticos e nas superfícies de resposta obtidos, como os regimes de alimentação, com o objetivo de minimizar a inibição pelo acetato e maximizar a produção de PRP de alta massa molecular;

- Ainda com os modelos, aprofundar o entendimento sobre as vias metabólicas do microrganismo, elucidando os mecanismos de formação de PRP e de acetato, dos fenômenos de inibição metabólica, da eficiência energética, etc. 


\section{REFERÊNCIAS*}

Aiba S, Shoda M, Nagatani M. Kinetics of product inhibition in alcohol fermentation. Biotechnol Bioeng. 1968;10(6):845-64.

Albani SMF, Silva MR, Takagi M et al. Improvement in the purification process of the capsular polysaccharide from Haemophilus influenzae type b by using tangential ultrafiltration and diafiltration. Appl Biochem Biotechnol. 2012;167(7):2068-75.

Albani SMF, Silva MR, Fratelli $F$ et al. Polysaccharide purification from Haemophilus influenzae type $b$ through tangential microfiltration. Carbohydr Polym. 2015;116:67-73.

Anderson $\mathrm{P}$, Smith $\mathrm{DH}$. Isolation of the capsular polysaccharide from culture supernatant of Haemophilus influenzae type b. Infect Immun. 1977;15(2):472-7.

Biberstein EL, Mini PD, Gills MG. Action of Haemophilus cultures on delta-aminolevulinic acid. J Bacteriol. 1963;86:814-9.

Bisgard KM, Kao A, Leake $\mathrm{J}$ et al. Haemophilus influenzae invasive disease in the United States, 1994-1995: near disappearance of a vaccine-preventable childhood disease. Emerg Infect Dis. 1998;4(2):229-37.

Borisov VB, Gennis RB, Hemp $\mathrm{J}$ et al. The cytochrome bd respiratory oxygen reductases. Biochim Biophys Acta. 2011;1807(11):1398-413.

Brul S, Coote P. Preservative agents in foods. Mode of action and microbial resistance mechanisms. Int J Food Microbiol. 1999;50(1-2):1-17.

Burnham KP, Anderson DR. Model selection and multimodel inference: a practical information-theoretic approach. New York: Springer; 2002.

Cecchini G, Schröder I, Gunsalus RP et al. Succinate dehydrogenase and fumarate reductase from Escherichia coli. Biochim Biophys Acta. 2002;1553(1-2):140-57.

Cintra FO, Takagi M. Comparison among different sample treatment methods for analysis of molecular weight and concentration of exopolysaccharide produced by Haemophilus influenzae type b. In: Mendez-Vilas A, Editor. Microbes in applied research: current advances and challenges. Singapore: World Scientific Publishing Company; 2012. p. 513-7.

Cintra FO, Takagi M. Study of the chemical stability of the capsular polysaccharide produced by Haemophilus influenzae type b. Carbohydr Polym. 2015;116:167-72.

Crisel RM, Baker RS, Dorman DE. Capsular polymer of Haemophilus influenzae, type b. I. Structural characterization of the capsular polymer of strain Eagan. $J$ Biol Chem. 1975;250(13):4926-30.

De Haan A, Van der Put RMF, Beurret M. HPAEC-PAD method for the analysis of alkaline hydrolyzates of Haemophilus influenzae type $b$ capsular polysaccharide. Biomed Chromatogr. 2013;27(9):1137-42.

Egan W, Schneerson R, Werner KE et al. Structural studies and chemistry of bacterial capsular polysaccharides. Investigations of phosphodiester-linked capsular polysaccharides isolated from Haemophilus influenzae types $a, b$, c, and $f:$ NMR spectroscopic identification and chemical modification. J Am Chem Soc. 1982;104(10):2898-910. 
Eldere J, Brophy L, Loynds B et al. Region II of the Haemophilus influenzae Type b capsulation locus as involved in serotype-specific polysaccharide synthesis. Mol Microbiol. 1995;15(1):107-18.

Evans NM, Smith DD, Wicken AJ. Haemin and nicotinamide adenine dinucleotide requirements of Haemophilus influenzae and Haemophilus parainfluenzae. J Med Microbiol. 1974;7(3):359-65.

Fleischmann RD, Adams MD, White $\mathrm{O}$ et al. Whole-genome random sequencing and assembly of Haemophilus influenzae Rd. Science. 1995;269(5223):496-512.

Global Alliance for Vaccine Inovation. Hib vaccine. Disponível em: <http://www.gavialliance. org/support/nvs/hib/>. Acesso em: 12 nov. 2013.

Greaves RI. Preservation of living cells by freeze-drying. Ann N Y Acad Sci. 1960;85(2):7238.

Hamidi A, Beurret MF. Process for producing a capsular polysaccharide for use in conjugate vaccines. US 7582459B2. 10 set. 2004; 01 set. 2009.

Hinshelwood C. The chemical kinetics of the bacterial cell. Oxford: Clarendon Press; 1946.

Instituto Brasileiro de Geografia e Estatística. Projeção da População do Brasil por sexo e idade: 1980-2050 - Revisão 2008. Disponível em: <http://www.ibge.gov.br/home/ estatistica/populacao/projecao_da_populacao/2008/default.shtm>. Acesso em: 21 out. 2014.

Kavanau JL. Enzyme kinetics and the rate of biological processes. J Gen Physiol. 1950;34(2):193-209.

Kyoto Encyclopedia of Genes and Genomes. KEGG PATHWAY Database. Disponível em: <http://www.genome.jp/kegg/pathway.html>. Acesso em: 12 nov. 2013.

Kroll JS, Moxon ER. Capsulation and gene copy number at the cap locus of Haemophilus influenzae type b. J Bacteriol. 1988;170(2):859-64.

Krulwich TA. Alkaliphiles: "basic" molecular problems of $\mathrm{pH}$ tolerance and bioenergetics. Mol Microbiol. 1995;15(3):403-10.

Kuhnert P, Christensen H. Pasteurellaceae: Biology, Genomics and Molecular Aspects. Norfolk: Caister Academic Press; 2008.

Kupcsulik B, Sevella B. Optimization of specific product formation rate by statistical and formal kinetic model descriptions of an HSA producing Pichia pastoris Muts strain. Chem Biochem Eng. 2005;19(1):99-108.

Li Y, Breaker RR. Kinetics of RNA Degradation by Specific Base Catalysis of Transesterification Involving the 2'-Hydroxyl Group. J Am Chem Soc. 1999;121(23):5364-72.

Liu L, Du G, Chen J et al. Enhanced hyaluronic acid production by a two-stage culture strategy based on the modeling of batch and fed-batch cultivation of Streptococcus zooepidemicus. Bioresour Technol. 2008;99(17):8532-6.

Loeb MR. Ferrochelatase activity and protoporphyrin IX utilization in Haemophilus influenzae. J Bacteriol. 1995;177(12):3613-5. 
Luedeking R, Piret EL. A kinetic study of the lactic acid fermentation. Batch process at controlled pH. J Biochem Microbiol Technol Eng. 1959;1(4):393-412.

Mawas F, Bolgiano B, Belgrave D et al. International collaborative study to evaluate a candidate international standard for Haemophilus Influenzae type B Capsular Polysaccharide. Geneva; 2005. Disponível em: <http://www.who.int/iris/handle/ 10665/69141>. Acesso em: 24 out. 2014.

Mawas $F$, Bolgiano B, Rigsby $P$ et al. Evaluation of the saccharide content and stability of the first WHO International Standard for Haemophilus influenzae b capsular polysaccharide. Biologicals. 2007;35(4):235-45.

Merritt J, Allard G, O'Toole L et al. Development and scale-up of a fed-batch process for the production of capsular polysaccharide from Haemophilus influenzae. J Biotechnol. 2000;81(2-3):189-97.

Meunier DM. Molecular weight determinations. In: Settle FA, Editor. Handbook of Instrumental Techniques for Analytical Chemistry. Upper Saddle River: Prentice-Hall; 1997. p. 853-866.

Ministério da Saúde. Calendário Nacional de Vacinação. Disponível em: < http://portalsaude. saude.gov.br/index.php/o-ministerio/principal/leia-mais-o-ministerio/197-secretaria-svs/13600 -calendario-nacional-de-vacinacao>. Acesso em: 22 nov. 2014.

Mitchell P. Coupling of phosphorylation to electron and hydrogen transfer by a chemi-osmotic type of mechanism. Nature. 1961;191(4784):144-8.

Othman DSMP, Schirra H, McEwan AG et al. Metabolic versatility in Haemophilus influenzae: a metabolomic and genomic analysis. Front Microbiol. 2014;5:69.

Pereira MP, Brown ED. Bifunctional catalysis by CDP-ribitol synthase: convergent recruitment of reductase and cytidylyltransferase activities in Haemophilus influenzae and Staphylococcus aureus. Biochemistry. 2004;43(37):11802-12.

Ratkowsky DA, Olley J, McMeekin TA et al. Relationship between temperature and growth rate of bacterial cultures. J Bacteriol. 1982;149(1):1-5.

Ratkowsky DA, Lowry RK, McMeekin TA et al. Model for bacterial culture growth rate throughout the entire biokinetic temperature range. J Bacteriol. 1983;154(3):1222-6.

Reidl J, Schlör S, Kraiss A et al. NADP and NAD utilization in Haemophilus influenzae. Mol Microbiol. 2000;35(6):1573-81.

Rosso L, Lobry JR, Bajard S et al. Convenient Model To Describe the Combined Effects of Temperature and pH on Microbial Growth. Appl Environ Microbiol. 1995;61(2):610-6.

Schilling $\mathrm{CH}$, Palsson BO. Assessment of the metabolic capabilities of Haemophilus influenzae Rd through a genome-scale pathway analysis. J Theor Biol. 2000;203(3):249-83.

Silva MR. Estratégias de cultivo para a produção de polissacarídeo capsular por Haemophilus influenzae tipo b e determinação de parâmetros de qualidade para o produto. [dissertação (Mestrado em Biotecnologia)]. Universidade Federal de São Carlos, 2010. 
Sociedade Brasileira de Imunizações. Alteração do Calendário de Vacinação da Criança. Disponível em: <http://www.sbim.org.br/noticias-sbim/convocacao/>. Acesso em: 22 nov. 2014.

Stepanova N, Romanovskiĭ I, lerusalimskiĭ N. [Mathematical modelling of the growth of microorganisms in the case of continuous (uninterrupted) culture)]. Dokl Akad Nauk SSSR. 1965;163(5):1266-9.

Sukupolvi-Petty S, Grass S, St Geme JW. The Haemophilus influenzae Type b hcsA and hcsB gene products facilitate transport of capsular polysaccharide across the outer membrane and are essential for virulence. J Bacteriol. 2006;188(11):3870-7.

Takagi M, Cabrera-Crespo J, Baruque-Ramos $\mathrm{J}$ et al. Characterization of polysaccharide production of haemophilus influenzae Type $b$ and its relationship to bacterial cell growth. Appl Biochem Biotechnol. 2003;110(2):91-100.

Takagi M, Cabrera-Crespo J, Zangirolami TC et al. Improved cultivation conditions for polysaccharide production by $\mathrm{H}$. influenzae type b. J Chem Technol Biotechnol. 2006;81(2):182-8.

Takagi M, Zangirolami TC, Tanizaki MM et al. Improvement of simple cultivation conditions for polysaccharide synthesis by Haemophilus influenzae type b. In: Méndez-Vilas A, Editor. Communication Current Reasearch and Educational Topics in Applied Mibrobiology. Badajoz: Formatex; 2007. p. 602-8.

Tatusov RL, Mushegian AR, Bork $\mathrm{P}$ et al. Metabolism and evolution of Haemophilus influenzae deduced from a whole-genome comparison with Escherichia coli. Curr Biol. 1996;6(3):279-91.

United Nations Children's Fund. Vaccine Price Data. Disponível em: <http://www.unicef. org/supply/index_57476.html>. Acesso em: 12 nov. 2013.

United Nations Children's Fund. Historical Vaccine Procurement. Disponível em: <http:// www.unicef.org/supply/index_38554.html>. Acesso em: 21 out. 2014.

Watt JP, Wolfson LJ, O'Brien KL et al. Burden of disease caused by Haemophilus influenzae type b in children younger than 5 years: global estimates. Lancet. 2009;374(9693):903-11.

World Health Organization. Recommendations for the production and control of Haemophilus influenzae type b conjugate vaccines. Report. 2000. (WHO Technical Report Series, 897).

World Health Organization. Weekly epidemiological record, 2006. Disponível em: <http://www.who.int/wer/2006/wer8147/en/index.html>. Acesso em: 12 nov. 2013.

World Health Organization. Immunization surveillance, assessment and monitoring. Disponível em: <http://www.who.int/immunization_monitoring/diseases/Hib/en/index.html>. Acesso em: 12 nov. 2013.

Wilfert CM. Epidemiology of Haemophilus influenzae type $b$ infections. Pediatrics. 1990;85(4):631-5.

Yano T, Koga S. Dynamic behavior of the chemostat subject to product inhibition. J Gen Appl Microbiol. 1973;19(2):97-114. 
Yogev R, Arditi M, Chadwick EG et al. Haemophilus influenzae type b conjugate vaccine (meningococcal protein conjugate): immunogenicity and safety at various doses. Pediatrics. 1990;85(4):690-3.

Zolli M, Kobric DJ, Brown ED. Reduction Precedes Cytidylyl Transfer without Substrate Channeling in Distinct Active Sites of the Bifunctional CDP-Ribitol Synthase from Haemophilus influenzae. Biochemistry. 2001;40(16):5041-8. 


\section{APÊNDICES - Artigos de periódicos}

Artigo A: Cintra FO, Takagi M. Comparison among different sample treatment methods for analysis of molecular weight and concentration of exopolysaccharide produced by Haemophilus influenzae type b. In: Mendez-Vilas A, Editor. Microbes in applied research: current advances and challenges. Singapore: World Scientific Publishing Company; 2012. p. 513-7.

Artigo B: Cintra FO, Takagi M. Study of the chemical stability of the capsular polysaccharide produced by Haemophilus influenzae type b. Carbohydr. Polym. 2015;116:167-72. 


\title{
Comparison among different sample treatment methods for analysis of molecular weight and concentration of exopolysaccharide produced by Haemophilus influenzae type b
}

\author{
F. O. Cintra ${ }^{1}$ and M. Takagi: ${ }^{* 1}$ \\ ${ }^{1}$ Laboratório de Fermentação, Centro de Biotecnologia, Instituto Butantan, Av. Vital Brasil, 1500 - CEP 05503- \\ 900 - São Paulo - Brasil \\ *Corresponding author: e-mail: mtakagi@butantan.gov.br
}

\begin{abstract}
Haemophilus influenzae type $\mathrm{b}$ (Hib) is a human pathogenic bacterium causing meningitides mainly in children less than 2 years old. Capsular polysaccharide is the main factor of virulence and is used as antigen in the Hib vaccine. In this study a trustful protocol for removing the interferences from fermented broth based on the interaction of polysaccharide-surfactant was established. Interferences from the culture medium were removed by using dialysis, fractionation by ethanol and cetyltrimethylammonium bromide (CTAB), a cationic surfactant. CTAB protocols were able to eliminate interference better than dialysis or ethanol precipitation, giving low false positive values and allowing satisfactory molecular weight distribution analysis.
\end{abstract}

Keywords Haemophilus influenzae b; molecular weight; PRP; CTAB; ethanol; dialysis.

\section{Introduction}

Haemophilus influenzae type b (Hib) is a pathogenic encapsulated Gram negative bacterium responsible for pneumonia, septicemia and meningitis among children less than 2 years old, elderly and immunodeficient patients $[1,2]$. The capsular polysaccharide type $b$, a polymer formed of repeated units of ribosyl-ribitolphosphate (PRP) located in the outer region of the cell, is considered as main the factor of virulence of this microorganism [3]. Polysaccharides work as antigens capable of activating B cells which induce antibody synthesis in the absence of $\mathrm{T}$ cells $[4,5]$. On the other hand, the chemical conjugation between polysaccharide and protein contribute to increase the immunogenicity and produce immunological memory in young children, by activating the T cells [6]. In vitro, PRP is synthesized during cell growth and a considerable amount is released spontaneously into the supernatant [7].

Haemophilus influenzae is a fastidious microorganism that requires enriched medium to grow, demanding supplementation with amino acids, vitamins and growth factors like hemin and $\mathrm{NAD}^{+}$[8-11]. The complex medium, established by Carty et al. is based on soybean peptone and yeast extract, supplemented with $\mathrm{NAD}^{+}$ and hemin, and it is used for growing Hib to produce polysaccharide for immunobiological purpose [12].

In the conjugate Hib vaccine, polysaccharide is evaluated by physical-chemical assays not only in order to guarantee the manufacture consistency of batches $[13,14]$, but also for establishing the purification process where a large number of assays are carried out for characterizing the purified polysaccharide such as ribose and phosphorus content, molecular weight and also during the cultivation to study kinetic models [15]. Polysaccharide concentration is usually measured by Bial's colorimetric method [16] and molecular weight by high performance size exclusion chromatographic coupled to RID detector, or rheometry [17-19]. As the culture medium for growing Hib requires the presence of complex compounds, sample containing polysaccharide is pre-treated to avoid of interference. Dialysis of raw polysaccharide through cellulose membrane of $10 \mathrm{kDa}$ pore size has been used to remove small molecules [20,21]. Ethanol precipitation is traditionally used in the pharmaceutical industries for precipitating polysaccharide by eliminating small and hydrophobic molecules [22, 23]. Other compounds widely used in the food and pharmaceutical industries are the surfactants which reduce the superficial tension of water in low concentration. Cationic surfactant cetyltrimethylammonium bromide $(\mathrm{CTAB})$ is used in the purification of anionic polysaccharide such as PRP based on polymer-surfactant interaction [24-26].

In this work an accurate protocol to remove interferences from cell free culture broth was established in order to study the kinetic model for polysaccharide and molecular weight determination.

\section{Materials and Methods}

\subsection{Fermentations}

Haemophilus influenzae type b strain GB 3291 was obtained from the Brazilian National Center of Meningitis, Adolfo Lutz Institute, Department of Bacteriology, São Paulo, Brazil. Experiments were carried out as fed-batch 
cultures in a 13L bioreactor (Bioflo 2000 - New Brunswick Scientific) containing 8L of Modified MP medium (MMP) under parameters described previously [20]. Feed medium was composed by $20 \%$ of yeast extract and glucose.

\subsection{Sample treatment}

Supernatant from the culture broth was treated following three different protocols: a) Dialysis - samples were introduced into cellulose membranes of $10.404 \mathrm{kDa}$ cut-off (Sigma-Aldrich) and dialyzed against deionized water at $4^{\circ} \mathrm{C}$ under light agitation for $48 \mathrm{~h}$; changing the water periodically; afterwards, samples were carefully transferred into an eppendorf and centrifuged at $10.000 \mathrm{~g}$ and the clarified supernatant was used for PRP measurement [20-22], b) Ethanol precipitation - a solution of 30\% sodium acetate $\mathrm{pH} 5.8$ was added to the sample in order to achieve 5\%, followed by addition of $95 \%$ ethanol achieving $80 \%$ final concentration; the mixture was incubated at $-20^{\circ} \mathrm{C}$ for $1 \mathrm{~h}$ and centrifuged at 3,200g for 20min [23]; pellets were resuspended in $10 \mathrm{mM}$ sodium phosphate buffer ( $\mathrm{pH} 7.5$ ) containing $150 \mathrm{mM} \mathrm{NaCl}$. c) Cetyltrimethylammonium Bromide $(\mathrm{CTAB})$ precipitation - three volumes of CTAB $0.66 \%$ were added to 1 volume of the sample; the mixture was left to stand for $10 \mathrm{~min}$ at room temperature, and centrifuged at $15,000 \mathrm{~g}$ for $10 \mathrm{~min}$; pellets were washed with deionized water and ressuspended in $1 \mathrm{M} \mathrm{NaCl}$ [24].

\subsection{Analytical methods}

Samples from the bioreactor were centrifuged at $9500 \mathrm{~g}$ for $10 \mathrm{~min}$ at $4^{\circ} \mathrm{C}$; the supernatant was frozen for further analysis. The polysaccharide present in the supernatant was isolated by the different treatments described above and the ribose content was determined by the modified Bial's method [16]. The molecular weight values were obtained by High-Performance Size Exclusion Chromatography (HPSEC), in an all Shimadzu system composed of: an oven (CTO-10ASvp) set-up at $40^{\circ} \mathrm{C}$; two columns connected in series (TSK gel $\mathrm{GMPW}_{\mathrm{XL}}$ ), an isocratic pump (LC-10ADvp) running at $0.6 \mathrm{~mL} / \mathrm{min}$, an Refraction Index Detector (RID-10A) and an UV-VIS absorbance detector (SPD-10Avp) reading at $260 \mathrm{~nm}$ (for protein/nucleic acid like impurities) and 405nm (for iron containing molecules). Data was acquired on a $2 \mathrm{~Hz}$ frequency with Class VP software, version 6.2, as a function of the retention time. The mobile phase was composed of $10 \mathrm{mM} \mathrm{Na}_{2} \mathrm{HPO}_{4}, 150 \mathrm{mM} \mathrm{NaCl}$ and $0.02 \%$ $\mathrm{NaN}_{3} \mathrm{pH}$ adjusted to 7.5 with $6 \mathrm{M} \mathrm{HCl}$. The retention time axis was transformed to the relative molecular weight through a calibration curve built from the elution times of dextrans with 1.5, 6, 10, 40, 70, 229 and 2,000 kDa. The relative weight average molecular weight of the samples was estimated from the RID elution profiles, being $\mathrm{Mw}=\Sigma \mathrm{h} * \mathrm{M} / \Sigma \mathrm{h}$, were $\mathrm{h}$ is the height of the RID signal (in volts) and $\mathrm{M}$ is the predicted molecular weight from the Dextran standard curve [27].

\section{Results and Discussion}

\subsection{Sample treatment for determination of PRP concentration}

The supernatant of the culture broth from Haemophilus influenzae type $\mathrm{b}$ fermentation should be treated previously to determination of polysaccharide concentration in order to remove the components of the culture medium and other molecules produced by the microorganism, resulting in a more accurate measurement. Three different methods were applied and improved for the removal of these impurities from the culture broth: a) Dialysis, b) Ethanol precipitation and c) CTAB precipitation. Figure 1A shows the kinetics profile of PRP production throughout a fed- batch cultivation in different sample treatment methods. Dialysis shows higher PRP concentration values than ethanol and CTAB treatments, suggesting that not all impurities interfering in the Bial's method were eliminated through the $10 \mathrm{kDa}$ pore size. This fact was evident when the methods were conducted with non-fermented culture medium as sample, where high background value was observed, as illustrated in Fig.1B. The same procedure was done with purified polysaccharide, and the results of each treatment method were compared to the untreated sample. While ethanol and CTAB precipitation methods showed no significant difference (results not shown), the dialyzed sample resulted in different values of PRP concentration indicating that the dialysis method was not robust. Figure 1C shows that the value of the nondialyzed sample was considerably lower than the dialyzed one.

Ethanol and CTAB protocols showed similar PRP profile at the end of the fed-batch phase, but in the first $6 \mathrm{~h}$ of cultivation a considerable background was observed for the ethanol procedure. As Fig.1B shows, the ethanol precipitation has the highest false positive value, followed by dialysis. 


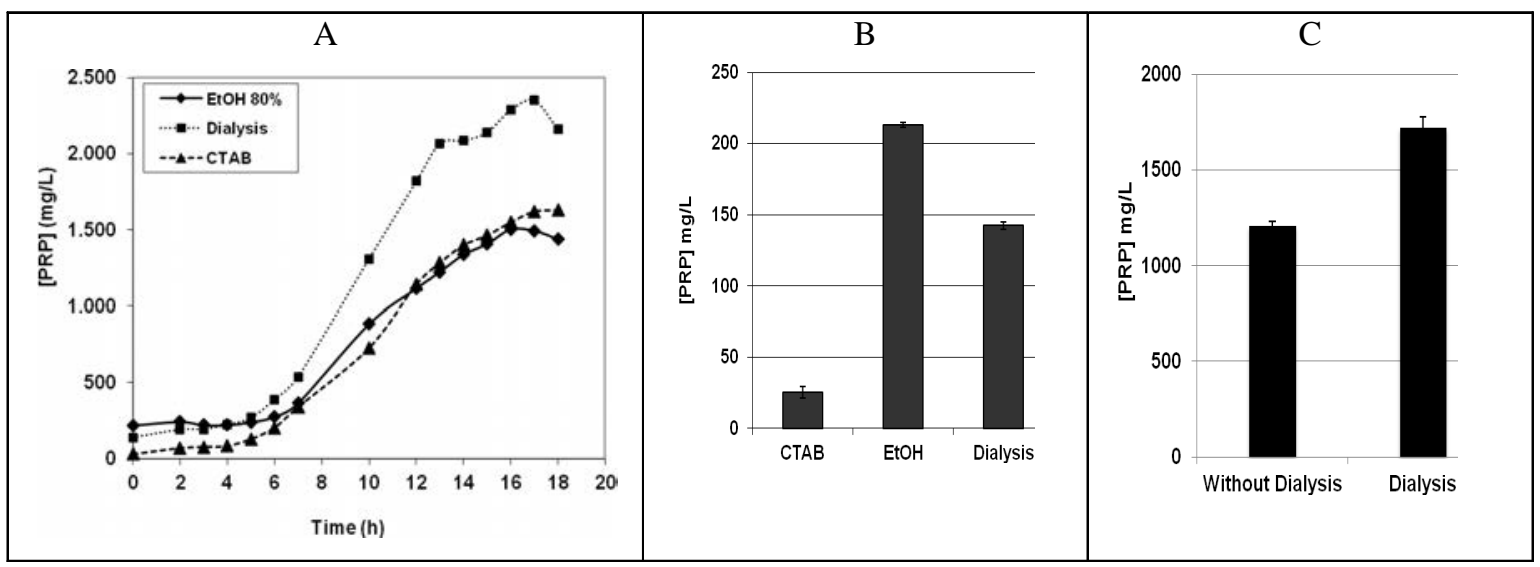

Fig. 1 A) Polysaccharide concentration kinetics profile obtained by different sample treatment; B) Culture medium treated in different protocols. C) Control -dialyzed and non-dialyzed purified PRP.

Sample treatment with cationic surfactant CTAB showed the best result, probably because it is able to select molecules that have both negatively charged groups and high molecular weight. Although ethanol is able to precipitate the PRP successfully, it is also able to precipitate other compounds, like uncharged polysaccharides, proteins and ethanol insoluble molecules of low molecular weight. Dialysis is by far the most unsuitable method for analytical purposes, i.e., as ethanol, dialysis also may hold uncharged polysaccharides and proteins, and brings a considerable amount of dispersion and error.

Figure 2 shows the kinetics of PRP production obtained through the protocol used by Merrit (1) [21] and the same samples with an improved protocol (2), both using CTAB precipitation. During the feed batch cultivation, the culture broth changes continuously by addition of sodium hydroxide, feed medium, and increase of metabolite and polysaccharide concentration, which result in changes of conductivity as shown in figure 2 . Diluting the sample to achieve conductivity similar to $2.5 \mathrm{mS} / \mathrm{cm}$ changed the PRP kinetic profile, showing a threshold in electrolyte concentration for the effectiveness of the CTAB precipitation. However some improvement in the protocol should be done taking in consideration its chemical properties such as: the critical micelle concentration (CMC); temperature, salt concentration, viscosity, $\mathrm{pH}$ and interaction polymer-surfactant [28-30]

As the medium composition may change throughout the fed-batch cultivation by both the cell metabolism and feed addition, the CTAB protocol seems to be the best choice for determination of the PRP concentration and for the study of kinetic models.

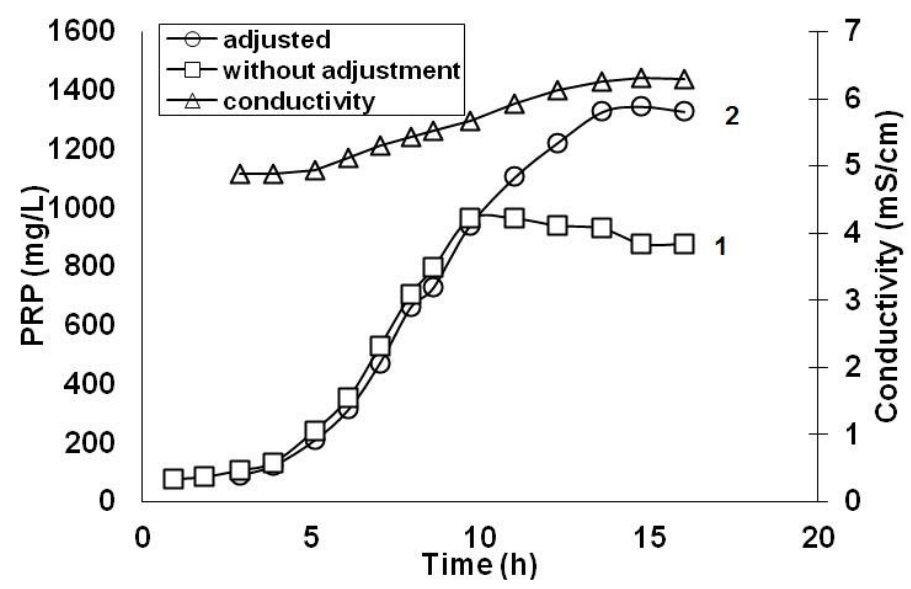

Fig. 2 Kinetics of PRP production with raw samples and conductivity corrected one.

\subsection{Sample treatment for determination of the molecular weight}

The determination of the average molecular weight through the HPSEC-RID profile requires samples with a certain purity degree to avoid peak overlapping, overestimating the signal at each retention time. Samples were treated with ethanol, following the same protocol described above for polysaccharide concentration. Figure $3 \mathrm{~A}$ shows the chromatogram with elution profile for RID, 260nm and $280 \mathrm{~nm}$ (PRP elutes between 20 and $25 \mathrm{~min}$ ). Ethanol is not able to eliminate some low molecular weight impurities, which oversize the polysaccharide 
signal. To overcome this interference, samples were dialyzed prior to ethanol precipitation as shown in Fig.3B. Although the PRP peak is now visible, the lower molecular fraction of the polysaccharide population has been eluted with another compound that has signal both on the RID and at $405 \mathrm{~nm}$. In sequence, samples were treated with three enzymes (nuclease and proteases) in order to remove or reduce that interference [23] following by dialysis and ethanol precipitation (Fig.3C). Despite it has been unable to remove all of the 260/405 nm interference; the enzymatic hydrolysis was capable of removing the contaminant fraction that would elute together with the polysaccharide. Thus, enzymatic hydrolysis is a suitable method for clarifying samples from the fermented broth for satisfactory average molecular weight determination. Notwithstanding, the use of enzymes makes this procedure expensive and requires long incubation periods. An alternative treatment of the sample was done with CTAB precipitation (as described above) followed by two steps of ethanol precipitation to remove $\mathrm{CTAB}$ residues (Fig.3D). Figure 3E shows the evolution of the treatments applied to the cell free culture broth, in which both CTAB and enzymatic hydrolysis removed impurities in an extent that trustful molecular weight distribution can be drawn. Enzymatic hydrolysis is more expensive and time consuming, while CTAB is a simpler and faster method. The protocol established by using CTAB and ethanol can be applied for determining the molecular weight during the culture and purification for evaluating the integrity and stability of the product.

A

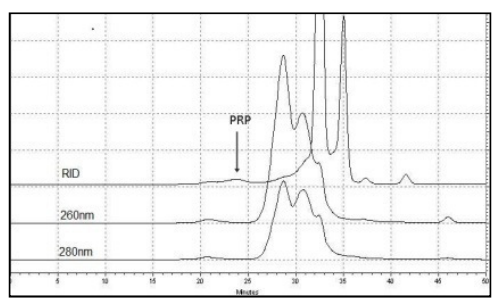

B

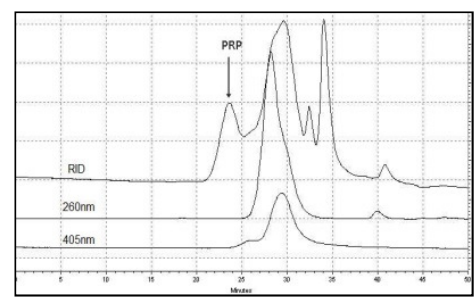

$\mathrm{C}$

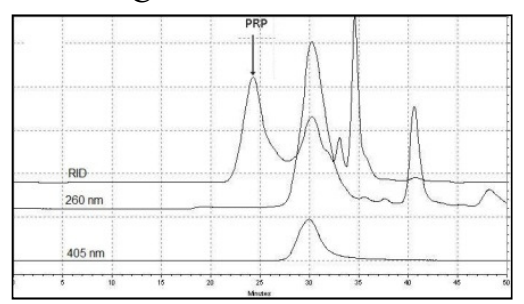

$\mathrm{D}$

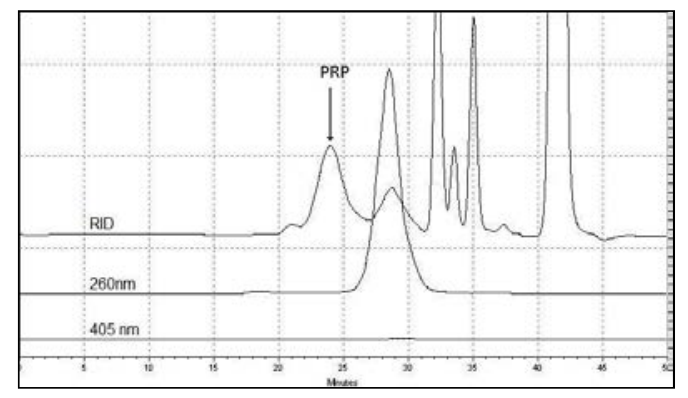

E

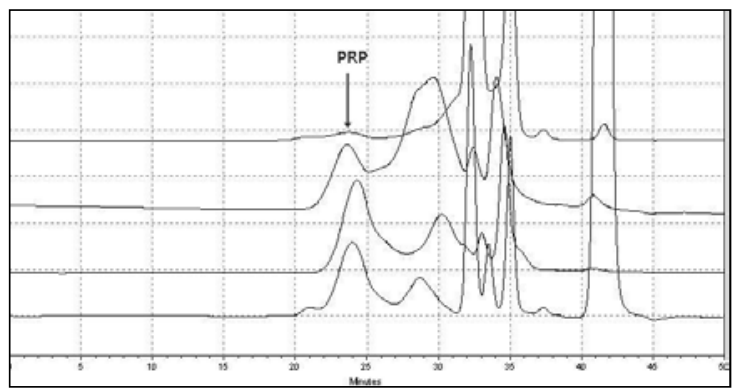

Fig. 3 HPSEC Chromatograms in different sample treatment method: A) Precipitation with ethanol 80\%; B) Dialysis followed by precipitation with ethanol $80 \%$; C) Enzymatic hydrolysis followed by dialysis and ethanol $80 \%$ precipitation; D) Precipitation with CTAB and ethanol 80\%; E) Comparison of elution profiles for PRP in all sample treatment methods.

\section{Conclusion}

Cell free culture broth samples were treated with $\mathrm{CTAB}$, a cationic surfactant, which removed more impurities than dialysis and ethanol treatments, with lower background of interferences resulting in a better quality of polysaccharide kinetic profile.

A simple, cheap and confident protocol was established by using CTAB for molecular weight determination through HPSEC, followed by ethanol precipitation in the cell free culture broth samples.

Acknowledgements Butantan Foundation for financial support and Mr. Lourivaldo Ignácio de Souza; Maximo de Moraes and Ms. Ana Maria Rodrigues Soares for technical assistance. 


\section{References}

[1] Kuhnert P, Christensen H (eds). Pasteurellaceae: Biology, Genomics and Molecular Aspects. Norfolk: Caister Academic Press, 2008.

[2] Shapiro ED, Ward JI. The epidemiology and prevention of disease caused by Haemophilus influenzae type b. Epidemiology. 1991;13:113-142.

[3] Goldblatt, D. Conjugate Vaccines. Clinical and. Experimental Immunology. 2000;119:1-3.

[4] Crisel RMO, Baker RS, Dorrman DE. Capsular polymer of Haemophilus influenzae, type b. I- Structural characterization of the capsular polymer of strain Eagan. Journal of Biological Chemistry. 1975;250:4926-4930.

[5] Ada G, Isaacs D. Carbohydrate-protein conjugate vaccines. Clinical Microbiology and Infectology. 2003;9:79-85.

[6] Breukels MA, Rijkers GT, Voorhorst-Ogink MA, Zegers BJM. Regulatory T cells in the antibody response to Haemophlus influenzae type b polysaccharide. Infectology and Immunology. 1999;67:789-793.

[7] Aanderson P, Pitt J, Smith DH. The synthesis and release of polyribophosphate by Haemophilus influenzae type b in vitro. Infectology and Immunology. 1976;13:581-589.

[8] Fildes P. The nature of the effect of blood-pigment upon the growth of $H$. influenzae. Brasilian Journal of Experimental Pathology. 1921;2:16.

[9] Lwoff A, Lwoff M. Studies on co-dehydrogenases. I. Nature of growth factor 'V'. Procedings of the Royal Society B, $1937 ; 122: 352$.

[10] Lwoff A, Lwoff M. Studies on co-dehydrogenases. II. Physiological function of growth factor ' $\mathrm{V}$ '. Procedings of the Royal Society B. 1937;122:360.

[11] Lwoff A, Lwoff M. Role physiologique de l'hemine pour $H$. influenzae Pfeiffer. Annales de l'Institut Pasteur. 1937;59:129.

[12] Carty CE, Mancinelli R, Hagopian A, Kovach FX, Rodriguez E, Burke P, Dunn NR, McAleer WL, Maigetter RZ, Kniskern P. Fermentation studies with Haemophilus influenzae. Developments in Industrial Microbiology. 1985;26:763-767.

[13] European Pharmacopeia. $3^{\text {rd }}$ ed. Supplement 1998.

[14] World Health Organization. Requirements for Haemophilus type b conjugate vaccines. Technical Report Series, $N^{\circ} 814$. Geneva, 1991.

[15] Laws AP, Leivers S, Chacon-Romero M, Chadha MJ. Variation in the molecular mass of exopolysaccharides during the time course of extended fermentations of skimmed milk by lactic acid bacteria. International Dairy Journal. 2009;19:768-771.

[16] Ashwell G. Colorimetric analysis of sugar. Methods Enzymology. 1957;3:87-90.

[17] Tranchepain F, Deschrevel B, Courel MN, Levasseur N, Le Cerf D, Loutelier-Bourhis C, Vincent JD. A complete set of hyaluronan fragments obtained from hydrolysis catalyzed by hyaluronidase: Application to studies of hyaluronan mass distribution by simple HPLC devices. Analytical Biochemistry. 2006;348:232-242.

[18] Bednar B, Hennessey Jr JP. Molecular size analysis of capsular polysacharid preparations from Streptococcus pneumoniae. Carbohydrate Research. 1993;243:115-130.

[19] Hoagland PD, Fishman ML, Konja G, Clausst E. Size Exclusion chromatography with viscosity detection of complex polysaccharides: component analysis. Journal of A griculture and Food Chemistry. 1993;41:1274-1281.

[20] Takagi M, Cabrera-Crespo J, Zangirolami TC, Raw I, Tanizaki MM. Improved cultivated conditions for polysaccharide production by $H$. influenzae type b. Journal Chemical Technology and Biotechnology. 2006;81:182-188.

[21] Gonçalves VM, Takagi M, Carneiro SM, Giordano RC, Tanizaki MM. Introduction of air in the anaerobic culture of Streptococcus pneumoniae serotype $23 \mathrm{~F}$ induces the release of capsular polysaccharide from bacterial surface into the cultivation medium. Journal of Applied Microbiology. 2006;101:1009-1014.

[22] Gonçalves VM, Takagi M, Lima RB, Massaldi H, Giordano RC, Tanizaki MM. Purification of capsular polysaccharide from Streptococcus pneumoniae serotype $23 \mathrm{~F}$ by a procedure suitable for scale-up. Biotechnology and Applied Biochemistry. 2003;37:283-287.

[23] Takagi M, Lima RB, Albani SMF, Zangirolami TR, Tanizaki MM, Cabrera-Crespo J. Purification of capsular polysaccharide produced by Haemophilus influenzae type b through a simple, efficient and suitable method for scaleup. Journal of Industrial Microbiology and Biotechnology. 2008;35:1217-1222.

[24] Merrit J, Allard G, Toole LO, Swartz R, Licari P. Development and scale-up of a fedbach process for the production of capsular polysaccharide from Haemophilus influenzae. Journal of Biotecnology. 2000;81:189-197.

[25] Kuo JSC, Doelling VW, Graveline JF, Mccoy DW. Evidence for covalent attachment of phospholipid to the capsular polysaccharide of Haemophilus influenzae type b. Journal of Bacteriology. 1985;163;769-773.

[26] Hamidi A, Beurret, MF. Process for producing a capsular polysaccharide for use in conjugate vaccines. US Patent 7,582,459 B2. 2009.

[27] Lucas EF, Soares BG, Monteiro EEC. Caracterização de polímeros: Determinação do peso molecular e análise térmica. Rio de Janeiro: E-papers; 2001.

[28] Li W, Han YC, Zhang JL, Wang LX, Song J. Thermodynamic modeling of CTAB Aggregation in water-ethanol mixed solvents. Colloid Journal. 2006;68:304-310.

[29] Biswas SC, Chattoraj DK. Polysaccharide-surfactant interaction: 1. Adsorption of cationic surfactants at the cellulosewater interface. Langmuir. 1997;13:4505-4511.

[30] Roopers MH, Novales B, Boué F, Axelos MAV. Polysaccharide/surfactant complexes at the air-water interface Effect of the charge density on interfacial and foaming behaviors. Langmuir. 2008;24:12849-12857. 


\title{
Study of the chemical stability of the capsular polysaccharide produced by Haemophilus influenzae type $\mathrm{b}$
}

\author{
Felipe de Oliveira Cintra, Mickie Takagi* \\ Laboratório de Desenvolvimento de Processos, Centro de Biotecnologia, Instituto Butantan, Brazil
}

\section{A R T I C L E I N F O}

\section{Article history:}

Received 31 December 2013

Received in revised form 13 March 2014

Accepted 3 April 2014

Available online 13 April 2014

\section{Keywords:}

PRP

Haemophilus influenzae type b

Alkaline transesterification

Polysaccharide depolymerization

Vaccine

\begin{abstract}
A B S T R A C T
Haemophilus influenzae type $\mathrm{b}(\mathrm{Hib})$ is a human pathogen that causes severe infections such as pneumonia, sepsis and meningitis. Vaccines for Hib infections are based on its capsular polysaccharide conjugated to a protein. This conjugated Hib antigen is included as one of the components of polyvalent vaccines and accounts for more than $50 \%$ of the total cost of the formulations. The instability of the polysaccharide is responsible for the high cost of the vaccine. In this study, the factors affecting the spontaneous degradation of the polysaccharide from Hib were evaluated based on the decrease in its molecular mass, as measured by size-exclusion chromatography. Temperature and $\mathrm{pH}$ were found to be the most significant variables, and the results showed that the conditions of bacterial cell growth $\left(37^{\circ} \mathrm{C}\right.$ and $\left.\mathrm{pH} 7.5\right)$ are favourable for depolymerization. An increase in the concentration of sodium ions up to $200 \mathrm{mM}$ intensified the effect of $\mathrm{pH}$, allowing higher rates of depolymerization at lower $\mathrm{pH}$ values, whereas the presence of magnesium ions showed no effects.
\end{abstract}

(C) 2014 Elsevier Ltd. All rights reserved.

\section{Introduction}

Haemophilus influenzae type $\mathrm{b}(\mathrm{Hib})$ is a human pathogen associated with various health complications such as pneumonia, sepsis and meningitis, mainly in children under two years of age and immunocompromised individuals (Wilfert, 1990). Vaccination against Hib was introduced in 1987 in North America and, in the rest of the developed world in the 1990s and is currently being extended to developing countries by international organizations, such as the Global Alliance for Vaccine Innovation (GAVI) and the United Nations Children's Fund (UNICEF) (Bisgard et al., 1998; GAVI, 2013; WHO, 2013). Today, the World Health Organization (WHO) recommends the use of polyvalent formulations, which combine the Hib antigen with the Diphteria-Tetanus-Pertussis (DTP) vaccine (tetravalent) or both DTP and Hepatitis B (HepB) vaccines (pentavalent). However, the inclusion of the Hib antigen increases the cost of the polyvalent vaccines, in fact, it; represent more than half of the overall cost per dose of the formulation (UNICEF, 2013).

One of the major factors contributing to the high cost of the Hib vaccine is the inherent instability of the polysaccharide molecule. It has been demonstrated that the polysaccharide molecule of Hib undergoes spontaneous degradation under certain ambient conditions, and a molecular mass decrease has been observed during

\footnotetext{
* Corresponding author at: Av Vital Brasil, 1500, Butantã, CEP 05503-900, São Paulo, SP, Brazil. Tel.: +55 1127269720 .

E-mail address: mickie.takagi@butantan.gov.br (M. Takagi).
}

the cell growth steps (Egan, Schneerson, Werner, \& Zon, 1982; Sturgess et al., 1999). The instability and consequent molecular mass decrease of the polymer has great significance on the final global productivity of the vaccine because many steps of the most recent purification and conjugation processes are based on ultrafiltration (Albani, da Silva, Takagi, \& Cabrera-Crespo, 2012; Takagi et al., 2008).

The Hib vaccine is composed of a polysaccharide-protein conjugate, and the polysaccharide is the molecule present in the extracellular capsule of the bacterium. The capsular polysaccharide of Hib is formed by units of ribosyl-ribitol, that are linked together by a phosphodiester linkage, denominated poly-ribosylribitol-phosphate, PRP (Egan et al., 1982).

The chemical structure of PRP is responsible for its natural instability. As shown in Fig. 1, the PRP molecule is structurally similar to the molecule of RNA: the hydroxyl at the carbon 2 of ribose is located in the proximity of the phosphate group, and in the presence of free hydroxyls in the milieu this carbon undergoes transesterification and consequent depolymerization (Egan et al., 1982). In the case of RNA, this reaction is not only affected by the concentration of hydroxyls, but also by the presence of mono and divalent metal ions, such as potassium and magnesium, which are capable of stabilizing the reactive form of the hydroxyl from ribose by reducing its pKa of ionization, by facilitating proton transfer or by acting as a Lewis acid catalyst (Li \& Breaker, 1999).

Through their analysis of the PRP molecule, Egan et al. (1982) demonstrated that ions of sodium and calcium do not become strongly associated with the polysaccharide chain, even though the 


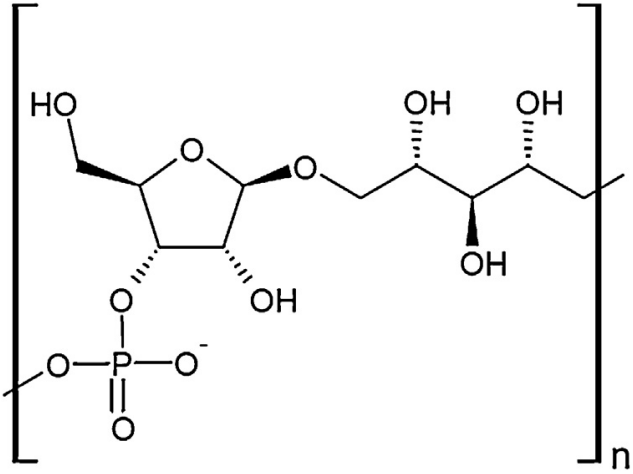

Fig. 1. Chemical structure of the poly-ribosyl-ribitol-phosphate repetitive unit.

divalent cation is indeed capable of catalysing the transesterification reaction and the monovalent cation has a significant effect on the rate of depolymerization.

The study of the depolymerization rate of PRP as functions of ambient conditions, such as $\mathrm{pH}$, temperature, and ions concentrations, is of great importance to the search for vaccine production processes that are less expensive and economically viable. During all stages of production, i.e., cell growth, purification and chemical conjugation, the molecule is exposed to specific conditions that may promote chain cleavage. In the PRP production process, cell growth is conducted at a mildly alkaline pH of 7.5 (Takagi, Cabrera-Crespo, Zangirolami, Raw, \& Tanizaki, 2006), demanding the addition of sodium hydroxide for $\mathrm{pH}$ control and thus increasing the concentration of monovalent cations. In the purification step, proteolytic enzymes and endonucleases are used for the removal of proteins and nucleic acids, and this reaction is conducted in the presence of magnesium ions at higher $\mathrm{pH}$ values (Albani et al., 2012).

Under these premises, this work proposes the study and quantification of the depolymerization rate of PRP by the measurement of molecular mass decrease, regarding the effects of $\mathrm{pH}$, temperature and, sodium and magnesium cations concentration.

\section{Materials and methods}

\subsection{Preparation of $P R P$}

Strain GB3291 of H. influenzae type b was purchased from Instituto Adolpho Lutz (São Paulo, Brazil). The cells were cultivated in $15 \mathrm{~L}$ of the Modified Medium Peptone (MMP) described by Takagi et al. (2006) in a BioFlo 5000 bioreactor (New Brunswick Scientific Co., USA), until all of the glucose was consumed, as measured using at Bioliquid glicose colorimetric enzymatic kit (Laborclin LTDA, Brazil). At this point, the feeding of a concentrated solution of glucose and yeast extract (20\% each) at a constant flow rate of $1.2 \mathrm{~L} \mathrm{~h}^{-1}$ was initiation, and this feeding was ended when the total volume in the reactor reached $60 \mathrm{~L}$. Throughout the cultivation, the $\mathrm{pH}$ was controlled at 7.50 with $5 \mathrm{M} \mathrm{NaOH}$, the temperature was maintained at $37^{\circ} \mathrm{C}$, the air flow rate was controlled at $15 \mathrm{Lmin}^{-1}$, and the dissolved oxygen was maintained at $30 \%$ of the saturation by controlling the agitation speed, which ranged from 100 to $500 \mathrm{rpm}$. The cells were separated from the culture broth in a continuous tubular centrifuge with automatic piston discharge (APD75 Celeros Inc, USA) at $20,000 \mathrm{~g}$ and $4{ }^{\circ} \mathrm{C}$ with a feed flow rate of approximately $200 \mathrm{~mL} \mathrm{~min}^{-1}$. The isolation of PRP from the supernatant was performed by a series of diafiltrations on $100 \mathrm{kDa}$ cut-off membranes, ethanol precipitations and enzymatic hydrolysis, as described by Albani et al. (2012). The final purified PRP was lyophilized and stored at $-20^{\circ} \mathrm{C}$ until use.
Table 1

Values of the variables at different levels in the $2^{4}$ RCCD for the analysis of PRP stability.

\begin{tabular}{lccrrr}
\hline Variables & \multicolumn{6}{l}{ Levels } & \multicolumn{1}{l}{} \\
\cline { 2 - 6 } & \multicolumn{1}{c}{-1} & \multicolumn{1}{c}{0} & \multicolumn{1}{c}{1} & \multicolumn{1}{c}{2} \\
\hline $\mathrm{NaCl}(\mathrm{mM})$ & 0 & 50 & 100 & 150 & 200 \\
$\mathrm{MgCl}(\mathrm{mM})$ & 0 & 0.75 & 1.50 & 2.25 & 3.00 \\
$\mathrm{pH}$ & 5.00 & 5.75 & 6.50 & 7.25 & 8.00 \\
$T\left({ }^{\circ} \mathrm{C}\right)$ & 25.00 & 28.75 & 32.50 & 36.25 & 40.00 \\
\hline
\end{tabular}

\subsection{Experimental design}

A rotational central composite design (RCCD) was used for the study of the effects of the four variables $\left(2^{4}\right)$, namely $\mathrm{pH}$, temperature $(T)$ and, the molarity of $\mathrm{NaCl}$ and $\mathrm{MgCl}_{2}$ according to Table 1 . The central point was performed in duplicate. The experiments were analysed using the STATISTICA ${ }^{\circledR} 11$ software.

\subsection{Measurement of PRP depolymerization rate}

The solutions of PRP were prepared to obtain a concentration of $1000 \mathrm{mg} \mathrm{L}^{-1}$ and incubated in a water bath at the conditions specified by the experimental design. Samples were collected over time for the measurement of the number average molecular mass $\left(M_{\mathrm{n}}\right)$. The $M_{\mathrm{n}}$ was measured by high-performance size exclusion chromatography (HPSEC) using two serially connected $30 \mathrm{~cm}$ TKS Gel GMPWxl columns (TOSOH Bioscience, Japan). The chromatography was performed on a Shimadzu HPLC system, composed of an isocratic pump (10ADVp), a column oven (CTO-10ASvp), an autosampler (SIL-10ADvp), a refraction index (RI) detector (RID$10 \mathrm{~A})$, a system control unit (SCL-10AVp) and the Class VP version 6.2 software for data acquisition (Shimadzu Corp., Japan). A frequency of $2 \mathrm{~Hz}$ was used for the collection of the elution data. The mobile phase consisted of a solution of $150 \mathrm{mM} \mathrm{NaCl}, 10 \mathrm{mM}$ $\mathrm{Na}_{2} \mathrm{HPO}_{4}$, and $0,02 \% \mathrm{NaN}_{3}$, $\mathrm{pH}$ of which was adjusted to 7.50 using $6 \mathrm{M} \mathrm{HCl}$; this solution was pumped at a rate of $0.6 \mathrm{~mL} \mathrm{~min}^{-1}$, and the temperature of the column and the detector cell were maintained at $40^{\circ} \mathrm{C}$. The injection volume of all of the samples was $50 \mu \mathrm{L}$. Under these parameters, the exclusion volume/time of the system was determined to be $21.85 \mathrm{~min}$ or $13.11 \mathrm{~mL}$ with Blue Dextran (Fluka Analytical, Sweden), whereas the total permeation volume/time was determined to be $35.00 \mathrm{~min}$ or $21 \mathrm{~mL}$ with dextrose; both reagents were prepared at a concentration of $1 \mathrm{~g} \mathrm{~L}^{-1}$. The elution time of the polysaccharide was converted into values of molecular mass through a linear correlation between the elution times of low-dispersity dextrans and the logarithm of their known molecular mass; six dextran standards with nominal molecular mass $\left(M_{\mathrm{p}}\right)$ values of $1.5,6,10,40,70$ and $229 \mathrm{kDa}$ were used (Fluka Analytical, Sweden). The data were then used to calculate the number average molecular mass $\left(M_{\mathrm{n}}\right)$ using Eq. (1) and the mass average molecular mass $\left(M_{\mathrm{w}}\right)$ using Eq. (2), where $h_{i}$ is the height of the chromatographic signal and $M_{i}$ is the molecular mass value relative to the elution time of fraction $i$ (Meunier, 1997). The ratio between the two averages, $M_{\mathrm{w}} / M_{\mathrm{n}}$, was defined as the dispersity $Ð$ of the distribution (Stepto, 2009).

$M_{\mathrm{n}}=\frac{\sum h_{i}}{\sum h_{i} / M_{i}}$

$M_{\mathrm{w}}=\frac{\sum h_{i} M_{i}}{\sum h_{i}}$

For the estimation of the rate of depolymerization, a linear curve was fitted to the plot of the inverse of the $M_{\mathrm{n}}$ values as a function of time. Based on the theory of random scission of polymers, the angular coefficient of this curve is proportional to the rate of 
Table 2

Real and codified values of the variables studied in the $2^{4}$ RCCD.

\begin{tabular}{|c|c|c|c|c|c|c|c|c|c|}
\hline \multirow[t]{2}{*}{ Assay } & \multicolumn{4}{|l|}{ Real values } & \multicolumn{4}{|c|}{ Codified values } & \multirow{2}{*}{$\begin{array}{l}\text { Depolymerization } \\
\text { rate }\left(\times 10^{-6} \mathrm{~h}^{-1}\right)\end{array}$} \\
\hline & $\mathrm{Na}^{+}(\mathrm{mM})$ & $\mathrm{Mg}^{2+}(\mathrm{mM})$ & $\mathrm{pH}$ & $T\left({ }^{\circ} \mathrm{C}\right)$ & $\mathrm{Na}^{+}$ & $\mathrm{Mg}^{2+}$ & $\mathrm{pH}$ & $T\left({ }^{\circ} \mathrm{C}\right)$ & \\
\hline 1 & 150 & 2.25 & 6.88 & 36.25 & 1 & 1 & 0.75 & 1 & 6.291 \\
\hline 2 & 150 & 2.25 & 6.88 & 28.75 & 1 & 1 & 0.75 & -1 & 0.950 \\
\hline 3 & 150 & 2.25 & 5.66 & 36.25 & 1 & 1 & -1.53 & 1 & 1.965 \\
\hline 4 & 150 & 2.25 & 5.66 & 28.75 & 1 & 1 & -1.53 & -1 & 0.000 \\
\hline 5 & 150 & 0.75 & 6.91 & 36.25 & 1 & -1 & 0.80 & 1 & 5.167 \\
\hline 6 & 150 & 0.75 & 6.91 & 28.75 & 1 & -1 & 0.80 & -1 & 0.970 \\
\hline 7 & 150 & 0.75 & 5.65 & 36.25 & 1 & -1 & -1.55 & 1 & 1.360 \\
\hline 8 & 150 & 0.75 & 5.65 & 28.75 & 1 & -1 & -1.55 & -1 & 0.000 \\
\hline 9 & 50 & 2.25 & 7.03 & 36.25 & -1 & 1 & 1.03 & 1 & 6.036 \\
\hline 10 & 50 & 2.25 & 7.03 & 28.75 & -1 & 1 & 1.03 & -1 & 1.224 \\
\hline 11 & 50 & 2.25 & 5.76 & 36.25 & -1 & 1 & -1.35 & 1 & 1.326 \\
\hline 12 & 50 & 2.25 & 5.76 & 28.75 & -1 & 1 & -1.35 & -1 & 0.000 \\
\hline 13 & 50 & 0.75 & 7.07 & 36.25 & -1 & -1 & 1.10 & 1 & 4.521 \\
\hline 14 & 50 & 0.75 & 7.07 & 28.75 & -1 & -1 & 1.10 & -1 & 1.600 \\
\hline 15 & 50 & 0.75 & 5.82 & 36.25 & -1 & -1 & -1.23 & 1 & 1.766 \\
\hline 16 & 50 & 0.75 & 5.82 & 28.75 & -1 & -1 & -1.23 & -1 & 0.217 \\
\hline 17 & 200 & 1.5 & 6.18 & 32.5 & 2 & 0 & -0.56 & 0 & 0.273 \\
\hline 18 & 100 & 3 & 6.27 & 32.5 & 0 & 2 & -0.39 & 0 & 0.437 \\
\hline 19 & 100 & 1.5 & 7.55 & 32.5 & 0 & 0 & 2.00 & 0 & 10.607 \\
\hline 20 & 100 & 1.5 & 6.3 & 40 & 0 & 0 & -0.34 & 2 & 3.782 \\
\hline 21 & 0 & 1.5 & 6.55 & 32.5 & -2 & 0 & 0.13 & 0 & 0.282 \\
\hline 22 & 100 & 0 & 6.33 & 32.5 & 0 & -2 & -0.28 & 0 & 0.127 \\
\hline 23 & 100 & 1.5 & 5.41 & 32.5 & 0 & 0 & -2.00 & 0 & 0.453 \\
\hline 24 & 100 & 1.5 & 6.29 & 25 & 0 & 0 & -0.36 & -2 & 0.171 \\
\hline 25 & 100 & 1.5 & 6.28 & 32.5 & 0 & 0 & -0.37 & 0 & 0.000 \\
\hline 26 & 100 & 1.5 & 6.28 & 32.5 & 0 & 0 & -0.37 & 0 & 0.000 \\
\hline
\end{tabular}

polymerization, as visualized from Eq. (3), where $M_{n 0}$ is the value of $\mathrm{M}_{\mathrm{n}}$ at the start of the experiment, $k$ is the rate of the depolymerizing reaction, and $m_{0}$ is the molecular mass of the repetitive unit of the polymer (Bradley \& Mitchell, 1988). In the case of PRP, $m_{0}$ is the molecular mass of the ribosyl-ribitol-phosphate unit and is equal to $345.22 \mathrm{Da}$.

$\frac{1}{M_{\mathrm{n}}}=\frac{1}{M_{\mathrm{n} 0}}+\frac{k}{2 m_{0}} t$

\section{Results and discussion}

The capsular polysaccharide from Hib, PRP, was produced through a fed-batch process and purified by ultrafiltration technology, ethanol precipitation and enzymatic hydrolysis with an overall recovery ratio of approximately $23 \%$ in terms of polysaccharide. For the molecular mass characterization of this polysaccharide, the necessary calibrations of the size-exclusion column were made using standard dextrans. The elution profile of six dextran standards is illustrated in Fig. 2A; the correlation of the elution time and the logarithm of the molecular weight of the standards is shown to be linear in Fig. 2B; and was used to determine the relative molecular weight of our samples.

The purified PRP was characterized as having an initial number average molecular mass of approximately $275 \mathrm{kDa}$, with a dispersity value not greater than 1.45 . The lyophilized polysaccharide was solubilized in solutions of known $\mathrm{pH}$, which was controlled with equimolar solutions of $\mathrm{Na}_{2} \mathrm{HPO}_{4}$ and $\mathrm{NaH}_{2} \mathrm{PO}_{4}(10 \mathrm{mM})$, and with known $\mathrm{NaCl}$ and $\mathrm{MgCl}_{2}$ molarities. A total of 26 solutions were prepared, according to the variations proposed by the $2^{4}$ RCCD. However, the solubilization of the lyophilized PRP had the effect of altering the $\mathrm{pH}$ of the solution, despite the presence of the phosphate buffer. This behaviour was observed due to presence of a phosphate group in the PRP molecule, which may change the ionization of the free phosphate groups. Therefore, the real $\mathrm{pH}$ values of the prepared solutions were directly measured, and the values were then rescaled into the codified values under the range from
-2 to +2 . Table 2 shows the final configuration of the experimental design, with the real $\mathrm{pH}$ values and the four codified variables.

Each of the 26 solutions were incubated at the determined temperature and sampled at progressive time intervals. The $M_{\mathrm{n}}$ was immediately measured, and the curve of $1 / M_{\mathrm{n}}$ was used to estimate the rate of transesterification of the phosphodiester linkage. This rate is also shown in Table 2, for each of the conditions tested. A quadratic model was considered for each of the four variables tested, and one-by-one interactions between them were also considered. The coefficients were tested for statistical significance by taking the standard error from the linear regression and building a $t$ statistic. A level of significance of 0.05 was initially considered to account for significant effects. The effects considered significant and their statistics are listed in Table 3.

The global quadratic model, which accounted for four linear effects, four quadratic effects, six interactions and one intercept, had many insignificant variables. These were removed one by one, starting from the least significant, i.e., from the one with the smallest absolute value for the $t$ statistic. Through this process the model can be reduced to a simpler model in which all of the coefficients with the exception of one were under the level of significance. As detailed in Table 2, the coefficient related to the effect of $\mathrm{Na}^{+}$molarity in this simplified model has a $p$-value of 0.082 , which is above the level of significance. Although, we observed that the removal of this coefficient decreased the overall quality of the model. In fact,

Table 3

Coefficients and statistical significance of the factors considered for PRP depolymerization.

\begin{tabular}{lllcr}
\hline Factor & Coefficient & Error & $t$ statistic (18) & $p$-Value \\
\hline$\left[\mathrm{Na}^{+}\right]$(Linear) & $4.30 \mathrm{E}-07$ & $2.34 \mathrm{E}-07$ & 1.84 & 0.082 \\
$\mathrm{pH}$ (linear) & $2.78 \mathrm{E}-06$ & $2.10 \mathrm{E}-07$ & 13.19 & $<0.001$ \\
$T$ (linear) & $2.08 \mathrm{E}-06$ & $2.34 \mathrm{E}-07$ & 8.90 & $<0.001$ \\
{$\left[\mathrm{Na}^{+}\right]$vs. pH } & $4.98 \mathrm{E}-07$ & $2.36 \mathrm{E}-07$ & 2.11 & 0.049 \\
$\mathrm{pH}$ vs. T & $8.37 \mathrm{E}-07$ & $2.34 \mathrm{E}-07$ & 3.58 & 0.002 \\
$\mathrm{pH}$ (quadratic) & $1.81 \mathrm{E}-06$ & $2.09 \mathrm{E}-07$ & 8.69 & $<0.001$ \\
$T$ (quadratic) & $6.44 \mathrm{E}-07$ & $2.22 \mathrm{E}-07$ & 2.91 & 0.009 \\
\hline
\end{tabular}



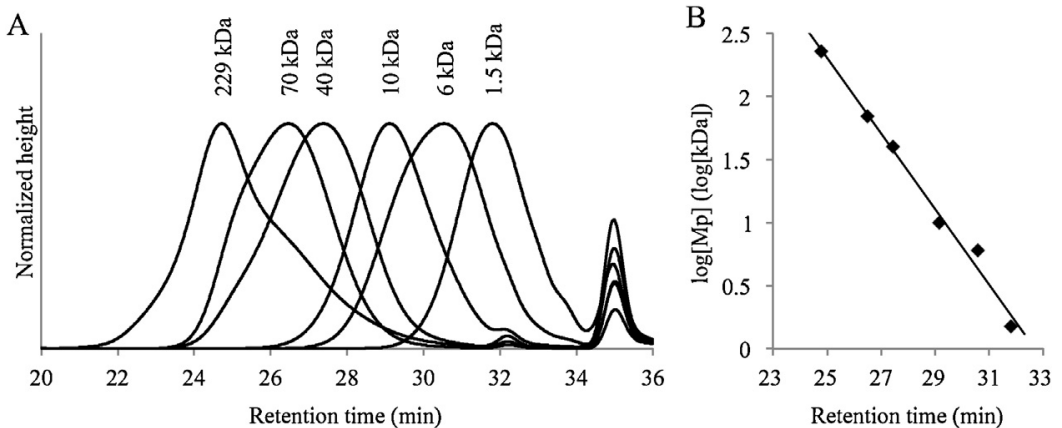

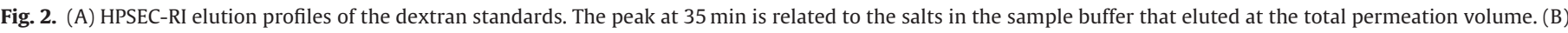
Linear correlation between the retention times and the logarithm of the molecular weights of the dextran standards.

the removal of this coefficient increased the $p$-value of the interaction between the molarity of $\mathrm{Na}$ and $\mathrm{pH}$ from 0.049 to 0.121 , thereby considerably surpassing the level of significance. Additionally, both the normality of the residuals and the adjusted coefficient of correlation decreased. Based on this scenario, we chose to tolerate a higher level of significance for the model to include the effect of the molarity of $\mathrm{Na}^{+}$. Therefore, the experimental data may provide detailed insights into the factors that contribute to PRP depolymerization. The $\mathrm{pH}$, temperature $(T)$ and molarity of $\mathrm{Na}^{+}$ were characterized as significant, whereas the molarity of $\mathrm{Mg}^{2+}$ did not appear to have an effect.

The most significant variables, namely the $\mathrm{pH}$ and temperature, were expected to show significance. Fig. 3 shows the response surface for these two variables, at a constant $\mathrm{Na}^{+}$molarity of $100 \mathrm{mM}$. Over the range of values studied, it becomes clear that the depolymerization rate is increased at $\mathrm{pH}$ values over neutrality; and always increases with increases in temperature. At more acidic $\mathrm{pH}$ values, e.g., at $\mathrm{pH}$ values less than 6.5 , depolymerization is virtually non-existent. The quadratic model does predict an increase in the rate of reaction in the acidic direction, although it may be argued that it represents a lack of fit in this region because experimental values are not available.

The effect of $\mathrm{Na}^{+}$molarity can be visualized through its interaction with $\mathrm{pH}$, as shown in Fig. 4. The presence of these monovalent ions shift the response surface toward the acidic region. The analysis of the lines at a given $\mathrm{pH}$ shows, that an increase the concentration of sodium ions increases the rate of depolymerization, i.e., the monovalent cation increases the action of the hydroxyls in the alkaline catalysis process. This finding is consistent with a previous description of the action of potassium cations on the rate of transesterification of RNA. A monovalent ion may act by stabilizing the reactive form of the hydroxyl at carbon 2 from ribose, and by reducing the pKa of ionization of this group (Li \& Breaker, 1999).

The effect of $\mathrm{Mg}^{2+}$ molarity, despite being well characterized for the depolymerization of RNA, showed no statistical significance in this experiment. In the study reported by Li and Breaker (1999), the effect of this cation was assayed at higher $\mathrm{pH}$ values, in the range from 8.5 to 10.0. At lower $\mathrm{pH}$ values, i.e., in the range studied here, the effect may be not observable. Furthermore, Egan et al. (1982) reported that divalent calcium ions do not associate intimately with PRP, which is contrary to what is observed for other polyelectrolytes, and this finding may also be true for magnesium. These researchers also reported that the presence of sodium reduces the catalytic activity of calcium. In a study of RNA depolymerization, Li and Breaker (1999) also observed a reduction in the catalytic activity of magnesium due to the presence of potassium and therefore; argued that the monovalent ion may shield the phosphate group from association with the divalent ion. In our experimental design, no experiment was conducted with the presence of magnesium alone, i.e., in the absence of sodium. Thus, we may suggest that the catalytic activity of magnesium on the depolymerization of PRP was not observed due to both the presence of sodium cations and the low range of $\mathrm{pH}$ values studied.

The characterization of the main factors that contribute to depolymerization and the quantification of the rates of reaction as functions of these factors are important for the optimization and cost minimization of Hib vaccine production. In the upstream process, cell growth has limited productivity due to the
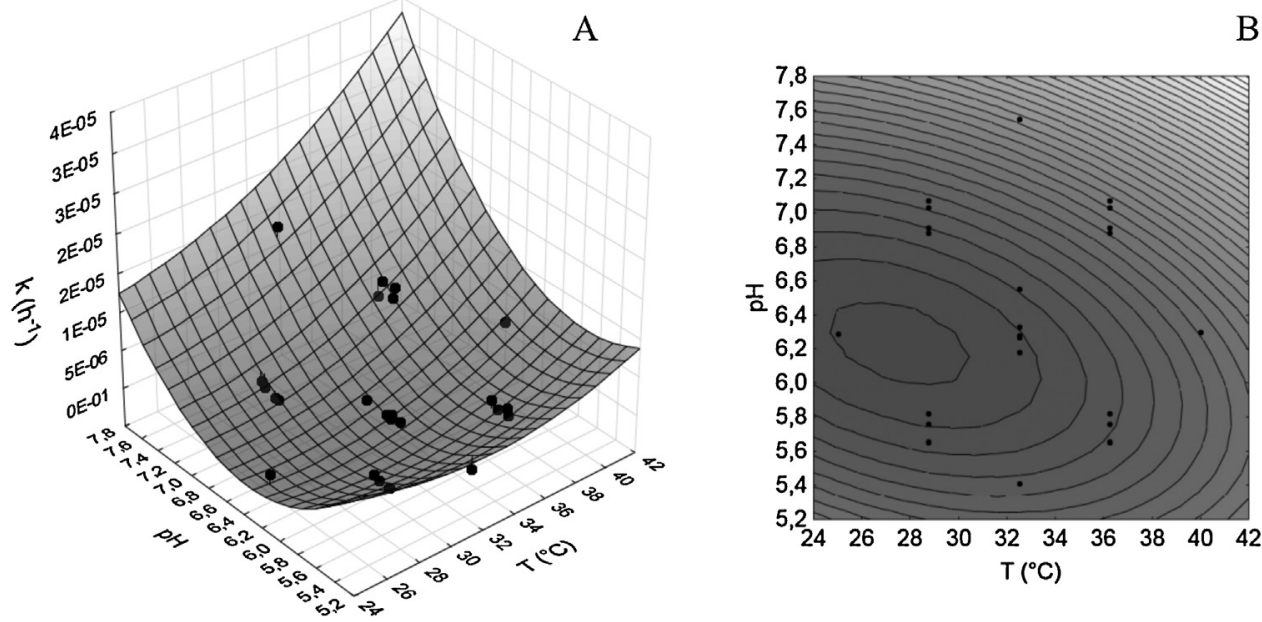

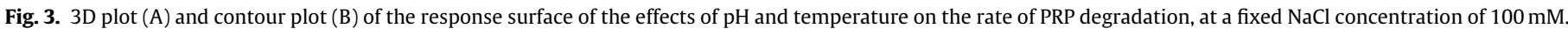




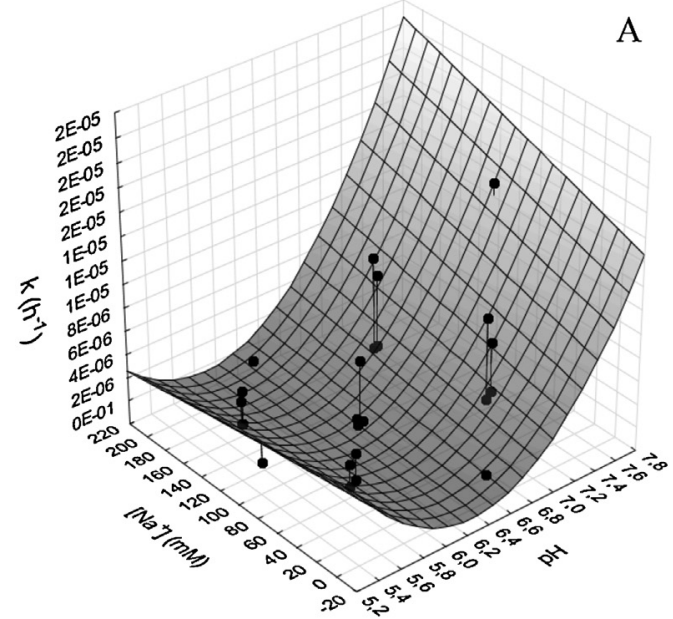

A

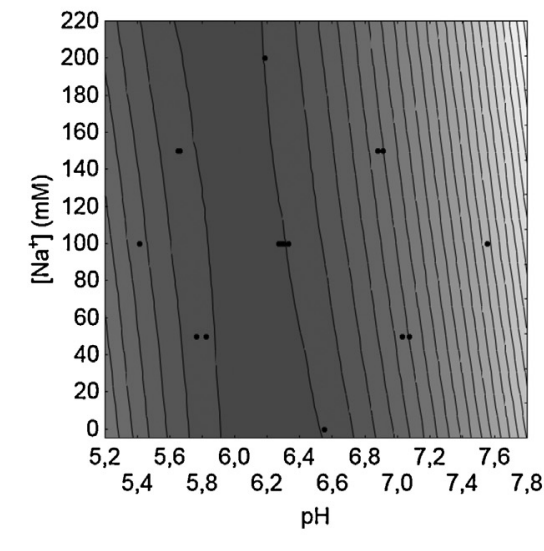

Fig. 4. 3D plot (A) and contour plot (B) of the response surface of the effects of $\mathrm{pH}$ and $\mathrm{NaCl}$ on the rate of PRP degradation, at a fixed temperature of $32.5{ }^{\circ} \mathrm{C}$.
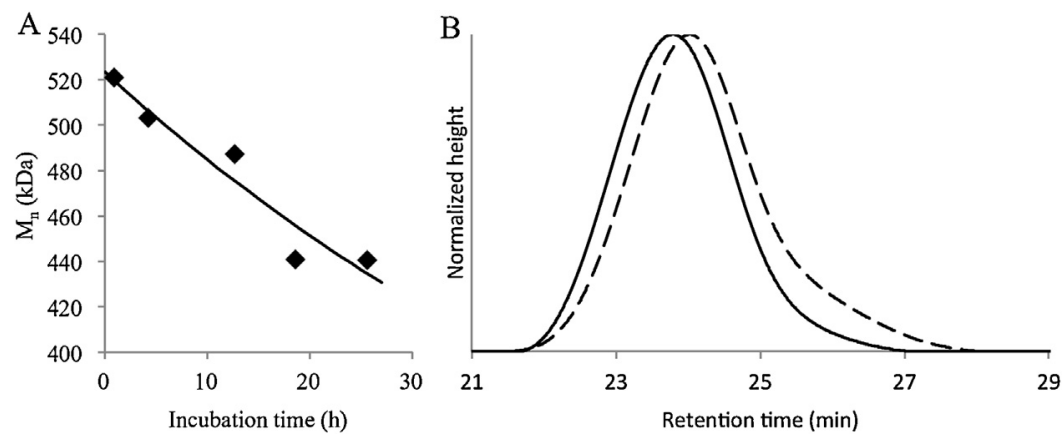

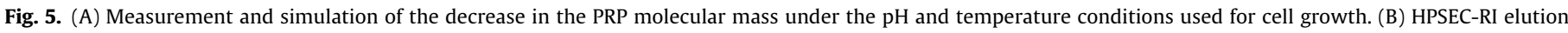

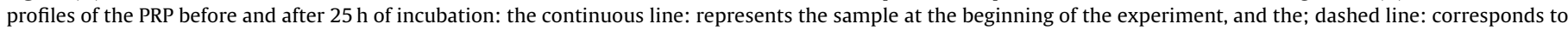
the sample at the end of the experiment.

fastidious nature of the bacterium's metabolic network, which limits the total PRP formation. The processes described in the literature for this step cite the use of mildly alkaline $\mathrm{pH}$ values, such as 7.30 and 7.50 , the use of physiological temperatures $\left(36-37^{\circ} \mathrm{C}\right.$ ) and the addition, of large quantities of $\mathrm{NaOH}$ (up to $900 \mathrm{mM}$ in the final broth) during the cell growth for the control of the $\mathrm{pH}$ (Merritt, Allard, O’Toole, Swartz, \& Licari, 2000; Takagi et al., 2006). Based on the results of this study, it is clear that these conditions are unfavourable for the stability of the PRP molecule. The ongoing depolymerization of PRP during cell growth shall result in a final product with a low molecular mass, which directly affects the purification process based on ultrafiltration technology. In our laboratory, we observed that long fed-batch cultivations resulted in a final PRP molecule with a molecule weight of less than $300 \mathrm{kDa}$ (data not shown).

To illustrate the severity of this issue, the conditions of cell

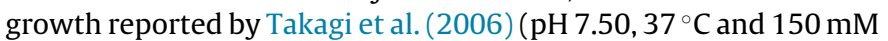
$\mathrm{NaCl}$ ) were replicated. A different sample of purified PRP, with a starting $M_{\mathrm{n}}$ value of $521 \mathrm{kDa}$ and a $Ð$ value of 1.31 , was incubated under these conditions using the same protocol that used for the experimental design. As shown in Fig. 5A, a decrease in the molecular mass was observed, which simulates the phenomenon that occurs in the bioreactor. During a period of $24 \mathrm{~h}$, which is a reasonable duration of a fed-batch process, the molecular mass was observed to decrease by approximately $16 \%$ with an overall depolymerization rate of $1.054 \times 10^{-5} \mathrm{~h}^{-1}$, as calculated using Eq. (3). Fig. 5B illustrates the elution profile of this sample at the beginning and end of the depolymerization reaction. As shown, it is possible to observe that the depolymerization process is responsible for shifting the whole distribution toward an increased retention time and; thus a lower molecular mass. It is also possible to observe increases in the fraction of smaller molecules in the population and its dispersity, which showed a value of 1.36 at the end of the assay.

\section{Conclusion}

By introducing an ultrafiltration-based PRP purification process, Albani et al. (2012), observed that low recovery ratios, (in the order of less than 25\%), are correlated with the duration of the cell growth step. These researchers used, a long fed-batch process, which resulted in the production of a relatively high quantity of PRP. However approximately half of the material was lost during the first ultrafiltration step. As quantified in this work is explained by the inherent instability of the molecule; associated with the cultivation conditions used. In addition, this instability is responsible for shifting the whole distribution of the polysaccharide toward a lower molecular mass and for increasing the fraction of smaller molecules in the population, which can be easily lost in ultrafiltration processes. In conclusion, we conclude that the conditions used during cell growth, mainly $\mathrm{pH}$ and temperature, must be changed to avoid the spontaneous degradation observed. Similarly, the conditions used for the purification process should also be adapted based on the influence of $\mathrm{pH}$, temperature, and sodium ions on PRP stability to achieve higher recovery ratios in the downstream processes. 


\section{Acknowledgments}

We gratefully acknowledge the financial support provided by the Butantan Foundation and BNDES ( $\mathrm{N}^{\circ}$ 11.2.0322.1/2012). We also thank Mr. Lourivaldo Inácio de Souza and Ms Ana Maria Soares Rodrigues for the technical assistance.

\section{Appendix A. Supplementary data}

Supplementary material related to this article can be found, in the online version, at http://dx.doi.org/10.1016/j.carbpol. 2014.04.004.

\section{References}

Albani, S. M. F., da Silva, M. R., Takagi, M., \& Cabrera-Crespo, J. (2012). Improvement in the purification process of the capsular polysaccharide from Haemophilus influenzae type b by using tangential ultrafiltration and diafiltration. Applied Biochemistry and Biotechnology, 167(7), 2068-2075.

Bisgard, K. M., Kao, A., Leake, J., Strebel, P. M., Perkins, B. a., \& Wharton, M. (1998). Haemophilus influenzae invasive disease in the United States, 1994-1995: Near disappearance of a vaccine-preventable childhood disease. Emerging Infectious Diseases, 4(2), 229-237.

Bradley, T. D., \& Mitchell, J. R. (1988). The determination of the kinetics of polysaccharide thermal degradation using high temperature viscosity measurements. Carbohydrate Polymers, 9(4), 257-267.

Egan, W., Schneerson, R., Werner, K. E., \& Zon, G. (1982). Structural studies and chemistry of bacterial capsular polysaccharides. Investigations of phosphodiester-linked capsular polysaccharides isolated from Haemophilus influenzae types a, b, c, and f: NMR spectroscopic identification and chemical modification. Journal of the American Chemical Society, 104(10), 2898-2910.

GAVI. (2013). Hib vaccine. Retrieved from http://www.gavialliance.org/support/ nvs/hib/

Li, Y., \& Breaker, R. R. (1999). Kinetics of RNA degradation by specific base catalysis of transesterification involving the 2'-hydroxyl group. Journal of the American Chemical Society, 121(23), 5364-5372.

Merritt, J., Allard, G., O’Toole, L., Swartz, R., \& Licari, P. (2000). Development and scale-up of a fed-batch process for the production of capsular polysaccharide from Haemophilus influenzae. Journal of Biotechnology, 81(2-3), 189-197.

Meunier, D. M. (1997). Molecular weight determinations. In F. A. Settle (Ed.), Handbook of instrumental techniques for analytical chemistry (pp. 853-866). Upper Saddle River: Prentice-Hall.

Stepto, R. F. T. (2009). Dispersity in polymer science (IUPAC recommendations 2009). Pure and Applied Chemistry, 81(2), 351-353.

Sturgess, A. W., Rush, K., Charbonneau, R. J., Lee, J. I., West, D. J., Sitrin, R. D. et al. (1999). Haemophilus influenzae type b conjugate vaccine stability: Catalytic depolymerization of PRP in the presence of aluminum hydroxide. Vaccine 17(9-10), 1169-1178.

Takagi, M., Cabrera-Crespo, J., Zangirolami, T. C., Raw, I., \& Tanizaki, M. M. (2006). Improved cultivation conditions for polysaccharide production by $H$. influenzae type b. Journal of Chemical Technology E' Biotechnology, 81(2), 182-188.

Takagi, M., Lima, R. B., Albani, S. M. F., Zangirolami, T. C., Tanizaki, M. M., \& Cabrera-Crespo, J. (2008). Purification of capsular polysaccharide produced by Haemophilus influenzae type b through a simple, efficient and suitable method for scale-up. Journal of Industrial Microbiology E' Biotechnology, 35(11), 1217-1222.

UNICEF. (2013). Vaccine Price Data. Retrieved from http://www.unicef.org/ supply/index_57476.html

WHO. (2013). Immunization surveillance, assessment and monitoring. Retrieved from http://www.who.int/immunization_monitoring/diseases/Hib/en/index.html

Wilfert, C. M. (1990). Epidemiology of Haemophilus influenzae type b infections. Pediatrics, 85(4 Pt 2), 631-635. 